\title{
Los bronces del "Conjunto sepulcral de Guerreiro" en el Museu Nacional de Arqueologia (Lisboa): En torno al Periodo Postorientalizante en el Sur de Portugal
}

\author{
Bronze Implements of the "Guerreiro Tomb" in the National \\ Museum of Archaeology (Lisbone): \\ About the Post-Orientalising Period in Southern Portugal
}

Javier Jiménez Ávila* y Ana Sofia T. Antunes**.

Recibido: 05-03-2018

Aceptado: 07-10-2019

\section{Resumen}

Desde finales de los años noventa se conserva en el Museo Nacional de Arqueología de Lisboa un conjunto de bronces protohistóricos de procedencia desconocida, aunque probablemente provengan del entorno del Bajo Guadiana. El lote está constituido por algo más de un centenar de objetos, destacando los componentes de carro y arreos ecuestres, pero también hay restos de vajilla, un asador y elementos de adorno. Algunas de las piezas más destacadas han sido presentadas o referidas de manera preliminar, pero el grueso del conjunto permanecía inédito, quedando pendiente su estudio detallado y su contextualización en la Edad del Hierro del Sur de Portugal. En este trabajo afrontamos estas tareas en el convencimiento de que se trata de uno de los conjuntos de bronces más completos e importantes del Periodo Postorientalizante en el suroeste peninsular.

Palabras clave:

Bronces, Edad del Hierro, Atalaje ecuestre, Carros, Aristocracia, Península Ibérica.

\begin{abstract}
From the end of the 1990's a set of Iron Age bronzes is conserved in the National Archaeological Museum of Lisbon. They are qualified as unknown origin although they come wide probably from the Low Guadiana region. The set consists of more than one hundred objects, highlighting the components of carriage and horse harness, but there are also some remains of vessels, a spit and ornament elements. Some of the most outstanding pieces have been presented or referred to in a preliminary way, but the bulk of the set remained still unpublished. A detailed study including its contextualisation in the Iron Age of the South Portugal waited to be done. In this paper we face this approach because we believe that is one of the Post-Orientalising bronze sets more complete and more important in the Southwestern Iberian peninsula.
\end{abstract}

Key words:

Bronzes, Iron Age, Horse harness, Chariots, Aristocracy, South Portugal.

* Consejería de Cultura e Igualdad, Junta de Extremadura. Paseo de Roma s/n Mérida (Badajoz), jjimavila@hotmail.com, https://orcid.org/0000-0002-3431-0395

** UNIARQ - Centro de Arqueologia da Universidade de Lisboa. Faculdade de Letras. Alameda da Universidade. 1600-214 Lisboa. anantunes@gmail.com 


\section{INTRODUCCIÓN}

En 1997 el Museo Nacional de Arqueología de Lisboa (MNA) adquirió un conjunto de bronces protohistóricos que resulta extraordinario tanto por su cantidad como por su coherencia funcional. Así, con sus más de 100 elementos, se erige entre los más significativos del actual territorio portugués, destacando abundantemente los objetos que se incluyen en la esfera del atalaje ecuestre. De manera adicional existen algunas piezas que se inscriben en el ámbito de los objetos de adorno o de la celebración de ceremonias vinarias y conviviales y que, asociados a los arreos ecuestres, contribuyen también a considerar este conjunto como un todo unitario.

Aunque el conjunto había sido ya referido y algunas piezas (las camas caladas y los pasarriendas cat. 4-5 y 9-10, respectivamente) publicadas (Jiménez Ávila y Muñoz, 1997: 158; Gomes, 2001: 116: fig. 4; Quesada, 2005), la mayor parte de los componentes se encontraba, a efectos bibliográficos, prácticamente inédita y pendiente de un estudio detallado. No obstante, toda la información museográfica de este material ${ }^{1}$ era y es accesible a través de la plataforma on line MatrizNet, correspondiente a los museos públicos portugueses (www.matriznet.dgpc.pt).

Tal vez debido al hecho de que en el Mediterráneo Occidental se encuentran elementos de atalaje ecuestre en contextos funerarios, este conjunto pasó a denominarse como "Conjunto sepulcral de Guerreiro" en los registros del MNA. Consideramos, sin embargo, que esta designación debe ser comentada atendiendo a diversos motivos. En primer lugar, y como tendremos ocasión de comprobar en este trabajo, hasta hoy no se han registrado depósitos de elementos de atalaje ecuestre en las sepulturas de la Edad del Hierro del Alentejo Interior, optándose comúnmente por otro tipo de ofrendas o pertenencias personales. Por el contrario, los sitios donde en el entorno del Guadiana Medio e Inferior se documentan este tipo de artefactos son enclaves no funerarios, que suelen desempeñar un importante papel en la gestión del territorio circundante, incorporando funciones áulicas o aristocráticas tal y como sucede en yacimientos como Cancho Roano o Azougada. Por otro lado, la designación de "guerreiro" parece poco adecuada habida cuenda de la inexistencia de armas asociadas a este

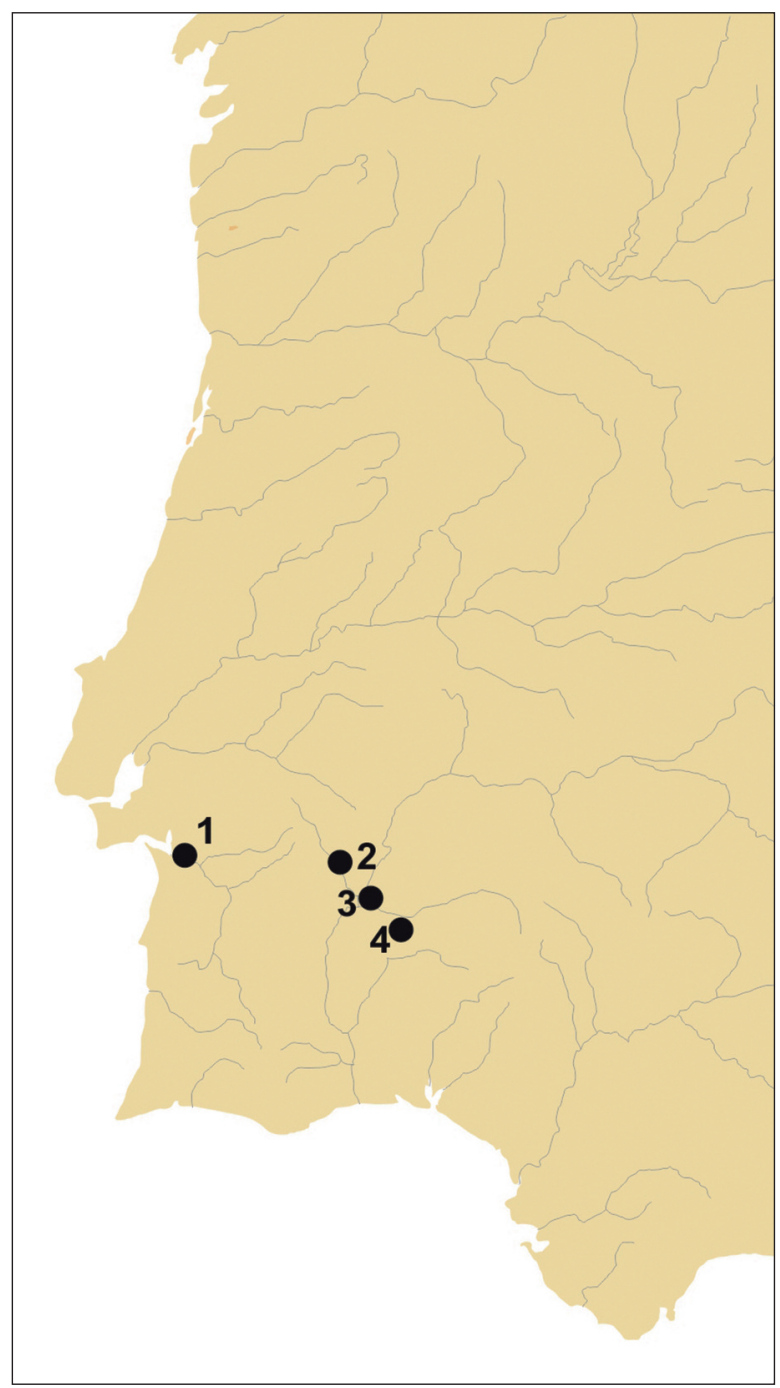

Figura 1. Mapa de Portugal con las localizaciones que se han referido como posibles lugares de procedencia del "Conjunto sepulcral de Guerreiro". 1. Alcácer do Sal; 2. Valle del río Degebe; 3. Azougada; 4. Cabeço Redondo.

conjunto siendo, tal vez más justificable la de caballero o, mejor aún, la de auriga ${ }^{2}$.

La procedencia de este conjunto es desconocida, si bien todas las posibilidades que se han apuntado coinciden con localidades del Sur de Portugal (Fig. $1)$.

En el MNA se le presume un origen en Alcácer do Sal que vendría avalado por el hecho de que el vendedor del lote (Duarte van-Zeller) tendría algunas propiedades en la zona, factor que coincide,

\footnotetext{
1 Con excepción, probablemente por error, de nuestra pieza $n .^{\circ} 11$.

2 Ver, no obstante, lo que se dice infra, en la nota 12.
} 
además, con la importancia de la ocupación protohistórica en este enclave. No obstante, estos argumentos no nos resultan muy concluyentes, a pesar de que en la conocida necrópolis del Olival do Senhor dos Martires se hallaran elementos que no están muy alejados de algunos de los que aquí estudiamos (Schüle, 1969: lám. 108, n. ${ }^{\circ}$ 8; Gomes, 2016: lám. CXVIII). M.V. Gomes sugirió su procedencia de Azougada (Gomes, 2001) debido a las afinidades con la cultura material de este sitio y a sus particulari-

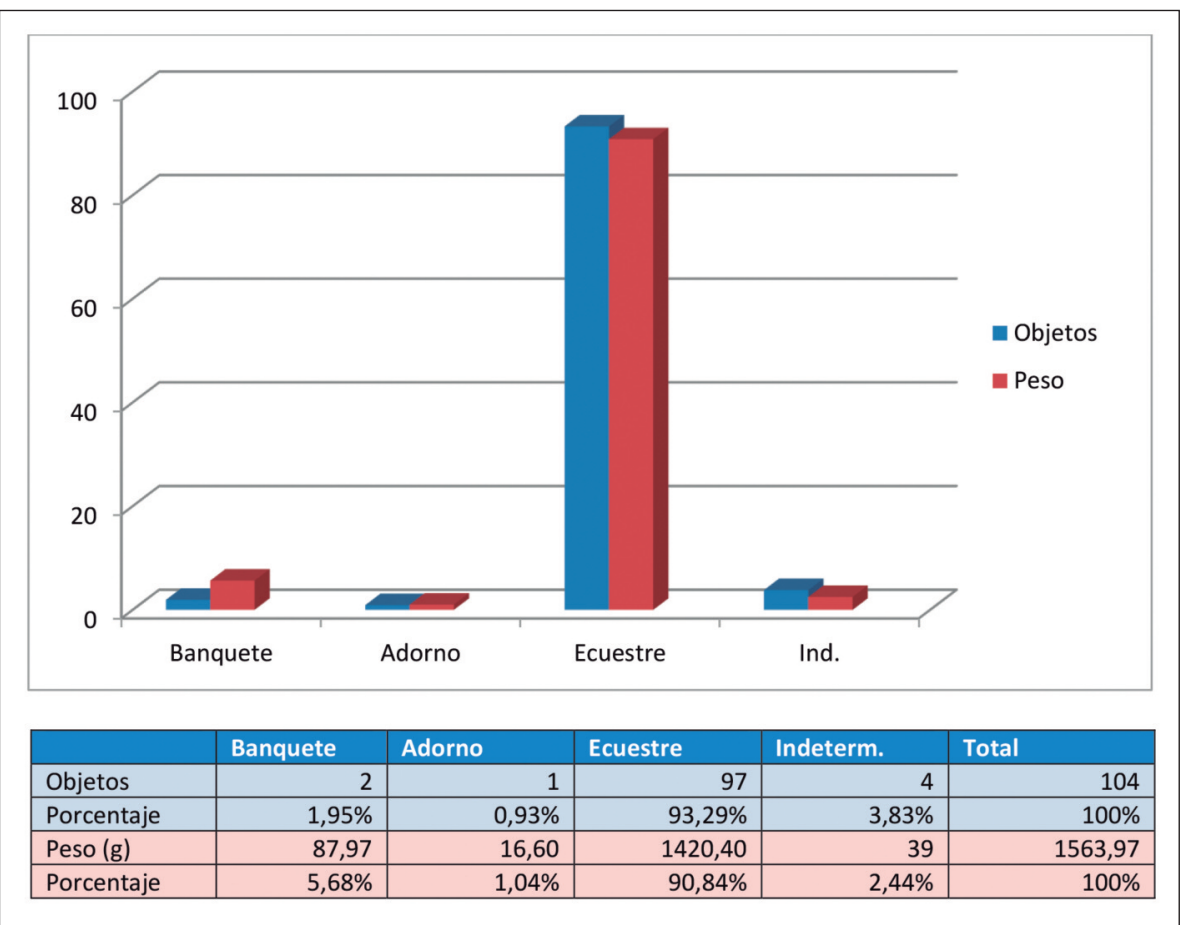
dades. También se ha señalado la proximidad temporal de la adquisición del lote con las destrucciones del Cabeço Redondo de Moura, un sitio muy próximo a Azougada, e identificado como una construcción monumental similar a Cancho Roano, de donde proceden los mejores referentes para estos bronces (Soares 2012; Soares y Soares, 2017). Otras informaciones, por último, apuntan al valle del Degebe (ver infra).

Y si no resulta fácil situar la procedencia exacta, tampoco lo es indagar en las circunstancias deposicionales pues la adquisición del MNA solo contempla este lote de bronces, sin que se entregaran otros objetos asociados (cerámicas, armas...) que podrían haber permitido conocer mejor las características de un posible contexto ${ }^{3}$.

A pesar de todas las limitaciones que provoca el desconocimiento de la procedencia y del contexto de estos bronces a la hora de afrontar su análisis, entendemos que la importancia del conjunto en el panorama del postorientalizante del Sur de Portugal torna incontrovertible la necesidad de su publicación y estudio detallados. Ese es el objetivo que nos proponemos abordar con este trabajo, sin perjuicio de reconocer la conveniencia de complementarlo $a$ posteriori con estudios arqueometalúrgicos que contribuyan a conocer mejor aspectos concernientes a la producción artesanal y a la circulación de este tipo de creaciones, aspectos que son igualmente

Figura 2. Diagrama de frecuencia (\%) y tabla de valores de los distintos grupos funcionales representados en el conjunto.

esenciales para una más completa valoración histórica.

\section{ESTUDIO DEL MATERIAL POR TIPOS}

El conjunto de bronces protagonista de este estudio está integrado por un centenar de objetos reconocibles, si bien algunos de ellos, como los colgantes con campanillas (cat. 13-15), son elementos complejos compuestos por varias piezas distintas unidas entre sí. Además, se conservan cuatro pequeños fragmentos de barra de bronce de insegura identificación (cat. 101). Todo el conjunto suma en total más de un kilo y medio de metal.

En el plano funcional están afectadas tres esferas básicas, aunque desde el punto de vista cuantitativo se ven representadas de un modo muy desigual. Los grupos funcionales que pueden establecerse son 1) los elementos de banquete, con tan solo dos componentes; 2) el adorno personal, con un solo elemento y 3) los arreos ecuestres, que es el que está mejor representado y al que pueden adscribirse el resto de las entradas del catálogo (Fig. 2). Estos grupos, a su vez, pueden ser objeto de subdivisiones menores

3 Ver infra, nota 12. 


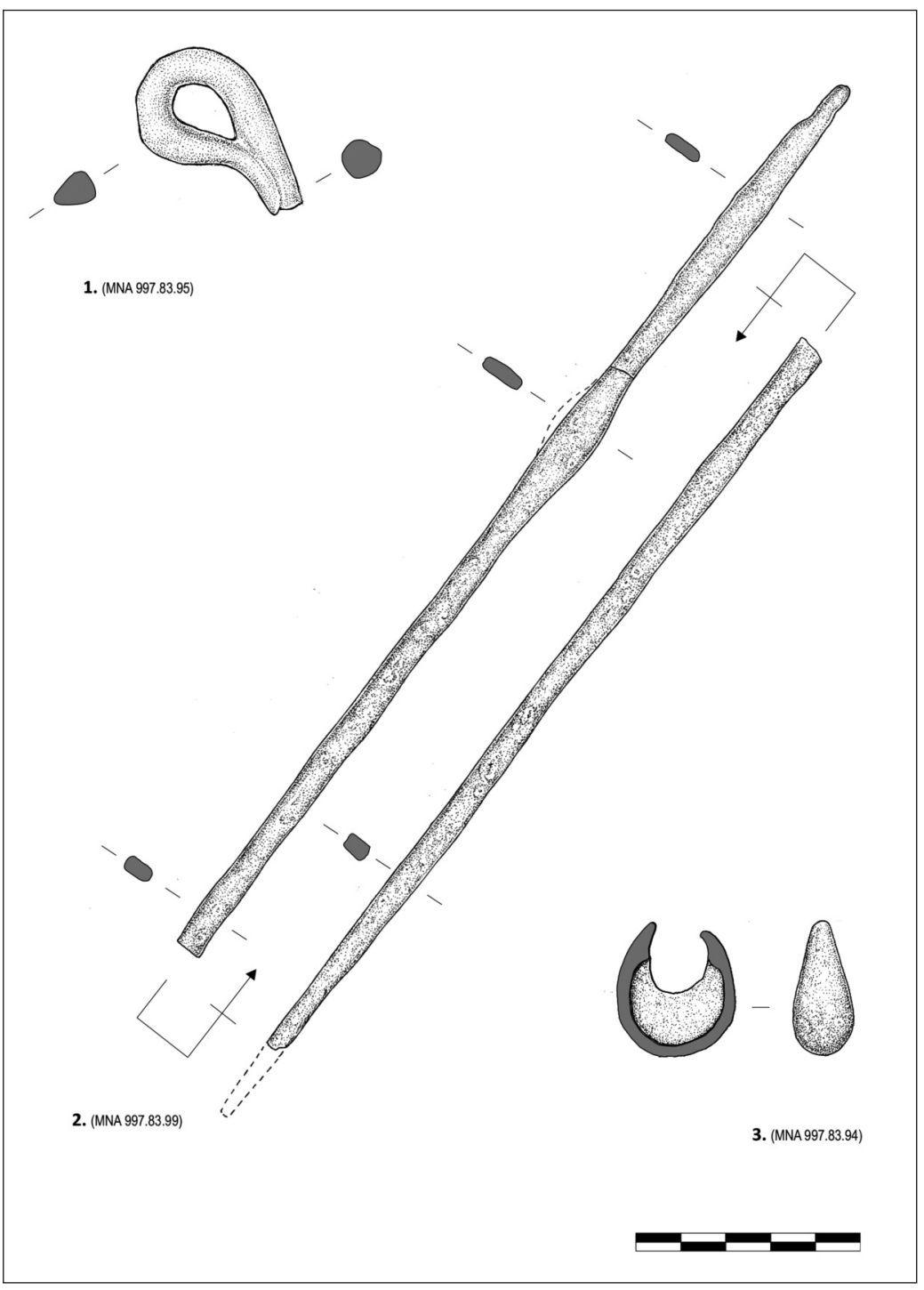

Figura 3. "Conjunto sepulcral de Guerreiro", cat. 1-3: materiales relacionados con el banquete y el adorno corporal. 1. Extremo proximal de un mango de recipiente ansado; 2 . Asador de tipo andaluz;

3. Colgante amorcillado. Museu Nacional de Arqueologia (Dibujos J.M. Jerez).

más específicas. De este modo, los elementos de banquete incluyen una pieza de vajilla ritual y un asador y los objetos ecuestres pueden subagruparse en: 3 a) objetos relacionados con el control directo del caballo y $3 \mathrm{~b}$ ) elementos de carro que, en este caso, parecen todos relacionados con el yugo y su unión al tiro. Los objetos de adorno personal, apartado en el que solo se incluye un colgante amorcillado, no son obviamente susceptibles de divisiones menores.

Por su condición de objetos de bronce, todos estos elementos unen a sus funciones primarias un fuerte contenido simbólico y de prestigio que, en algunos casos concretos, se ve reforzado por la iconografía o la decoración que portan.

\subsection{Elementos de banquete}

\subsubsection{Vajilla (cat.1)}

Descrito como "argolla" en los inventarios del MNA, se conserva integrando este conjunto el fragmento de un objeto en forma de barra de sección oval que se vuelve sobre sí misma rematando en una forma escultórica que reproduce, en modo algo sumario, la cabeza de un pato o de un cisne. El pico está fundido conjuntamente con la zona de contacto con la barra, de manera que la "argolla" que efectivamente forma el objeto está completamente cerrada (Fig. 3.1).

Este objeto puede identificarse como el extremo proximal del asa figurativa de un instrumento de bronce de tipo infundíbulo (colador) o símpulo (cazo) (Jiménez Ávila y Muñoz, 1997: 158).

La adopción de cabezas de anátidas como remate de asas figuradas de vasijas de bronce $u$ otros materiales es un recurso frecuente en las vajillas de lujo de numerosas culturas de la Antigüedad. En las coordenadas espaciotemporales que aquí nos afectan interesa detenernos, sobre todo, en las series de coladores, y en menor medida cazos, que se producen en Grecia e Italia en época arcaica (Hill, 1942) y que llegan a la Península Ibérica a partir de mediados del siglo VI a.C. Como se ha señalado en alguna ocasión, y por lo que a Iberia se refiere, se trata de un material mal estudiado y mal sistematizado (Jiménez Ávila, 2002: 381 ss.; 20067: 324). No obstante, se han realizado algunas aportaciones más recientes que permiten ir mejorando nuestro conocimiento al respecto (Botto y Vives-Ferrándiz, 2006). Los infundíbulos etruscos -reconocidos como el tipo de material de bronce que más exporta esta cultura- comienzan a llegar con las producciones de la primera mitad del siglo VI a.C., como evidencian los ejemplares de Cancho Roano y Játiva -este último dotado de cabeza de pato- para continuar con las series posteriores, fundidas en una sola pieza, como las de Alcurrucén, con cabeza de anátida, o la de Iznalloz, que ya la ha sustituido por la terminación en cuer- 
necillos propia de los coladores que rozan el siglo IV a.C. (Botto y Vives-Ferrándiz, 2006: 45-46; 5051). A esta misma época correspondería el colador hallado en Villajoyosa, que tampoco cuenta con remate zoomorfo (Vives-Ferrándiz, 2006-7: 321). Por su parte, los coladores griegos se reconocen principalmente por las asas, pues comúnmente están fundidos separadamente, sin que se conserve el vaso propiamente dicho, como sucede en los ejemplares hispanos de Mirador de Rolando (Arribas, 1967: 74 ss.), Castañuelo (Jiménez Ávila, 2001: fig. 9) o Museo de Granada (Pozo, 2003: 21: fig. 30). No obstante, también se realizaron imitaciones de esta modalidad en área itálica,

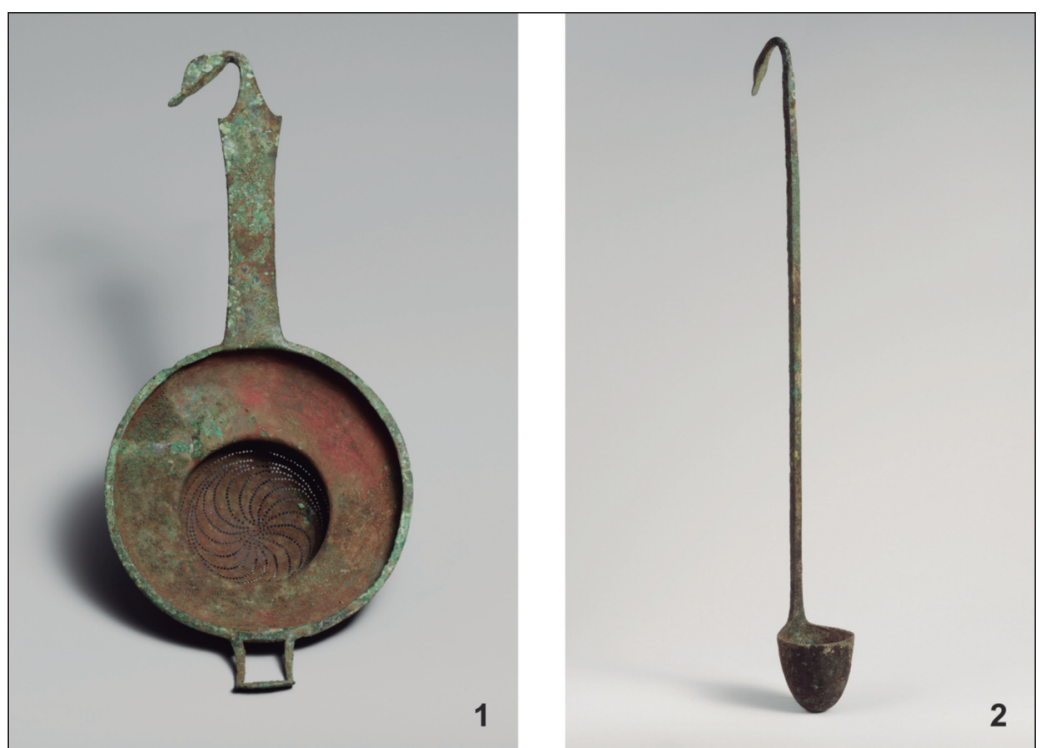

Figura 4. Vajilla de bronce itálica del siglo V a.C. con enmangues rematados en cabeza de anátida. 1. Infundíbulo; 2. Símpulo

(Fotos Metropolitan Museum of Art, N. York). aunque, normalmente, de circulación más restringida (Tarditi, 1996).

Aparte de estas producciones, que empiezan a constatarse ya con cierta asiduidad en el ámbito peninsular, se fabrican en ámbito griego e itálico otros vasos abiertos, como los cazos o las pateras, decorados igualmente con cabezas de patos en los extremos que, por el momento, no se han constatado fehacientemente en el extremo occidente del Mediterráneo, aunque tal vez pertenezca a este tipo un asa localizada en el Castelo de Castro Marim (Pereira 2008: fig. 23). Tampoco faltan estas decoraciones sobre asas móviles de vasos cerrados de tipo sítula, etc. que se han documentado en la Península (Vives-Ferrándiz, 2006-7), donde también se aplicaron a recipientes abiertos de tipo "brasero", de fabricación local (Jiménez Ávila, 2002: lám. XXI).

Las abundantes producciones de Grecia e Italia están muy estandarizadas y presentan rasgos muy reconocibles que permiten una relativamente fácil sistematización e, incluso en algunos casos, su adscripción a centros productivos concretos (Tarditi, 1996). Todas ellas presentan un rasgo del que no participa la pieza del MNA, que es la apertura del asa, de manera que no forman en el extremo de agarre una argolla cerrada sino una curvatura abierta (Fig. 4). De ahí que, aunque íntimamente relacionada con esta generación de vajillas mediterráneas, debamos considerar que nuestro fragmento no se corresponda propiamente con un producto salido de talleres griegos o itálicos, sino que, más probablemente, se trate de una producción local relacionada con ellos. Tratán-

dose, por tanto, de lo que constituiría el primer exponente de fabricación peninsular para este tipo de recipientes de inspiración mediterránea, son escasos los argumentos basados en ejemplos similares que se puedan traer a colación. Sin embargo, contamos con algunos puntos de apoyo para poder sostener esta afirmación, como la fabricación de vasos coetáneos de inspiración mediterránea en talleres peninsulares. A tal efecto se debe citar, primordialmente, la conocida serie de olpes de tipo Oral, sobre los que hubo algunas dudas iniciales en cuanto a su adscripción etrusca o peninsular (Abad, 1988), pero que, a la vista de los continuos hallazgos hispánicos y de su igualmente constante ausencia entre la abundantísima serie de olpes hallados en Italia (así como a otros razonamientos de tipo tecnológico), parece apropiado tener por genuinamente ibéricos (Shefton, 1995; Jiménez Ávila, 2002: 381; 2006-7: 306; Botto y VivesFerrándiz, 2006: 49). Precisamente, estos olpes cuentan también con asas terminadas en cabezas de ánades. A estos elementos de vajilla hispánica de imitación mediterránea habría que agregar otras producciones apenas valoradas, como los trípodes, atendiendo a los bien razonados argumentos que se han expuesto recientemente para incluir en esta serie de bronces peninsulares algunas piezas ya tratadas por la investigación anterior, como la pata leonina del yacimiento abulense de Las Cogotas (Graells et al., 2014). El mayor número de evidencias que la investigación está reconociendo para estas producciones hispánicas añade, por tanto, 
mayor verosimilitud al planteamiento que aquí presentamos para esta asa, que apunta en la misma dirección de imitaciones locales de bronces griegos e itálicos.

Resulta complicado intentar determinar el tipo de vasija concreta a la que corresponde este remate zoomorfo del Museo de Lisboa habida cuenta de su carácter incompleto. Desde el punto de vista estadístico ya hemos señalado cómo son los infundibula o coladores los artefactos que más frecuentemente se reconocen en la Península, por lo que cabría pensar que este fragmento pudiera corresponder a uno de estos utensilios destinados a filtrar el vino. Pero otras modalidades, como símpulos o cazos -que empezarán a ser mucho más frecuentes en época helenística (Mansel, 2004: 20-22)- no son del todo descartables.

En cualquier caso, este fragmento es una evidencia más de la presencia de vajilla de bronce mediterránea (de inspiración mediterránea, en este caso) muy probablemente relacionada con el consumo del vino para su uso en banquetes conviviales que aparece asociada a otros elementos aristocráticos -como el conjunto ecuestre adjunto-en contextos postorientalizantes e ibérico-antiguos del sur peninsular. A pesar de que la cronología de algunas de las importaciones pueda ser anterior al 550 , como el caso de los infundíbulos etruscos más antiguos, la mayoría de los contextos apuntan hacia unas fechas ya posteriores que, incluso, implican a los objetos más arcaicos. El caso más evidente lo constituyen los dos coladores de Cancho Roano, hallados entre las ruinas de un incendio producido a finales del siglo $\mathrm{V}$, a pesar de la anterior cronología de los modelos que representan (Zuffa, 1960). Cancho Roano marca uno de los mejores referentes para contextualizar el hallazgo del MNA, al convivir en el mismo espacio este tipo de vajilla vinaria con equipos ecuestres, asadores, elementos de adorno personal, etc.

$\mathrm{El}$ vaso al que correspondiera nuestro extremo zoomorfo o, de forma más evidente, los olpes de tipo Oral, testimonian así una aún mal conocida serie de versiones hispánicas de bronces grecoitálicos correspondientes a los siglos VI y V a.C. que arrancaría con el desarrollo de la broncística hispano-arcaica, que cuenta con creaciones tan reseñables como el Vaso de Valdegamas (Jiménez Ávila, 2002: 368 ss.).

\subsubsection{Asador (cat.2)}

El segundo elemento vinculable con actividades de comensalidad es un asador que se conserva en modo fragmentado y fragmentario, pues además de estar partido en tres trozos, le falta la zona de la punta (Fig. 3, n. ${ }^{\circ}$ 2). A pesar de su estado incompleto y de estar bastante corroído por algunas partes, sus dimensiones y su morfología, con un mango de sección plana que presenta una parte ensanchada de separación del pincho, permiten adscribirlo sin gran dificultad al tipo andaluz establecido por M. Almagro-Gorbea en su ya clásico estudio sobre estos objetos (1974).

Los asadores de tipo andaluz son enormemente escasos en Portugal donde, por el contrario, abundan los de tipo alentejano, que parecen presentar una cronología anterior (Ibidem). Las unidades que pueden traerse a colación en territorio luso son muy pocas y en muchas ocasiones inciertas (Ibidem: fig. 19; Jiménez Ávila, 2002: fig. $231^{4}$ ). Así sucede, por ejemplo, con un antiguo hallazgo procedente de Figueiras (Cadaval), descrito por Almagro-Gorbea con rasgos del tipo Alentejano, pero representado como andaluz (Ibidem: 259: fig. 2.2); o con el cercano hallazgo de Alguber, que presenta componentes mixtos (Ibidem: 259: fig. 2.3; Jiménez Ávila, 2002: 308). Clasificados como de tipología dudosa son los ejemplares de Azougada (Almagro-Gorbea, 1974: 387), repartidos entre los museos de Moura y Belem, aunque a la vista de los mismos y del propio contexto de este yacimiento (Antunes, 2009a) parece adecuado considerarlos definitivamente como de tipo andaluz. Los asadores de Azougada resultan especialmente importantes en este discurso por dos razones básicas: la primera de ellas es que son de los pocos ejemplares que proceden de un yacimiento cuya secuencia cronológica es relativamente bien conocida y que, gracias a los recientes estudios realizados por uno de nosotros a partir del registro cerámico, puede situarse fundamentalmente en época postorientalizante, con alguna pervivencia inmediatamente posterior (Ibidem). La segunda razón es que el entorno de Azougada es uno de los posibles lugares de procedencia que se han señalado para este conjunto de bronces, como ya hemos indicado con anterioridad, si bien es necesario tomar esta propuesta con muchas reservas. En cualquier caso,

\footnotetext{
4 En este mapa, que recoge los asadores de tipo andaluz, aparece por error el ejemplar de Monte Beirão, que es de tipo alentejano, ver Silva y Gomes, 1992: fig. 46A.
} 
a la hora de valorar la presencia de asadores de este tipo en territorio portugués, no hemos de olvidar la situación fronteriza de Azougada, en la orilla izquierda del Guadiana.

Menos problemas de clasificación presenta el asador de Fernão Vaz (Ourique), publicado con posterioridad al trabajo de Almagro-Gorbea. Fue descubierto casualmente en 1966, lo que propició la identificación del hábitat de la Edad del Hierro posteriormente excavado (Beirão, 1986; Beirão y Correia, 1993). Las características del objeto, de mango completamente plano, lo sitúan sin duda en el tipo andaluz, convirtiéndose, prácticamente, en el único espécimen de esta clase claramente confirmado en el interior de Portugal. Aparte de este factor de interés, el asador de Fernão Vaz resulta útil de cara a nuestros propósitos por proceder, como los de Azougada, de un yacimiento cuya cronología es conocida y que, a la luz de los materiales arqueológicos recogidos en las excavaciones, debe situarse en el siglo V a.C. (Jiménez Ávila, 2001: 215; Arruda, 2005a)

En fecha muy reciente se ha añadido al catálogo de espetos portugueses un ejemplar procedente del yacimiento de Lapa da Cova (Sesimbra). Se halló en un contexto revuelto donde se mezclan materiales protohistóricos para los que se ha puesto una cronología que va desde los siglos VII y VI a finales del V a.C., si bien la mayoría del conjunto ergológico se fecha en los momentos más avanzados de este intervalo. Tratándose de un objeto al que le falta el mango no es posible, sin embargo, determinar el tipo al que corresponde (Calado et al., 2018; Jiménez Ávila et al., 2018).

Curiosamente, y a pesar de su mayor presencia en España, y especialmente en el valle del Guadalquivir, los ejemplares españoles están comúnmente carentes de contexto arqueológico (AlmagroGorbea, 1974; Jiménez Ávila, 2002: 307 ss.). No obstante, contamos también con algunas notables excepciones dignas de mención, en particular el lote de Cancho Roano (Extremadura), de donde procede una docena de ejemplares, algunos muy próximos en su morfología al que aquí tratamos (Maluquer de Motes, 1982; Celestino y Zulueta, 2003: 36 ss.). Los ejemplares de Cancho Roano cobran aquí especial significado por haberse hallado en este yacimiento elementos muy similares a los que componen el conjunto broncístico del MNA, en particular toda la serie de arreos ecuestres, encabezados por las célebres camas decoradas. El abandono de Cancho Roano, bien fechado por las cerámicas griegas, se sitúa a finales del siglo $\mathrm{V}$ a.C., y a este momento corresponde la práctica totalidad de los asadores localizados en el sitio, si bien hay algún ejemplar correspondiente a las llamada fase B (Celestino y Zulueta, 2006: 36-37) que debe situarse en un momento anterior, aunque aún dentro del siglo $\mathrm{V}$, como denuncian las cerámicas griegas halladas en los sedimentos de esta fase (Jiménez Ávila y Ortega, 2004: 127-128).

De todo este corolario se extrae que la fecha más habitual para este tipo de objetos en su contexto regional más inmediato es la del siglo $\mathrm{V}$ a.C., algo que coincide con lo que, conforme iremos avanzando, sugiere el resto del material.

La mayor parte de los asadores peninsulares procedentes de contextos conocidos corresponden a hallazgos no funerarios: poblados, edificios áulicos o grandes depósitos rituales como el del museo de Sevilla, que reúne una treintena de unidades (Fernández Gómez, 1992-93). Solo los fragmentos hallados en la tumba castulonense de Torrubia, fechable en el siglo VII (Blanco, 1965), y el más reciente hallazgo de asadores en raras tumbas de El Raso de Candeleda (Ávila), rompen esta norma (Fernández Gómez, 1997: 92). Este dato estadístico habrá de ser tenido en cuenta de cara a la interpretación contextual de todo el conjunto en estudio.

Desde el punto de vista funcional parece admitido que estos instrumentos se empleaban en ceremonias conviviales en las que intervenía el consumo de carne asada. Dichas ceremonias, siempre cargadas de un fuerte componente simbólico y ritual, habrían tenido lugar en espacios religiosos y, sobre todo, en espacios palaciales y de representación social. Su inicio en la Península Ibérica se sitúa en el Bronce Final, como atestiguan los primeros ejemplares documentados, correspondientes al tipo articulado o Alvaiázere (Almagro-Gorbea, 1974), y parecen tener su origen en la adopción por parte de las élites locales de algunas de las prácticas culturales llegadas del Mediterráneo oriental en momentos precoloniales (Armada, 2005).Al mismo tiempo, deben considerarse como un elemento de prestigio que permite identificar a quienes participan en este tipo de ritos aristocráticos, pero su depósito en tumbas es poco frecuente.

Aunque únicamente hemos inventariado un asador dentro de este conjunto, cabe señalar, solo como posibilidad, que alguno de los fragmentos de barras de bronce que complementan el lote (cat. 101) pudiera corresponder, vistas sus características, a uno o más ejemplares de este tipo de objetos. Pero su estado es demasiado fragmentario como para poder afirmarlo de manera taxativa.

La rareza de estos utensilios en territorio portugués añade verosimilitud a la noticia de que este 
conjunto de bronces pueda proceder de un entorno situado en la orilla izquierda o en el Bajo Guadiana, próximo a la actual frontera con España, donde son más frecuentes.

\subsection{Elementos de adorno personal}

A este grupo solo corresponde un objeto que no es de los más usuales dentro de esta categoría funcional normalmente integrada por fíbulas, broches de cinturón, brazaletes, etc. Se trata de un colgante amorcillado, tipo bien conocido en la Protohistoria peninsular y especialmente en el Sur de Portugal.

\subsubsection{Colgante amorcillado (cat.3)}

El colgante amorcillado es hueco al interior, de aspecto bolsiforme, y está bastante deteriorado, tanto por la corrosión en su superficie como por faltarle la mayor parte de las asillas (Fig. 3.3).

Aunque no se han realizado estudios específicos para esta clase de objetos, fueron tratados por W. Schüle en su monografía sobre la Edad del Hierro peninsular, presentando un mapa de distribución de los mismos que refleja esta especial concentración sudportuguesa (Schüle, 1969: lám. 17).

La valoración como objetos de adorno para este tipo de productos no ha sido unánime, habiéndose propuesto otros usos, como el de lingotes de cobre, justificada por el formato algo tosco que presentan algunas unidades. No obstante, la presencia de ejemplares mucho más elaborados y trabajados en hueco al interior, como el que aquí nos ocupa, aleja esta posibilidad. El hallazgo de algunos de estos elementos unidos a pulseras o ajorcas circulares, huecas al interior, refuerza su interpretación funcional como objetos de adorno (Schüle, 1969; Arruda et al., 2017). La convivencia de un ejemplar aislado con un equipo como el nuestro, compuesto casi exclusivamente por arreos ecuestres, podría sugerir un uso como adornos de caballerías. Sin embargo, en los demás contextos conocidos no parece producirse esta asociación, por lo que esta posibilidad pierde verosimilitud.

La mayoría de los colgantes de este grupo corresponden al tipo macizo y tosco antes referido, que parece iniciar su arranque en momentos del Bronce Final y mantenerse hasta el Periodo Postorientalizante. Así lo atestiguan algunos hallazgos realizados en yacimientos que ostentan estas cronologías, como los de La Mata o El Chaparral en la Extremadura española (Rodríguez Díaz, 2004: 285; Jiménez Ávila et al., 2005: 478) y el de la sepultura 11 de la Vinha das Caliças, en el Alentejo (Arruda et al., 2017: fig. 10).
El colgante que aquí estudiamos, como ya hemos avanzado, corresponde a una modalidad algo diferente, que se caracteriza por su mayor tamaño y un interior ahuecado, dando un resultado algo más refinado que requiere de una mayor elaboración.

Esta modalidad hueca ha aparecido en Alcácer do Sal, donde los colgantes amorcillados, tanto en su versión hueca como maciza, son especialmente frecuentes, pero así como conocemos el contexto de los más pequeños, los huecos aparecen siempre sin referencias a tumbas concretas (Schüle, 1969: 215). También están presentes en algunos yacimientos orientalizantes tardíos y postorientalizantes del entorno del Guadiana medio y bajo, como El Palomar (Rovira et al., 2005: fig. 1.21), El Cuco (Jiménez Ávila, 2017: fig. 7); Azougada (Schüle, 1969: 215) o El Castañuelo (Amo, 1978: fig. 2.1), lo que podría sugerir una fecha reciente para esta modalidad, a pesar de la permanencia en el tiempo de los colgantes macizos. La mayoría de los ejemplares repertoriados, sin embargo, carece de contextos conocidos.

\subsection{Arreos ecuestres}

La mayor parte de los elementos que componen este conjunto de bronces son arreos ecuestres asimilables a una brida y al yugo de un carro. No se han hallado objetos correspondientes a otras zonas del vehículo, como las ruedas o la caja, reiterando un fenómeno ya constatado en otros yacimientos peninsulares y europeos en los que han aparecido equipos similares (Jiménez Ávila y Muñoz, 1997).

El conjunto guarda un estrecho parecido con los atalajes hallados en el complejo palacial de Cancho Roano, a pesar de lo cual, de su estudio se deriva una formación compleja y una procedencia múltiple y variada -tanto en lo geográfico como en lo cronológico- de los distintos componentes que lo integran.

\subsubsection{Camas caladas (cat. 4 y 5).}

Entre las piezas más destacadas del conjunto ecuestre se encuentran dos camas laterales de bocado de caballo decoradas con calados figurativos representando un personaje antropomorfo sobre una sintética forma equina. Las fuertes analogías de estos asientos con el conocido despotes de Cancho Roano, que ha pasado a convertirse en una pieza emblemática de este ya de por sí emblemático yacimiento, han propiciado que estas piezas hayan sido referidas y tratadas en varios trabajos anteriores (Jiménez Ávila y Muñoz, 


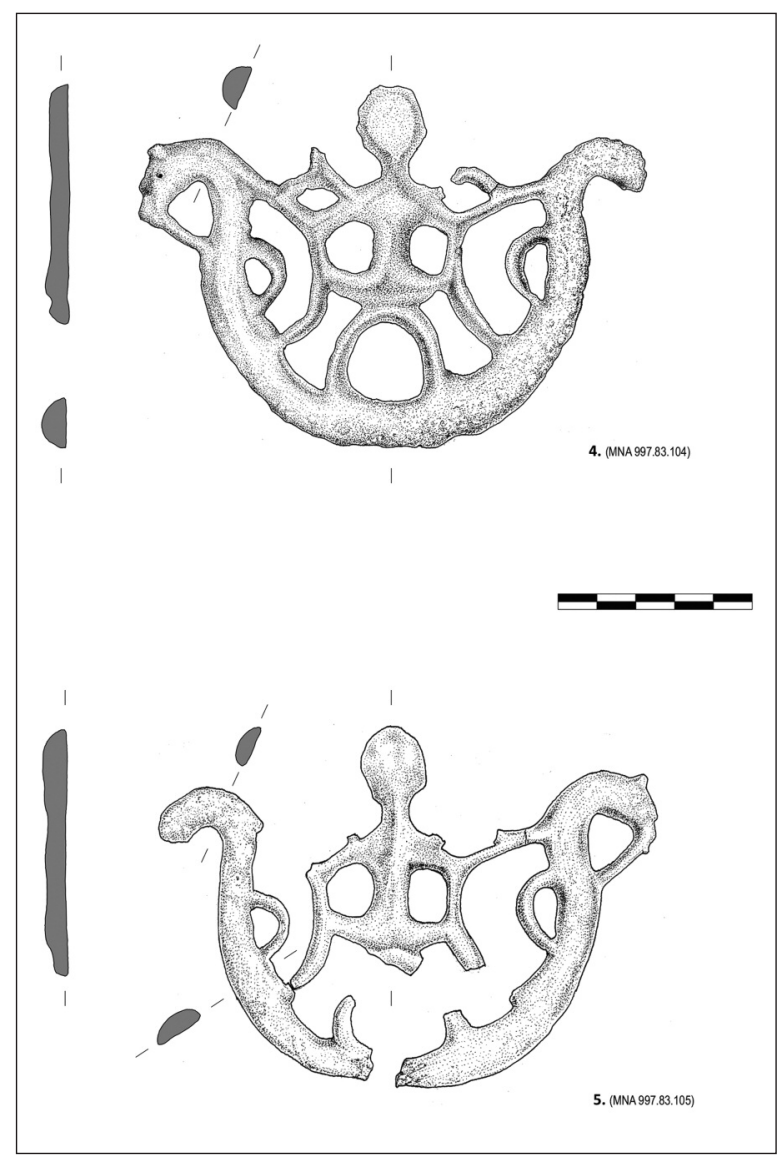

Figura 5. "Conjunto sepulcral de Guerreiro", cat. 4 y 5: placas con decoración calada correspondientes a las camas laterales de un bocado de caballo. Museu Nacional de Arqueologia (Dibujos J.M. Jerez).

1997: 158; Gomes, 2001: 115 ss.; Blech, 2003: 161 s.; Quesada, 2002-03; 2005: 110 ss.).

Las dos placas son prácticamente iguales, aunque disimétricas entre sí, y presentan distinto grado de conservación, estando la n.$^{\circ} 4$ muy completa, a falta de algunos fragmentos de las "palomas" de la parte superior, mientras que la $\mathrm{n} .^{\circ}$ 5 se halla fragmentada en tres partes, con pérdida de algunas extremidades, tramos de sujeción y segmentos intermedios (Fig. 5).

Una inmediata comparación con sus homólogas de Cancho Roano, en particular con la que se conserva en mejor estado, denota fuertes diferencias en cuanto a la calidad del trabajo, pues en las nuestras apenas están representados los detalles anatómicos de las figuras, ni los rasgos faciales de los personajes, ni las guedejas o tocados, ni otros elementos estructurales que aparecen bien definidos en relieve en los ejemplares de dicho yacimiento (Fig. 6). Una comparación más detallada, que parece no haberse realizado hasta ahora, denota que, además, existen diferencias compositivas e iconográficas importantes, pues los caballos de estas placas portuguesas no son bifrontes, sino que presentan una sola cabeza, acabando la composición, por el lado opuesto, en una sinuosa extremidad curvada y vuelta que es continuación del gran arco basal que enmarca todo el conjunto. Esto no es algo que pueda atribuirse a problemas de conservación ni a defectos de fundición (como podría sugerir la mediocre calidad de la colada), sino que es un efecto deliberado y debido al diseño específico de estas placas. Así lo confirma la ausencia en los extremos curvados de cualquier vestigio de la barra oblicua que representa las riendas, que sí se conserva en los prótomos equinos de las dos camas. Además, las placas están configuradas de manera especular, de forma que en la n. ${ }^{\circ} 4$ la cabeza del caballo queda a la izquierda y el extremo vuelto a la derecha, mientras que en la cama opuesta (n. ${ }^{\circ}$ 5) sucede exactamente lo contrario. Esta configuración provocaría que, al estar el bocado instalado en su sitio, sobre el hocico del animal, las dos cabezas equinas miraran hacia el mismo lado (presumiblemente hacia adelante). Sin embargo, esta coherente colocación generaría ciertas "molestias" al fundidor, pues para realizar estas piezas disimétricas se requiere el uso de dos moldes diferentes en lugar de uno solo, como después precisaremos.

Esta diferencia iconográfica con las camas de Cancho Roano, que reduce la bifrontalidad de los caballos, obliga a cuestionar si los personajes antropomorfos que aparecen sujetándolos son bifrontes o si también se han modificado como

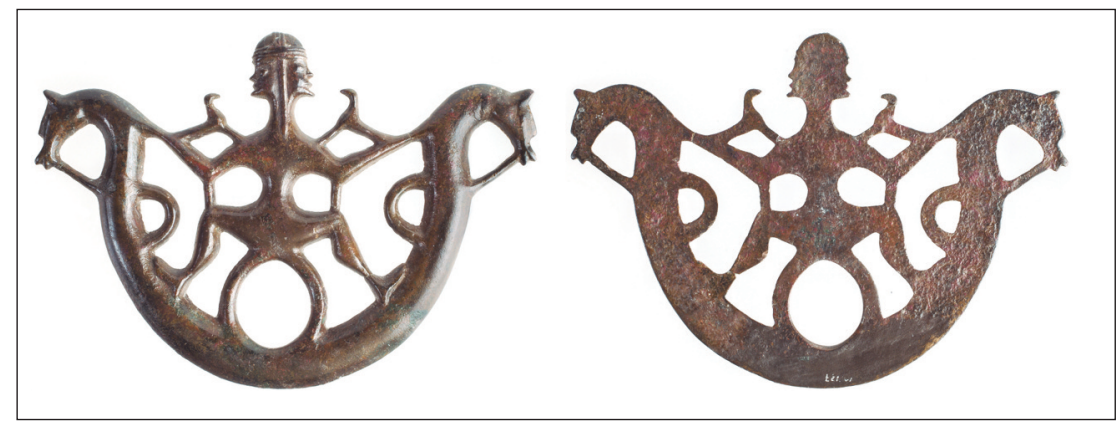

Figura 6. Cancho Roano. Placa con decoración calada correspondiente a la cama lateral de un bocado de caballo, anverso y reverso. Museo Arqueológico provincial de Badajoz (Fotos C. López). 
aquellos, y si en su nuevo diseño solo exhiben una cara en disposición frontal. La escasa definición de los rasgos faciales impide poder verificar este extremo con certeza, aunque en la silueta de ambas cabezas se pueden percibir rasgos que permitirían reconocer una figura de perfil mirando hacia la cabeza equina (Fig. 7). Por el contrario, M.V. Gomes apunta en su trabajo hacia una orientación frontal (2001: 118). La posibilidad de que se trate de personajes bifrontes es por tanto la menos defendible. Esto también nos permite cuestionar si las formaciones que aparecen sobre los brazos del personaje, que no se conservan completas, evocaban figuras ornitomorfas en la misma medida en que pueden reconocerse en las placas extremeñas, pues las nues-

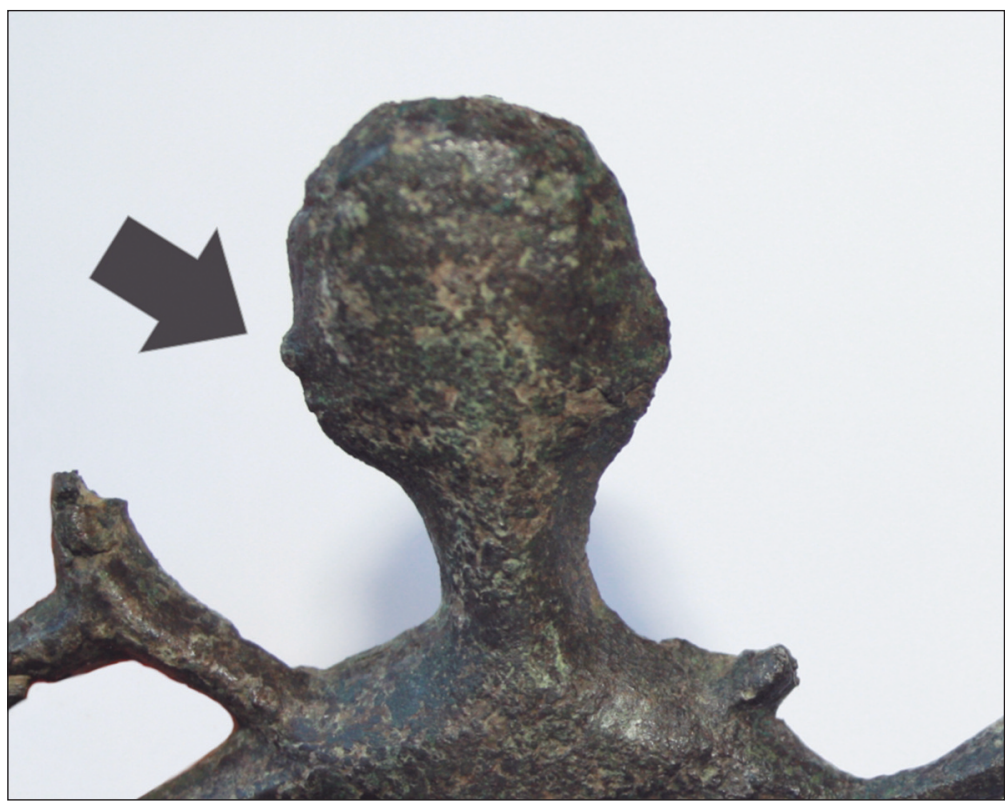

Figura 7. "Conjunto sepulcral de Guerreiro", detalle de la placa calada $n .^{\circ} 4$ donde se aprecia el trabajo de una posible silueta facial

(Foto A.S. Antunes). tras son mucho más esquemáticas, aunque se hallan incompletas.

Debemos considerar, por tanto, que las placas del MNA no son una copia fiel del modelo representado en las de Zalamea, sino una versión deliberadamente modificada del mismo.

Desde el punto de vista técnico también existen algunas diferencias, aunque todas estas placas, a pesar de sus distintas calidades, parecen fundidas en molde abierto (Figs. 8 y 42). Pero para camas asimétricas, como las del MNA se requiere del uso de dos moldes, mientras que las de Cancho Roano,

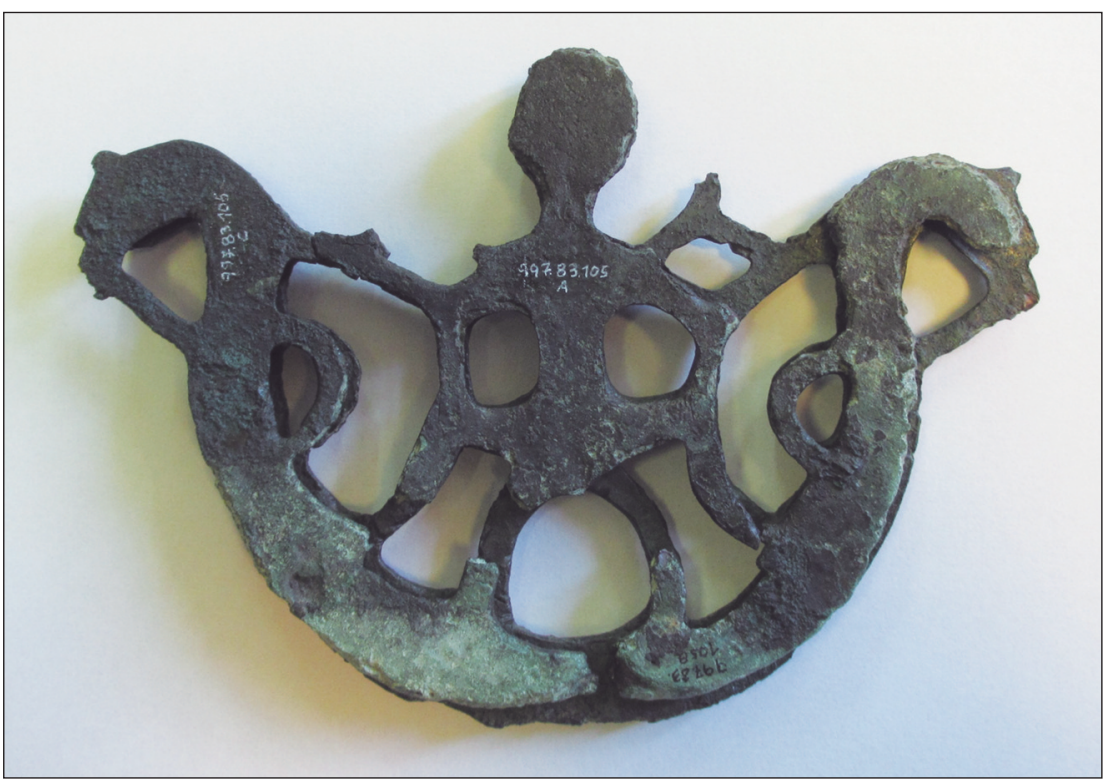

Figura 8. Superposición de las placas cat. 4 y 5 donde, a pesar de la disimetría, se aprecia la coincidencia de las siluetas de las figuras. al ser iguales entre sí, se pueden haber producido en uno solo. Para la realización de los moldes de las dos camas portuguesas, verosímilmente de arcilla, se han usado las mismas matrices, como se puede comprobar cuando se observa la coincidencia de siluetas en los elementos centrales, y en particular en la figura antropomorfa, al superponer una sobre la otra (Fig. 8). Estas matrices, sin embargo, son distintas de las que se han usado para las camas de Cancho Roano, como se deduce de la comparación de las siluetas. Posteriormente, ha habido que ir adaptando los elementos a la pretendida estructura especular para confeccionar dos moldes diferentes, lo que requiere de un cierto trabajo de reajustes y de enmendaduras hasta obtener el resultado deseado.

Aparte del magnífico ejemplar completo, en Cancho Roano se ha recuperado una segunda cama fragmentada y un segmento de una tercera placa, lo que permite recomponer dos equipos diferentes que tampoco parecen fundidos con el mismo molde. Los elementos fragmentarios, al contrario que el ejemplar más conocido y reproducido, conservan los clavos de 
unión a las riendas en las argollas de sujeción que aparecen a la altura de las grupas de los caballos y que en nuestros ejemplares se hallan ausentes (Maluquer de Motes, 1981: fig. 37; Blech, 2003: fig. $2 \mathrm{c}$ y $2 \mathrm{~d}$ ). Con posterioridad se ha publicado un fragmento de cama de este mismo tipo, correspondiente a la zona del personaje central, procedente de la región de Murcia (Quesada, 2002-03). A ellos podemos agregar un fragmento similar, inédito, que fue ofrecido hace algunos años al Museo Arqueológico de Badajoz y redirigido desde allí al IGESPAR de la zona del Alentejo, pues se decía proceder del Castro de Segóvia en Elvas 5 .

Todos estos ejemplares permiten definir un grupo homogéneo de placas similares que, atendiendo a su distribución, debemos considerar como una producción genuinamente peninsular, pues hasta ahora solo se han hallado -y ya con cierta profusión- en la mitad meridional de la Península Ibérica, y de forma más concentrada en el cuadrante suroccidental. Sin embargo, este nuevo conjunto contribuye a matizar algunas cuestiones que se han propuesto al tratar sobre la producción de estos objetos, que suelen atribuirse a un mismo taller (Maluquer de Motes, 1983: 63; Quesada, 2005: 110). Las diferencias formales, de calidad técnica y de matrices que se observan entre los ejemplares del MNA y los de Cancho Roano evidencian su procedencia de centros artesanales distintos. Y a estas mismas conclusiones se llega cuando se examinan otros de los elementos que componen estos equipos ecuestres, como los botones, tal y como tendremos ocasión de comprobar después.

También se deben realizar algunos comentarios sobre la cronología de estas composiciones, pues algunos autores han defendido su datación en el siglo VI a.C., aunque normalmente con escasa base argumental (Almagro-Gorbea y Domínguez de la Concha, 1988-89: 340; Quesada, 2005: 114). La aparición de equipos homogéneos en Cancho Roano, bien fechados por la cerámica griega a finales del siglo $\mathrm{V}$ a.C., y ahora en este conjunto del MNA, formado básicamente por los mismos componentes metálicos, apunta a que estas combinaciones de arreos se fabricaran y se usaran de manera prioritaria a lo largo de la centuria del cuatrocientos. Es cierto que la existencia de placas decoradas con divinidades junto a otras donde solo aparecen caballos contrapuestos (el tipo A de
Cancho Roano) puede sugerir la mayor antigüedad de aquéllas, respondiendo a los procesos de transformación social que se experimentan en la Península Ibérica por estas fechas, y donde el peso y la presencia de la divinidad va perdiendo fuerza en la imaginería de la legitimación aristocrática (Almagro-Gorbea, 1996). Pero, la reiteración de las mismas placas en los mismos conjuntos postorientalizantes lleva a pensar que estén en pleno uso en el siglo $\mathrm{V}$ a.C., y que no se trate solo de pervivencias. En cualquier caso, el registro, aunque significativo, es aún escaso y en gran parte descontextualizado, por lo que cabe esperar más de futuros hallazgos de cara a poder precisar mejor las cronologías.

Pero quizá haya sido la iconografía el aspecto más tratado por quienes se han aproximado al estudio de estos artefactos a partir, sobre todo, de los hallazgos de Cancho Roano (Maluquer de Motes, 1983: 54 ss., Blech, 2003: 171 ss.; Gomes, 2001: 117 ss.; Quesada, 2002-03; 2005: 114 ss.).

En todos estos trabajos se pone de relieve el remoto origen oriental de la temática representada: un personaje divino que aparece dominando dos caballos contrapuestos, motivo que aparece aplicado a bocados ecuestres ya en los bronces del Luristán, y que después se sigue utilizando a lo largo y ancho del Mediterráneo (Ibidem). Y todos ellos se ilustran con una más o menos amplia lista de referentes y paralelos de Oriente, Grecia e Italia central, sin olvidar la Península Ibérica, donde versiones de este motivo aparecen tanto en la toréutica orientalizante (también en forma de bocados, del que constituye el mejor ejemplo el archiconocido Bronce Carriazo y sus homólogos del Metropolitan Museum de Nueva York (Jiménez Ávila, 2002: 230; 2015: fig. 40), como en la orfebrería o en la escultura ibérica, donde lo encontramos en los relieves de Villaricos (Chapa, 1985: lám. XVIII). Por lo que a los bocados se refiere, los más recientes modelos mediterráneos se fechan en el siglo VI a.C. Sin embargo, en la Península Ibérica, el motivo iconográfico parece mantenerse con posterioridad.

Por tanto, se puede considerar que este tipo de bocados hunde sus raíces en tradiciones orientales y mediterráneas ya presentes en la Península Ibérica en el Periodo Orientalizante, y que se debieron formar a partir de estos estímulos y de

5 Hemos intentado localizar la pieza sin éxito. 


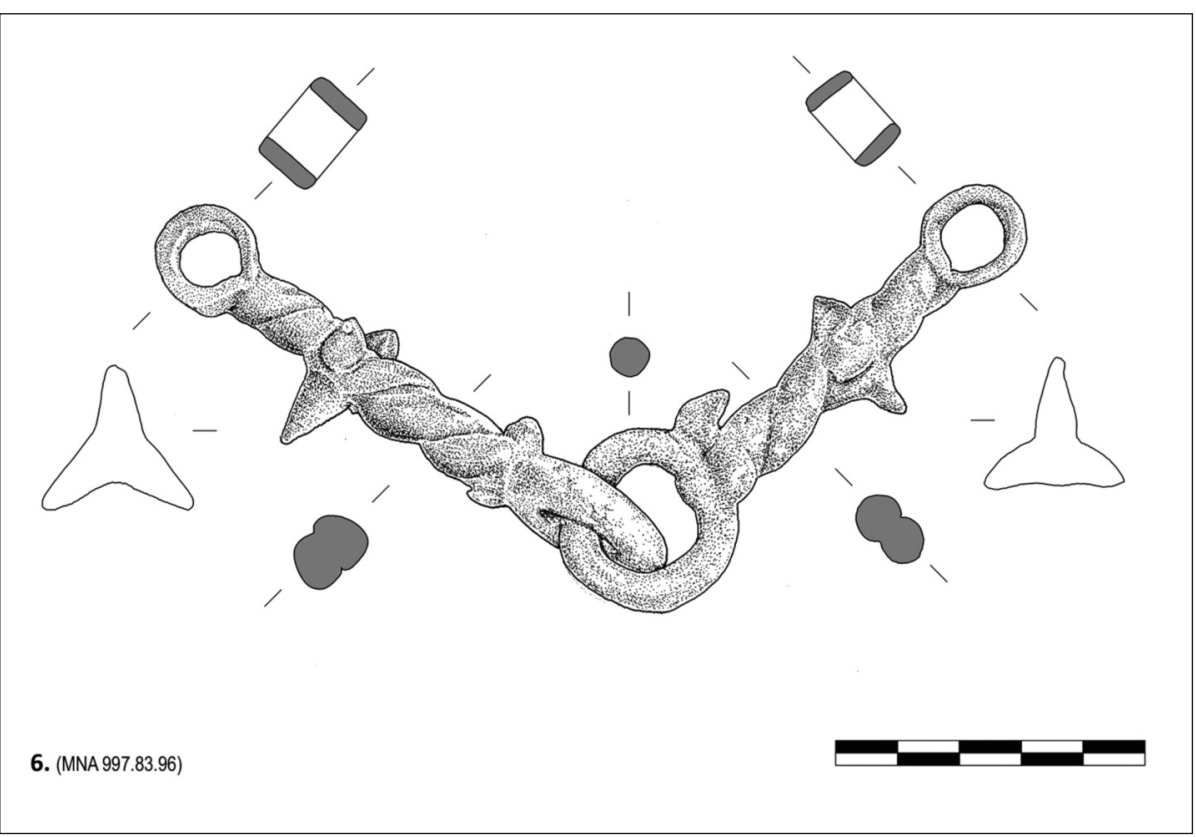

Figura 9. "Conjunto sepulcral de Guerreiro", cat. 6: bocado articulado. Museu Nacional de Arqueologia (Dibujo J.M. Jerez). tico, aunque sería esperable que, en este caso, contase con una brida equivalente a la que tienen los caballos. De no ser así, tendríamos que aceptar que la composición resultante asume algunas incoherencias compositivas respecto del original, pues la figura central estaría sujetando al animal por la cabeza y por la cola al mismo tiempo. En este sentido, y sin salir del terreno de lo fantástico, la silueta zoomorfa, tal y como aparece representada, puede recordar la morfología de un hipocampo. Esto es algo que, a pesar otros nuevos debidos a los contactos que se establecen con Grecia y, en menor medida, con Italia central, en los siglos posteriores.

Sobre el carácter masculino (Despotes) o femenino (Potnia) de la divinidad representada en estos bocados se ha generado algún debate (Gomes, 2001: 117 s.), sin que los argumentos sean del todo convincentes y sin que la indefinición iconográfica de nuestros ejemplares contribuya a aclarar grandemente el problema. La presencia simultánea de palomas, un animal habitualmente consagrado a las divinidades femeninas, junto a caballos, que son más propios de deidades masculinas, tal vez pueda relacionarse con el carácter dual de las representaciones originales y con su consignada indefinición sexual.

Pero, tal vez, más que inquirirnos sobre estas cuestiones surgidas a la vista de las placas de Cancho Roano, convendría preguntarse sobre el porqué de las transformaciones de que es objeto el modelo original en las camas del MNA y qué es lo que estas representan.

La silueta que adquiere la terminación de las camas en la zona opuesta a las cabezas equinas no se percibe como una forma naturalista reconocible. En este sentido, parece poco probable que se trate de una cola de caballo. Si aceptamos el esquema original, donde la figura central aparece sujetando dos cabezas, tendría que tratarse de la cabeza de otro animal (que tampoco resulta reconocible), de lo que resultaría un ser híbrido de carácter fantás- de la escasez de representaciones de este tipo de seres mitológicos en la protohistoria hispánica (Olmos, 1992: 53), no contrasta con algunas ideas que se han señalado en los estudios iconográficos de este tipo de imágenes, que las identifican con representaciones de míticas embarcaciones, a veces relacionadas con el tránsito al Más Allá (Maluquer de Motes, 1957; 1983: 54). Si se verifica que los personajes centrales han perdido la bifrontalidad quizá estemos, tanto en el caso del caballo como en el de los antropomorfos, ante un ejemplo de desmitificación del motivo fantástico y su conversión en otro de carácter más realista, quizá un jinete algo idealizado. Ya hemos señalado cómo en Cancho Roano parece producirse una tendencia a abandonar los motivos religiosos por los propios de la aristocracia ecuestre en los dos tipos de bocados presentes en este yacimiento. Las camas que aquí estudiamos podrían estar materializando un punto intermedio en este proceso de conversión iconográfica, donde el despotes es sustituido por un jinete humano antes de desaparecer por completo en las camas de caballos afrontados. Pero el trabajo de las piezas es demasiado esquemático e indefinido como para poder proponer esta posibilidad, por sugerente que sea, de modo definitivo. No obstante, sí parece claro que el modelo original es el que aparece reflejado en las camas de Cancho Roano, que representa dioses y animales duplicados en disposición simétrica, y que el de las placas del MNA es una modificación posterior de dicho esquema. 


\subsubsection{Filete articulado (cat.6)}

En íntima relación con las camas, como componente esencial del freno del caballo, hay que situar un filete articulado que forma parte de este equipo ecuestre. Se conserva completo y está formado por dos cañones trenzados unidos entre sí por dos gruesas anillas de sección circular situadas en los extremos distales, mientras que por los proximales termina en dos anillas más pequeñas de constitución tubular. Sus medidas son de $9,5 \mathrm{~cm}$ cada uno de ellos y presentan dos series de tres púas de castigo situadas, respectivamente, en la mitad del cañón y junto a las anillas de unión. No obstante, las púas de la zona de las anillas de unión aparecen dobladas y amortizadas, habiendo perdido su función primigenia (Fig. 9).

$\mathrm{El}$ bocado ha sido fundido a la cera perdida, probablemente en dos fases: en primer lugar, se ha colado una de las mitades y después, sobre esta ya constituida, se habría sobrefundido la segunda, generando así la unión, aunque sin que el bronce entrara en contacto. A pesar de que se trata de un producto de considerable calidad técnica, en muchas zonas de su superficie se aprecian vacuolas debidas a una defi-

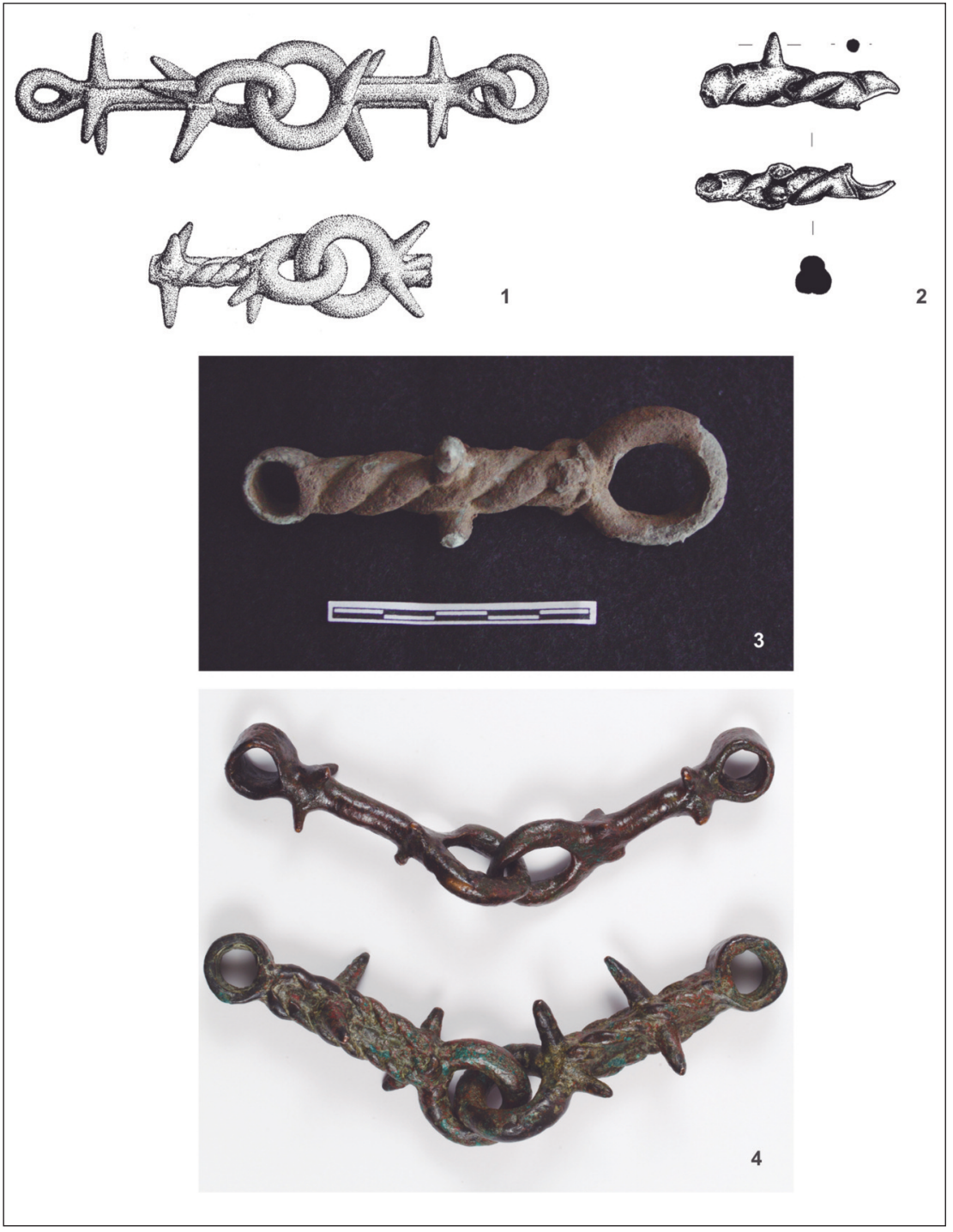

Figura 10. Bocados de bronce postorientalizantes e ibéricos. 1. Dos ejemplares de Cancho Roano (s. Maluquer 1983); 2. Torrejón de Abajo, Cáceres (s. Jiménez Ávila y Ortega Blanco, 2008); 3. Fundación A. Concha, Navalmoral de la Mata (s. Jiménez Ávila y González Cordero, 2012: fig. 7); 4. Ejemplares del Museo Juan Cabré (Foto Hugo Pañellas). Escalas no uniformadas. ciente desgasificación durante el proceso de colada.

Las dos partes del filete se diferencian entre sí por la relación de los planos que forman sus respectivas anillas, que en un caso son paralelos y en otro perpendiculares, de manera que, al estar engarzadas las piezas, las anillas proximales quedan en paralelo, facilitando así el funcionamiento del bocado. Esta característica es habitual en este tipo de utillaje desde las más antiguas creaciones conocidas.

A la vista de esta pieza y de su convivencia con las camas caladas, surge la inmediata tentación de buscar sus referentes entre los filetes de Cancho Roano, con los que sin duda debe relacionarse. Sin embargo, existen algunas diferencias entre nuestro bocado y los de este yacimiento, de donde se conservan tres ejemplares (uno de ellos incompleto). Dos de los filetes de Cancho Roano son fasciculados y no torsionados y terminan sus cañones en unas anillas de sección circular que, a su vez, aprisionan argollas de bronce a las que se sujetarían las riendas; el tercer ejemplar, del que solo se conserva la parte central, parece tener un trabajo de torsión en el cañón algo más elaborado que los nuestros, que se configuran con un simple cordón doble (Fig. 10.1). (Maluquer de Motes, 1983: 53 s.; Blech, 2003: fig. 3). En su lugar, el filete del MNA parece más próximo desde el punto de vista tipológico a tres ejemplares que han sido dados a conocer con 
posterioridad: uno de las excavaciones de El Torrejón de Abajo, Cáceres (Fig. 10.2), otro de la Fundación Antonio Concha de Navalmoral de la Mata, de procedencia desconocida, aunque segura- mente de la provincia de Cáceres (Fig. 10.3) y un tercer bocado, también sin origen, conservado en el Museo Juan Cabré de Calaceite (Fig. 10.4) recientemente publicado (Jiménez Ávila 2018a). Todos

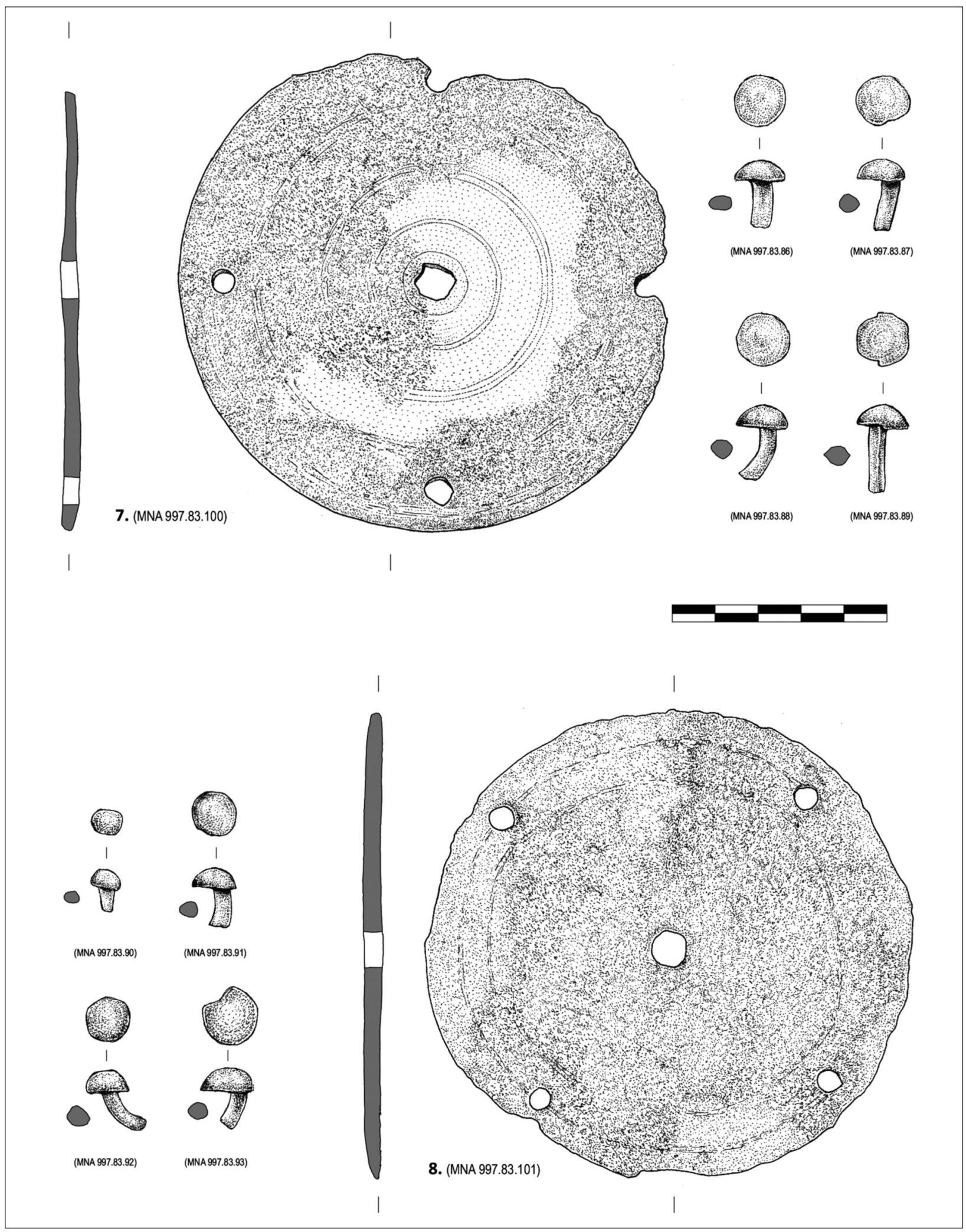

Figura 11. "Conjunto sepulcral de Guerreiro”, cat. 7 y 8: faleras. Museu Nacional de Arqueologia (Dibujos J.M. Jerez). 
ellos presentan el cañón torsionado, las dos series de tres púas y las sujeciones externas en forma tubular, al igual que los nuestros. Todos estos bocados parecen formar parte de una misma familia de frenos postorientalizantes a la que habría que agregar algún material inédito y otros ejemplares actualmente desaparecidos (Jiménez Ávila, 2018a).

Como ya ha sido señalado en otras ocasiones, todos ellos presentan algunos rasgos que permiten diferenciarlos de los pocos ejemplares que hasta ahora conocemos del Periodo Orientalizante (en particular de los de la tumba 17 La Joya), destacadamente, la presencia de púas de castigo, pero también su menor longitud y, por el contrario, un mayor tamaño de las anillas de unión (Jiménez Ávila, 2002: 229). Sin embargo, estos nuevos ejemplares con terminaciones tubulares se aproximan más a los bocados de Úbeda la Vieja, algo más recientes que los de La Joya, estableciendo lógicos puentes de unión entre ambas generaciones de frenos.

Se podría, por tanto, decir que con los filetes sucede algo similar a lo que acontece con las camas que se les asocian: presentan elementos de conexión con la tradición de bocados orientalizantes, muy mal conocidos en la Península Ibérica, y reciben influjos posteriores, sobre todo del mundo griego, que es donde aparecen de manera más evidente los frenos con elementos de castigo durante los siglos VII y VI a.C. (Donder, 1980; Quesada, 2005: 115). Esta generación de bocados de bronce será prontamente sustituida por los frenos de hierro que, en algunos casos, conviven ya con los mismos tipos de atalajes ecuestres, como parece ser el caso del conjunto procedente de Talavera la Vieja (Jiménez Ávila y González Cordero, 2012) o como pone de manifiesto la convivencia de ambos tipos de arreos entre el material de Cancho Roano (Blech, 2003).

En cuanto a lo que puede aportar el bocado del conjunto del MNA respecto de las medidas del ganado al que iría destinado, el espacio que dejan las anillas es de unos $14 \mathrm{~cm}$, magnitud que se encuentra en los estándares de los frenos mediterráneos de la Edad del Hierro, siendo algo mayores que los de Cancho Roano, sus congéneres más próximos desde el punto de vista tipológico (Balkwill, 1973; Jiménez Ávila, 2002: 229).

Finalmente, hay que señalar que la diferente constitución de las anillas externas del bocado del MNA con respecto a los ejemplares conocidos de Cancho Roano quizá deba relacionarse con un diferente sistema de unión de las riendas, pues en ninguno de los casos que presentan terminaciones tubulares se han preservado anillas accesorias.
Aunque no es descartable que éstas se hubieran perdido, se pueden proponer otras formas de unión de las riendas a los extremos de los cañones, como la confección de anillas supletorias de otros materiales perecederos. El paso de la rienda a través de las anillas tubulares y su costura sobre sí misma (tal y como, presumiblemente, se efectuaría en los bocados con anilla supletoria) resulta más problemático, por el escaso diámetro de los agarres y el poco juego que este sistema permitiría a la correa.

\subsubsection{Placas discoidales ofaleras (cat.7 y 8)}

Junto a las camas y a la embocadura recién examinadas, se pueden considerar como complementos de la cabezada del caballo dos placas discoidales de bronce o faleras que forman parte del conjunto. Ambas son de similar formato y análogas características: tienen algo menos de $12 \mathrm{~cm}$ de diámetro cada una y presentan cuatro perforaciones perimetrales dispuestas en cruz, más otra de situación central y mayor tamaño. Están fundidas a molde abierto y pulidas por una de sus caras, donde se han grabado a compás varias series de círculos concéntricos próximos que constituyen toda su decoración y que, en función del grado de conservación de cada una de ellas, se perciben con mayor o menor nitidez (Fig. 11).

Con estos dos discos deben relacionarse ocho tachuelas de cabeza hemisférica incluidas en el conjunto. Las tachuelas son prácticamente iguales en tamaño y forma, aunque también difieren entre sí en su grado de conservación. Están fundidas a molde bivalvo, como denuncian las costuras laterales que presentan en los vástagos y, en algún caso, los desajustes en la zona de la cabeza hemisférica. El hecho de que el número de perforaciones y el de tachuelas no coincidan puede ser debido al mero azar de la conservación o a contingencias de la recogida, y hay que tener en cuenta que uno de los discos está corroído por dos de las perforaciones, que han quedado abiertas, lo que ha podido facilitar el desprendimiento de sus dos correspondientes remaches. Sin embargo, la circunstancia de que todas las tachuelas sean del mismo tamaño y que dos de ellas estén muy mineralizadas (podrían ser las que corresponden a estas zonas más deterioradas), provoca que pensemos que las ocho unidades correspondan a las sujeciones externas, aunque cuando se han preservado discos de este tipo completos, como sucede en Cancho Roano, se conserve también el elemento de sujeción central (Maluquer de Motes, 1981, figs. 11 y 40; 1983, figs. 16 y 17; Blech, 2003: fig. 20). 
Precisamente, es de nuevo en el yacimiento de Cancho Roano donde encontramos los mejores -casi los únicos- referentes conocidos para este tipo de aditamentos, pues con la salvedad de este célebre centro palacial, apenas se pueden citar algunos discos más procedentes de Azougada que se conservan inéditos en el MNA de Lisboa $^{6}$ (Fig. 12) y, con menor certeza, algunos adornos de bronce localizados en la tumba 350 de la necrópolis de $\mathrm{La}$ Osera (Ávila) que originalmente se interpretaron como complementos de cinturón y cuya función podría revisarse (Cabré et al., 1950, lám. LIV). Entre las ruinas del complejo palacial de Cancho Roano se hallaron alrededor de una veintena de faleras que podemos relacionar con las nuestras, aunque presentan problemas debidos tanto a su estado de conservación como a su parcial y desigual publicación.

Del interior del edificio principal proceden varias unidades que se han adscrito a tres tipos/tamaños diferentes: 1) los más grandes, de alrededor de 11-12 cm de diámetro, presentan cinco tachuelas, círculos concéntricos incisos y una placa circular superpuesta con un motivo floral repujado. Se le han

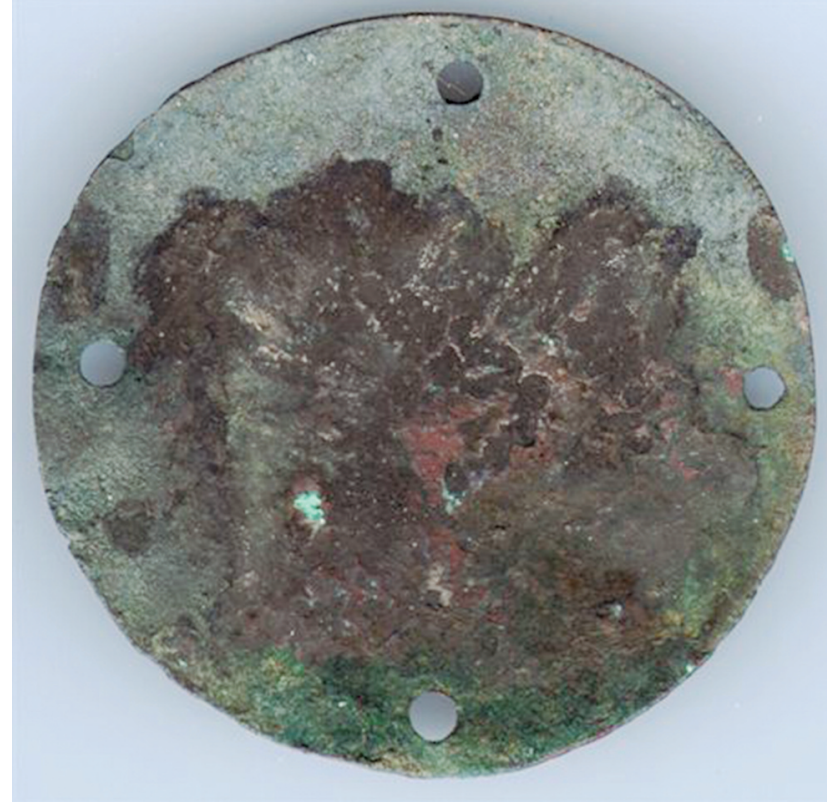

Figura 12. Azougada. Disco perforado o falera (Foto Museu Nacional de Arqueologia).
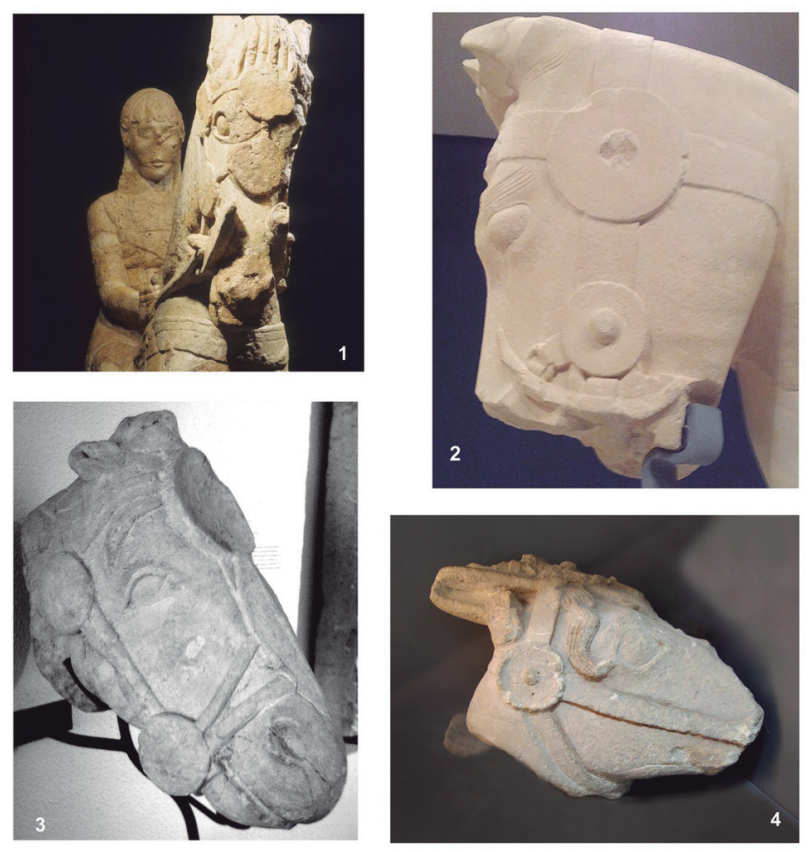

Figura 13. Esculturas ibéricas representando caballos decorados con discos o faleras. 1. Los Villares (Albacete); 2. Cerrillo Blanco (Jaén); 3. Fuente la Higuera

(Valencia); 4. Cigarralejo (Murcia), (s. diversos autores). adscrito cuatro o cinco ejemplares, pero solo se han dibujado dos a los que, curiosamente, les falta un sector correspondiente a uno de los remaches, por lo que no es imposible (aunque sí poco probable) que solo tuvieran tres tachuelas perimetrales y una central. A los otros, únicamente descritos, les falta la roseta central, sin que se pueda asegurar, sin ver el material, si esto se debe a que se han extraviado o a que nunca las tuvieron. 2) Un tipo intermedio está formado por cinco o seis discos de en torno a 7,5 $\mathrm{cm}$ de diámetro con tres remaches periféricos y uno central. Uno de ellos presenta roseta repujada, los otros cuatro, círculos concéntricos. 3) Formado por seis discos menores, todos iguales, $(4,5 \mathrm{~cm}$ de diámetro medio) dotados de círculos concéntricos y un único remache central (Maluquer de Motes, 1981: 106 ss.; 1983: 59 ss.; Blech, 2003: 183 ss.). A estas placas hay que añadir un disco procedente de la habitación perimetral N-5 de tamaño mediano y dotado solo de tres perforaciones: una central y dos laterales, dispuestas diametralmente, que no ha sido incluido en el estudio general de los atalajes de Cancho Roano (Celestino Pérez y Jiménez Ávila, 1993: fig. 29.1).

6 MNA cat. 51150 - 51153, actualmente preparamos el estudio del material de bronce de Azougada. 
De todos ellos, los más próximos a los nuestros son los de tipo 1. Sin embargo, los problemas señalados, impiden verificar si en Cancho Roano había discos idénticos a ellos, es decir, con cinco tachuelas y sin rosetas. Tampoco es descartable que los discos del MNA llevaran rosetas en origen, aunque esto es más difícil de admitir porque, de ser así, las rosetas ocultarían las series de círculos grabados más próximas al centro. En cualquier caso, lo que parece claro es que el material ecuestre de Cancho Roano está necesitado de una revisión, pues no parece que se haya vuelto a analizar con suficiente detalle desde las descripciones de Maluquer de Motes, hace 30 años.

No obstante, a la vista del ejemplar de N-5, de diámetro similar a los nuestros y con una disposición diferente de perforaciones, parece lícito pensar que estos discos adoptaran distintas modalidades conforme al uso final que se les quisiera dar.

A similar conclusión se llega cuando se observa la variada disposición que adoptan las faleras de las cabezadas de algunos caballos representados en una serie cada día más numerosa de esculturas ibéricas en las que estos adornos están presentes. Desde que se descubrieron los primeros bronces de Cancho Roano estas figuraciones ibéricas se han venido refiriendo, acertadamente a nuestro juicio, como evidencia del uso ecuestre que debieron tener los discos de bronce perforados (Maluquer de Motes, 1983: 63; Blech, 2003).

Las muestras de cabezas equinas dotadas de este tipo de arreos, aisladas o integradas en conjuntos más amplios, que se pueden traer a colación son las de El Cigarralejo (Murcia), Fuente la Higuera (Valencia), Cerrillo Blanco (Jaén), Los Villares (Albacete) y Alcantarilla (Murcia) todas ellas muy próximas desde el punto de vista cronológico al periodo que aquí nos interesa (Fig. 13).

Aunque no es el objetivo de este trabajo realizar un estudio pormenorizado de este tipo de cabezadas en la plástica ibérica, resulta útil sistematizar su morfología de cara a percibir su variedad y a comprender mejor el uso de los hallazgos reales realizados en el Suroeste. El trabajo se ha realizado a partir de las fotografías y dibujos publicados y no sobre el material real, por lo que puede que requiera de algunas correcciones de detalle. No obstante, de cara a nuestros propósitos, el esquema resultante nos permite observar la gran variedad de soluciones que se arbitran, tanto en el número de discos como en su diseño, tamaño y disposición (Fig. 14). Así, encontramos cabezadas con solo tres discos, como parece ser el caso de El Cigarralejo, donde las quijeras se superponen a los elementos que aparecen en la parte inferior de las mismas, lo que

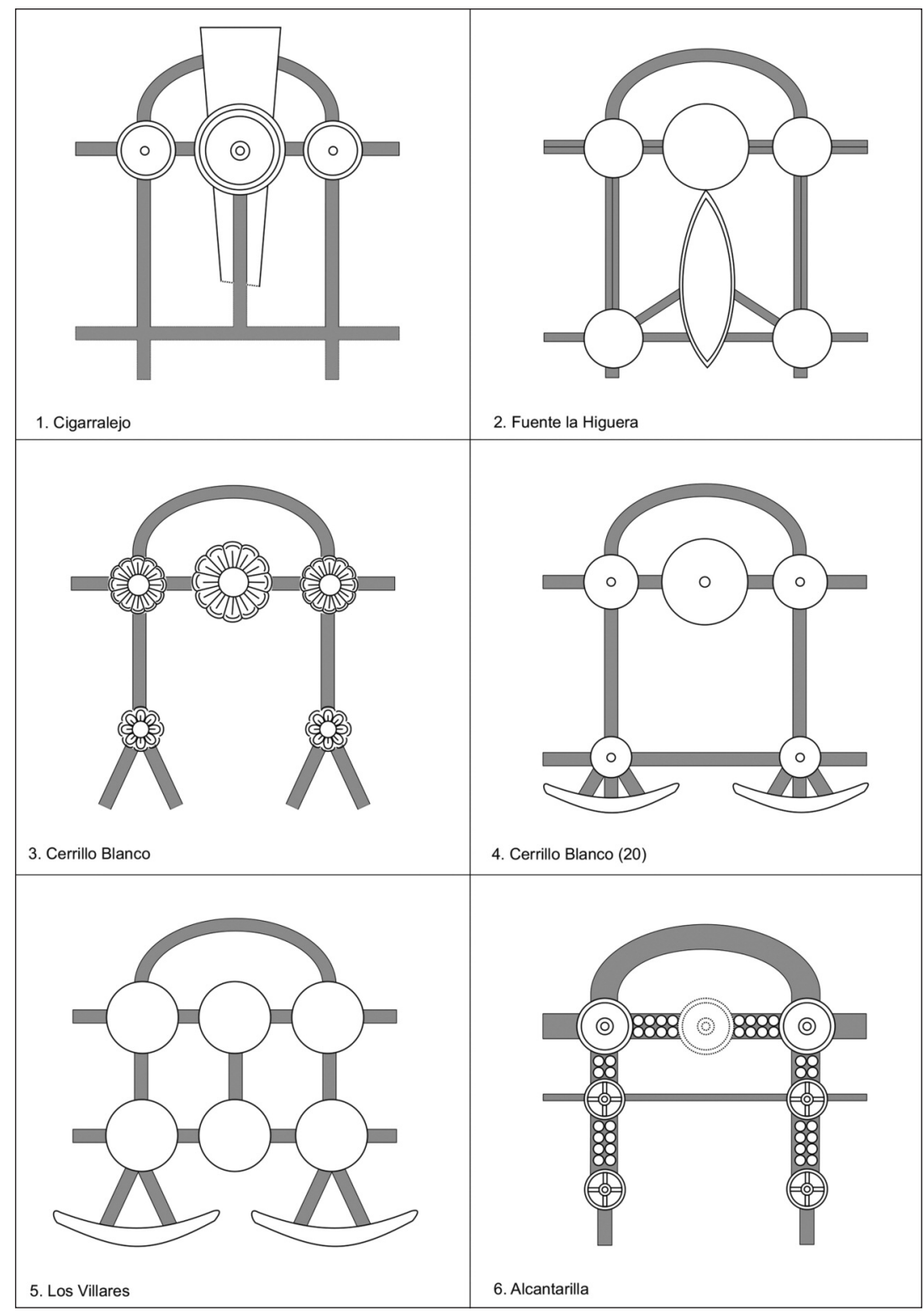

Figura 14. Esquema de la disposición de los discos en diversas esculturas ibéricas de temática ecuestre. 
excluye que pueda tratarse de discos (Ruano, 1998: 60 , fig. 23); cabezadas con cinco discos, las más numerosas, aunque adoptan muy diversas modalidades, incluso dentro de los mismos conjuntos escultóricos, como sucede en los dos caballos representados en el Cerrillo Blanco, que ostentan diseños diferentes, incluyendo adornos florales que recuerdan las rosetas de Cancho Roano (Negueruela, 1990: lám. XX); o se combinan con elementos de tipo diverso, como el frontal oblongo de Fuente la Higuera, del que parece haberse hallado un testimonio real en una tumba de El Cigarralejo (Cuadrado, 1987: lám. XXI) -curiosamente no se encuentran verdaderos discos en las necrópolis ibéricas-; cabezadas de seis discos, como la del magnífico jinete de Los Villares (Hoya Gonzalo), en el Museo de Albacete, que, a falta de un estudio pormenorizado, nos permite afirmar que este tipo de jaeces se usaban en caballos de monta (Blánquez, 2011: 77), e, incluso, cabezadas de hasta más de seis discos, como podría ser el caso de Alcantarilla, aunque la reconstrucción que hacen sus editores a partir del fragmento conservado no sea obvia (Lillo y Serrano, 1989). Esta última pieza, además, permite inferir el uso de pequeños botones como complemento de las correas de las cabezadas, como posteriormente tendremos ocasión de precisar.

Pero volviendo a nuestros discos, para proponer su ubicación en la cabezada debemos tener en cuenta, aparte de las observaciones realizadas a partir de todos estos referentes, dos factores sustanciales: su número y la disposición de los agarres. Conforme a ello, lo más probable es que los ejemplares del MNA se colocaran en posición lateral, pues su número par requiere una disposición simétrica ${ }^{7}$ y, además, la presencia de cinco remaches aleja la posibilidad de una posición frontal, pues aquí solo se requerirían dos o, a lo sumo, tres sujeciones exteriores. En esta situación, lo más probable es que se ubicaran en la parte superior, a la altura de las sienes, que es donde se justifican de mejor modo los cuatro remaches externos, como se aprecia en, prácticamente, todas las cabezadas escultóricas examinadas. Su posición en la parte baja es más difícilmente sostenible pues aquí son menos frecuentes los cruces de cuatro correas, y no se dan casos donde existan discos grandes en la parte inferior sin que los haya en la superior (ver
Fig. 14). Por otro lado, la instalación de grandes discos en la parte baja de la cabezada entraría en concurrencia con la visibilidad de los bocados calados, interfiriendo, incluso, su movilidad, por lo que es probable que en esta zona se arbitraran otras soluciones decorativas, aunque hay representaciones escultóricas donde discos y bocados están muy próximos.

\subsubsection{Pasarriendas (cat. 9 y 10)}

Con el análisis de los pasarriendas nos alejamos del ámbito de los componentes de cabezada para entrar en el terreno de las piezas de enganche o unión al carro, todas ellas relacionadas con el yugo, como suele ser habitual en los hallazgos protohistóricos de la Península Ibérica (Jiménez Ávila y Muñoz, 1997). No obstante, hay elementos, como los botones o los colgantes sonoros, que pueden haberse integrado indistintamente en ambos sistemas de correajes, por lo que serán estudiados al final de este apartado.

Los pasarriendas constituyen dos de los elementos más característicos del conjunto, de ahí que fueran publicados, con su dibujo incluido, en el trabajo de M. Varela Gomes en que se refiere su hallazgo (Gomes, 2001: fig. 4, C y D). Posteriormente han sido tratados en varios estudios dedicados a este tipo de artefactos (Jiménez Ávila, 2002: 214 ss.; Jiménez Ávila y González Cordero, 2012: 216: fig. 3).

A pesar de su evidente dimorfismo (Fig. 15), ambos elementos corresponden al tipo de pasarriendas de vástago, bien conocido en la Península Ibérica desde la aparición del primer ejemplar en la necrópolis de Alcácer do Sal (Fig. 16, n. ${ }^{\circ}$ 1), que constituía, hasta la aparición de los nuestros, el único ejemplar reconocido en Portugal (Schüle, 1969, lám. 108, n. o 8; Gomes, 2016: lám. CXVIII, n. ${ }^{\circ}$ 998).

Estos pasarriendas son típicamente hispánicos, sin parangones fuera del territorio peninsular, a pesar de sus claras referencias iconográficas al mundo fenicio y mediterráneo (Jiménez Ávila y Muñoz, 1997; Jiménez Ávila, 2002: 214 ss.).

Dentro las clasificaciones realizadas los ejemplares del MNA se adscriben al subtipo $2 \mathrm{~b}$-con decoración de crestería- quedando las diferencias entre ellos únicamente en el nivel de la variante, ya que el ejemplar $n{ }^{\circ} 10$ se decora con crestería simple

\footnotetext{
7 Partimos de la base de que el conjunto está completo y no faltan en él elementos sustanciales, como posteriormente precisaremos.
} 
(variante $2 \mathrm{~b} 1$ ), formada por una sucesión de capullos florales cerrados (como en el ejemplar de Alcácer do Sal) mientras que en el n. ${ }^{\circ} 9$ la crestería alterna capullos cerrados con flores abiertas, como en el conocido ejemplar de la Colección Vives (Fig. 16, n. ${ }^{\circ}$ 2), que ejemplifica la variante de crestería compleja (2b2). A esta variante pueden adscribirse también algunos fragmentos de palmetas recogidos en la Colección Alhonoz (Jiménez Ávila, 2002: 516). No obstante, el modo en que se presenta la crestería de este ejemplar del MNAes sustancialmente más sencillo que los de las citadas colecciones, con flores bipétalas y yema central apenas moldurada en lugar de las completas palmetas y capullos bien perfilados de aquellos, $\mathrm{y}$ con un juego de calados mucho más simple (Fig. 15).

La cronología que abarca el uso de estos pasarriendas de vástago comprende un periodo de al menos 300 años, como evidencian los ejemplares de El Peñón de la Reina (Almería), hallado en un poblado con una ocupación de finales del siglo VIII-principios del VII a.C., y el de Cancho Roano (finales del siglo V a.C.), tratándose en ambos casos de ejemplares

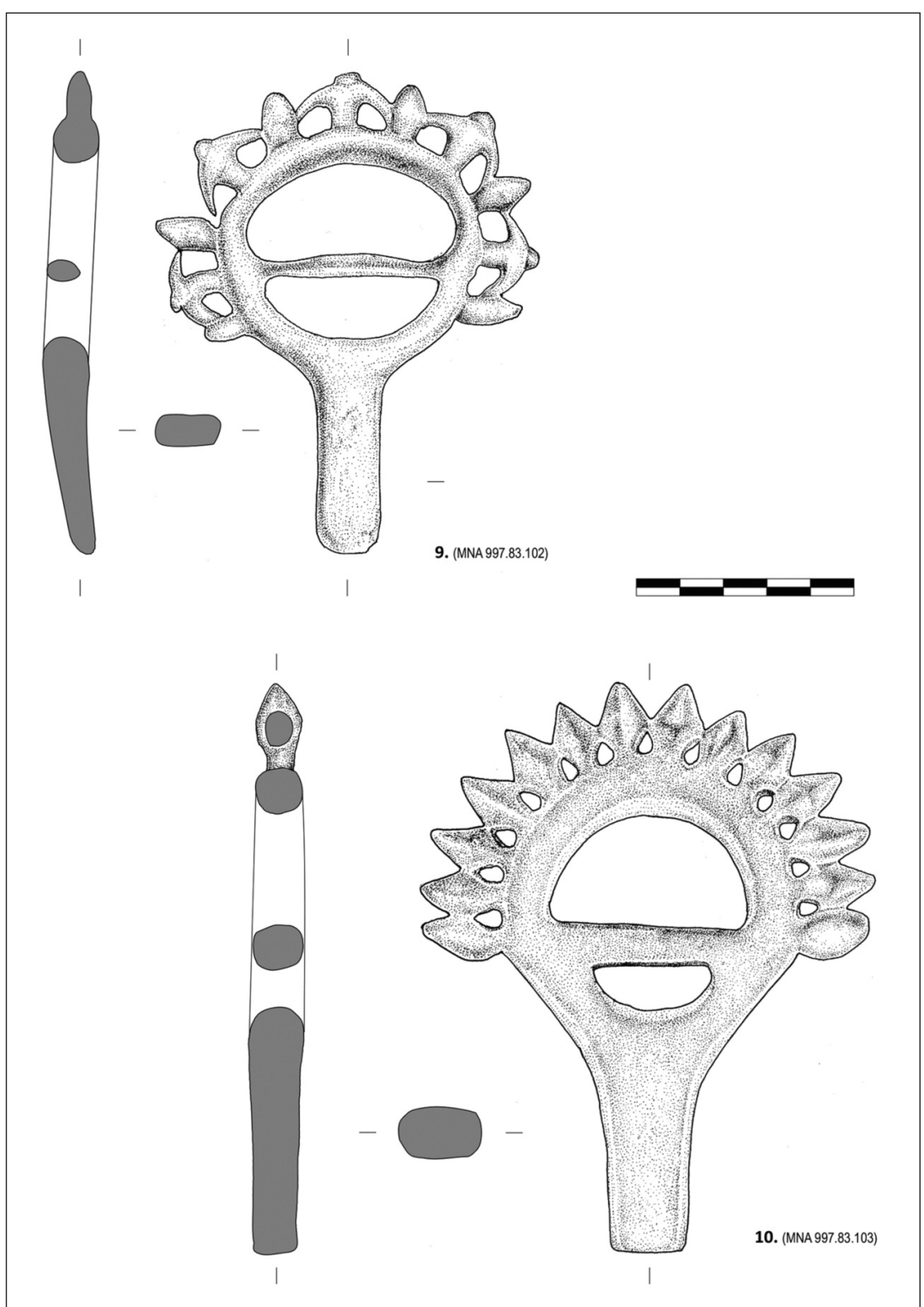

Figura 15. “Conjunto sepulcral de Guerreiro”, cat. 9 y 10: pasarriendas. Museu Nacional de Arqueologia (Dibujos J.M. Jerez). anilla simple (Jiménez Ávila, 2002: 218). Ninguno de los ejemplares con crestería procede de contextos fiables, si bien se han señalado cronologías de los siglos VII y VI para los de Úbeda la Vieja, fruto de actividades ilegales (Ferrer y Mancebo, 1991; Jiménez Ávila, 2002: 218, respectivamente). Composiciones como las del ejemplar de la Colección Vives pueden situarse en el siglo VII a.C.

En cualquier caso, de cara a tratar la cronología de la pareja de pasarriendas que aquí nos interesa, es necesario valorar, principalmente, sus acusadas diferencias, pues todos los casos conocidos en que se han recogido grupos de pasarriendas de vástago en contextos clara o presumiblemente cerrados (la tumba 17 de La Joya, Úbeda la Vieja, Talavera la
Vieja...), siempre corresponden a la misma modalidad.

Las diferencias entre estas dos unidades no solo se refieren a los aspectos formales, pues el peso (152 frente a $372 \mathrm{~g}$ ), el tamaño y la consistencia de ambos elementos también los alejan en modo sustancial, hasta el punto de que tengamos que considerarlos como productos inicialmente preparados para equipos ecuestres diferentes. No es descartable que se realizaran equipos de arneses formados por pasarriendas de tipología diferente unidos dos a dos, sobre todo en el caso de yugos con cuatro unidades. Pero esto es más difícilmente sostenible para hallazgos como el nuestro, donde solo aparecen dos ejemplares y donde a las disimilitudes formales se 

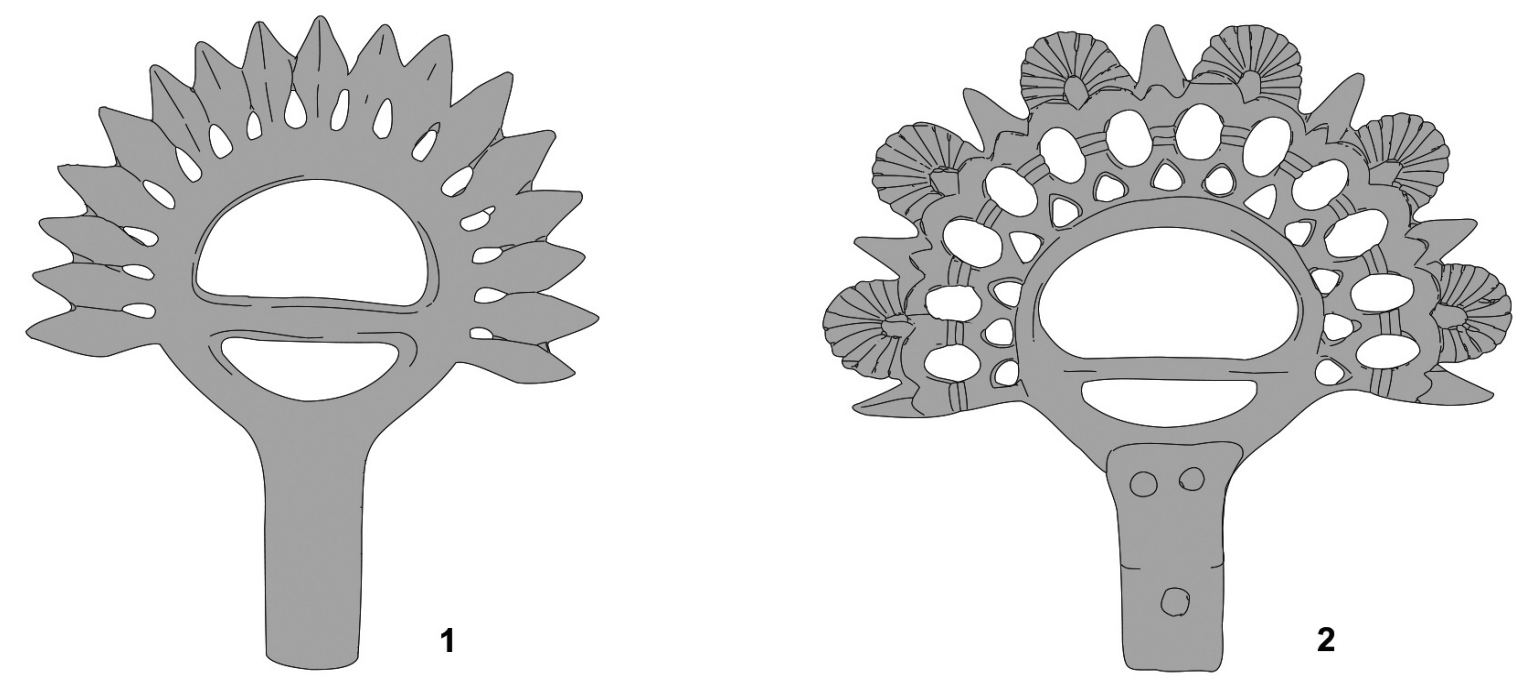

Figura 16. Pasarriendas de bronce hispánicos. 1. Alcácer do Sal; 2. Colección Vives (Dibujos J. Jiménez Ávila).

agregan otras como el peso o el tamaño, que ya hemos señalado.

Por todo ello, cabe conjeturar que los dos pasarriendas formaran parte, en origen, de dos equipos distintos y que fueran reunidos a posteriori para integrarse en un tercer vehículo, que sería el responsable de este conjunto. En esta tesitura, su cronología de fabricación, que puede situarse entre los siglos VII y VI a.C., resulta menos útil de cara a fechar el conjunto al que se incorporan, pues deben considerarse como pervivencias o reutilizaciones dentro del mismo, que debe situarse algo más tarde. No obstante, es de interés constatar estas pervivencias como un ejemplo más de un comportamiento cultural reiterado entre los bienes aristocráticos de época postorientalizante en el suroeste peninsular (Jiménez Ávila, 2006-2007).

En cuanto al uso de estos artefactos, los dos pasarriendas del conjunto del MNA son coherentes con el resto de los hallazgos peninsulares conocidos, que suelen mostrar la ratio de 2 pasarriendas/ 1 caballo, sugiriendo su instalación en los yugos, a ambos lados de la gamella (Jiménez Ávila, 2002: fig. 166). Este es el sistema que pervive en los pasarriendas de los carros de los coches de caballo actuales, sobre las colleras rígidas, aunque es cierto que en algunos modelos antiguos, como el representado en el pequeño carro de Oxus, la relación es distinta, reduciéndose a la mitad (1/1) (Littauer y Crouwel, 1979: 151). Los conjuntos antiguos mejor conocidos en la Península Ibérica parecen acreditar la relación 2/1. Así sucede en el bien documentado hallazgo de la tumba 17 de La Joya, con cuatro pasarriendas y dos bocados, que constituyen el único conjunto proce- dente de excavaciones (Garrido y Orta, 1978: 76 ss.); con los bronces de Úbeda la Vieja, que aúna dos bocados y tres pasarriendas (lo que sugiere la presencia de al menos uno más) y con el hallazgo de Talavera la Vieja, donde se recogieron cuatro pasarriendas y dos bocados de hierro (Jiménez Ávila y González Cordero, 2012). Las argumentaciones que, sucintamente, se han esgrimido cuestionando este planteamiento (Quesada, 2005: 108) pasan por aceptar la presencia de carros de cuatro caballos en la Protohistoria ibérica y, al mismo tiempo, de asumir la condición funcional como bocados para elementos que en absoluto pueden serlo, como inmediatamente tendremos ocasión de comprobar.

\subsubsection{Alamar (cat. 11)}

Con la zona del yugo y su unión al tiro debe relacionarse también una pieza que ha pasado desapercibida en las anteriores ocasiones en que este conjunto ha sido mencionado.

Se trata de un robusto objeto, constituido a partir de un cuerpo prismático horadado por una abertura rectangular que lo atraviesa de parte a parte, y dotado de dos gruesos apéndices laterales de sección circular y tendencia troncocónica. Debe de haber sido fundido a la cera perdida, aunque no es imposible que se haya realizado a molde bivalvo, y presenta huellas de uso por rozamiento en una de las aristas interiores de la ranura, que aparece desgastada a lo largo de toda su longitud (Fig. 17.11).

Objetos similares han aparecido relacionados con equipos ecuestres o en yacimientos donde se encuentran abundantes arreos de caballos corres- 


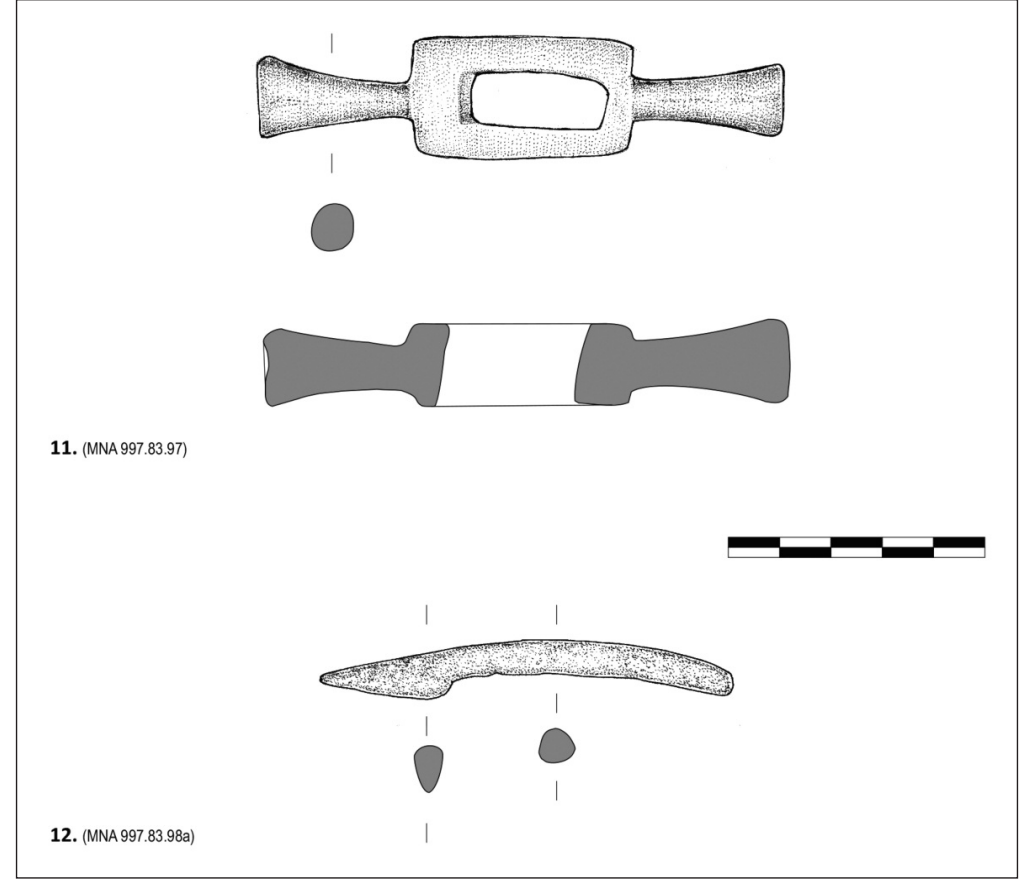

Figura 17. "Conjunto sepulcral de Guerreiro": cat. 11, alamar y 12, pasador sagital. Museu Nacional de Arqueologia (Dibujo J.M. Jerez).

pondientes de la I Edad del Hierro en la Península Ibérica que han sido recientemente estudiados (Jiménez Ávila, 2015b). Particularmente próximo es un ejemplar hallado en Cancho Roano, ya dado a conocer por Maluquer de Motes (Fig. 18, n. ${ }^{\circ}$ 1) e incluido en el estudio del material ecuestre del yacimiento realizado por M. Blech (2003: 165: fig. $\left.5 \mathrm{a}^{8}\right)$. De este mismo sitio procede un segundo ejemplar que presenta algunas diferencias morfológicas, pues los brazos son cilíndricos y rematan en sendas terminaciones esféricas caracterizadas como semillas de adormidera (Fig. 18, n. ${ }^{\circ}$ ). De la necrópolis de
La Joya, en Huelva proceden cuatro unidades, halladas junto a los componentes del carro, de menor tamaño y consistencia que los anteriores (Fig. 18, n. ${ }^{\circ}$ ). De la región de Sevilla proceden dos ejemplares, uno de Acebuchal, conservado en el Museo de Sevilla (Cañal, 1894: fig. 55; Jiménez Ávila, 2015b: fig. 3.4), y otro de la necrópolis romana de Carmona (Bonsor, 1931: lám. LXIX; Jiménez Ávila 2015b: fig. 3.5) muy similares entre sí (Fig. 18, n. ${ }^{\circ} 4$ ).

Sobre estos objetos peninsulares se ha desarrollado una errónea literatura que los considera como posibles camas de muerdos ecuestres, a raíz de su parecido con unos objetos similares, pero de brazos curvados, hallados por J. Cabré en sus excavaciones de la necrópolis celtibérica del Altillo del Cerropozo (Atienza, Guadalajara) (Cabré, 1930, lám. XVII; Schüle, 1969: 259; Fernández Gómez, 1986: 741; Blech, 2003: 165; Quesada, 2005: 108).

Resulta totalmente inviable desde el punto de vista técnico que algunos de estos artefactos hayan

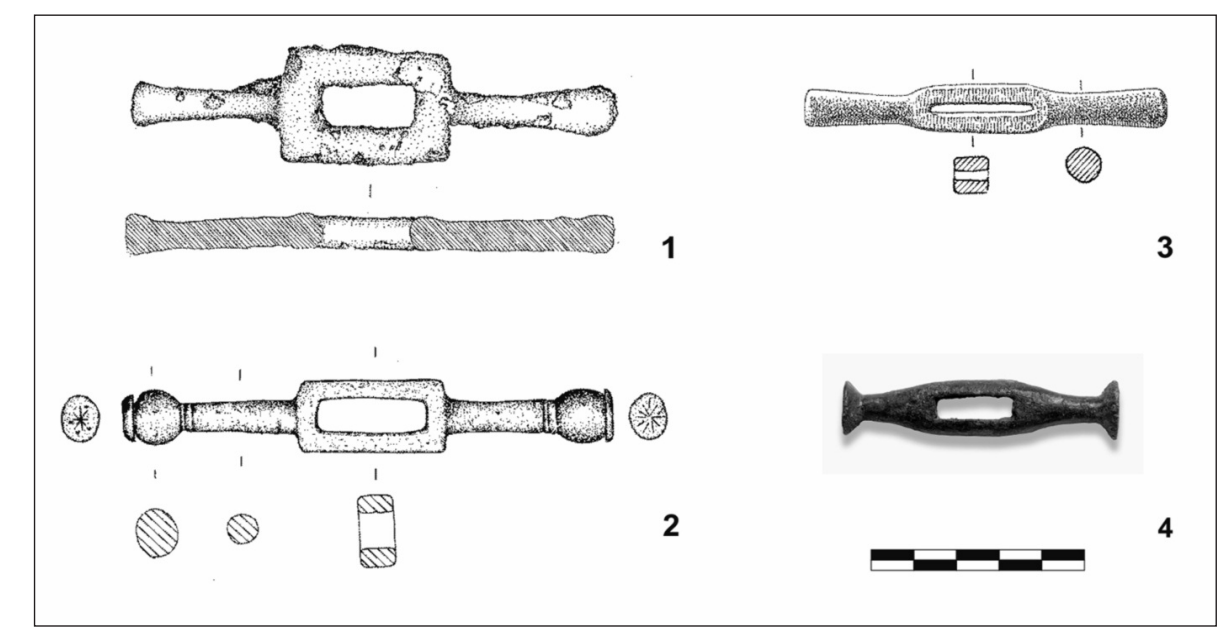

Figura 18. Alamares del Hierro Antiguo del Suroeste de la Península Ibérica. 1. Cancho Roano (s. Maluquer 1981: fig. 39); 2. Cancho Roano (s. Jiménez Ávila 2015b: fig. 3.7); 3. La Joya, Huelva (s. Garrido y Orta 1978: fig. 49); 4. Museo de Sevilla (Acebuchal?) (s. Jiménez Ávila 2015b: fig. 3.4).

\footnotetext{
8 Con algunos errores e imprecisiones, pues se incluye (aunque con dudas) entre los materiales de hierro, y se le atribuye la decoración incisa que, en realidad, corresponde al ejemplar inédito que describimos a continuación (fig. 18.2). El número de este ejemplar publicado en el inventario del Museo de Badajoz es el 10712. Para los problemas del material de Cancho Roano ver Jiménez Ávila $2015 b$.
} 
podido desempeñar semejante función, en particular los ejemplares de La Joya, por cuya ranura, de menos de medio centímetro de anchura, es del todo imposible introducir un cordón de bocado y que éste se mueva libremente, como sería necesario. Además, cuando aparecen estos objetos en conjuntos cerrados (incluidos los de Atienza) suelen combinarse con bocados completos, sin que haya ningún filete suelto que pueda atribuírseles. Lo mismo sucede en el ejemplar que ahora publicamos que, además, presenta huellas de uso impropias de haber acogido una embocadura metálica en su interior (aunque en este caso sí que cabría) (Jiménez Ávila, 2015b).

En lugar de esta atribución conviene avanzar en la línea que se ha propuesto en otras ocasiones, como cuando se presentaron los ejemplares de $\mathrm{La}$ Joya, donde fueron considerados pasadores y relacionados con el sistema de tracción (Garrido y Orta 1978: 83-84) o cuando, al tratar estas mismas unidades, planteó uno de nosotros en su trabajo de doctorado, considerándolos como pasadores o hebillas (Jiménez Ávila 1999: 342 ss.). A tal efecto, uno de los ejemplares de La Joya presenta restos de una sustancia en su interior que podría ser analizada de cara a conocer su naturaleza (posiblemente restos de cuero).

Resulta curioso que la atribución como camas de bocado que se ha propuesto para estos artefactos se realice a partir de las obras de J. Cabré (1930: lám. XVII) y, sobre todo, de W. Schüle, cuando es este investigador quien identifica el primer objeto peninsular perteneciente a esta categoría -el ejemplar de la necrópolis de Carmona- y lo relaciona con una serie de elementos similares hallados en tumbas de carros de los periodos $\mathrm{B}$ y C de Hallstatt, presentando una cartografía de los mismos (Schüle, 1969: 192-193). Estas analogías con ejemplares europeos no son luego referidas por ninguno de los autores hispanos que han tratado el tema. En Centroeuropa, estos objetos (el repertorio más completo en Trachsel, 2004) vienen siendo reconocidos como elementos de unión al yugo, y se han propuesto para ellos convincentes reconstrucciones de la forma en que serían usados: unidos a una correa de cuero y pasados después por una anilla de bronce a la que quedarían enganchados por tensión y por ser más largos que su diámetro (ver en Vaart, 2011). Este es el modo en que creemos que serían utilizados los ejemplares hispánicos en general y el del MNA en particular, en manera análoga a como funcionan los botones de las actuales trencas, lo que justifica la denominación de alamar que hemos propuesto para ellos y que se aplica a este sistema de cierre (Jiménez Ávila, 2015b). En el conjunto del MNA no hay anillas de bronce, pues podrían haber sido sustituidas por trabillas de cuero que, a la luz del resto de los actuales hallazgos, sería el modo habitual de enganche en los yugos del Hierro antiguo hispánico (Jiménez Ávila, 2015b: fig. 10). Otros objetos de yugo, como los de Ategua, aparecen unidos a anillas de hierro que podrían haber desempeñado esta función en casos similares (Jiménez Ávila y Muñoz, 1997: fig. 8).

La relación de alamares con caballos en las tumbas europeas parece de 1 a 1 en la mayoría de los casos conocidos (Kossack, 1953; Pare, 1992): el cincho estaría fijado al yugo por uno de sus extremos y suelto por el otro, donde se instalaría el alamar de cierre. En el caso del equipo del MNA se repetiría este esquema, y es posible que sucediera lo mismo para los cercanos ejemplares de Cancho Roano, donde han aparecido dos tipos diferentes que pueden corresponder a los dos tipos de bocados encontrados ${ }^{9}$. Sin embargo, en la tumba de La Joya, bastante más antigua y de tipología algo diferente, el número de agarres parece ser de dos por animal, ejemplificando un modelo distinto, que quizá se corresponda con algunos yugos antiguos donde han aparecido dos anillas metálicas a ambos lados de los puentes (Piggott, 1983: fig. 138).

No deja de resultar llamativo que en conjuntos tan cargados de remembranzas orientales y mediterráneas, como los de La Joya, Cancho Roano o el que aquí estudiamos, se incluyan artefactos que encuentren sus más numerosos y mejores referentes en el mundo hallstático. Quizá el sistema de cierres por alamares se usara ya en el Bronce atlántico, como podrían evidenciar algunos elementos (algo más complejos) presentes en el depósito de Vénat (Coffyn et al., 1981), y que por eso fuera conocido en el suroeste peninsular en los primeros momentos de la colonización fenicia, aplicándose a los primeros carros fabricados en suelo hispánico. Esto podría justificar un uso prácticamente simultáneo en la Europa Central, sin que tengamos

\footnotetext{
9 Es cierto que, conforme a esto, faltarían en Cancho Roano dos alamares, pero también lo es que en Cancho Roano falta mucho más material, como dos camas laterales, un filete, etc., ver Blech, 2003.
} 


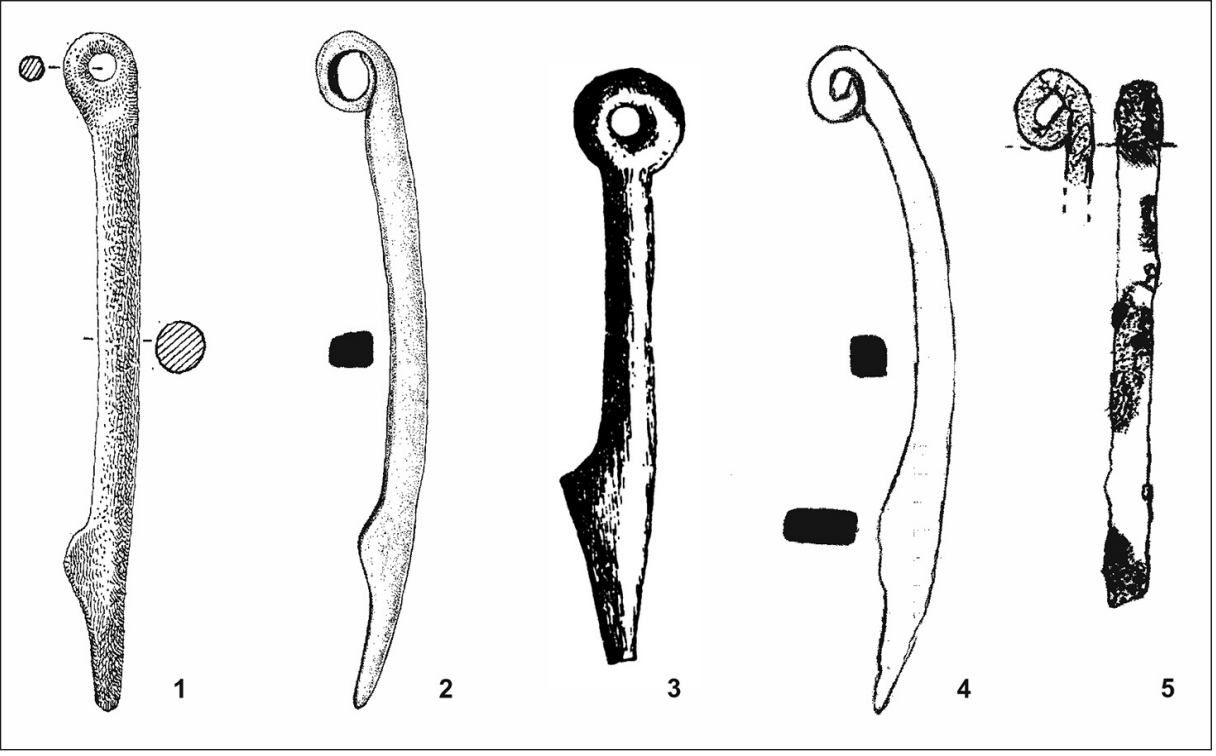

Figura 19. Pasadores sagitales del Hierro Antiguo del Suroeste de la Península Ibérica. 1. La Joya (s. Garrido y Orta 1978: fig. 48); 2. El Jardín (s. Jiménez Ávila 2007: fig. 7); 3. Acebuchal (s. Cañal, 1894: fig. 58); 4. Ejemplar de hierro de Setefilla, Museo Arqueológico de Sevilla ROD 8931 (Dibujo J. Jiménez Ávila); 5. Posible fragmento inédito de Cancho Roano (Dibujo M. Alfaro). Escalas no uniformadas.

ellos, que presenta una cierta curvatura, no parecen corresponder al mismo tipo de objetos (ver cat. 101).

Al igual que el alamar anteriormente descrito, este pasador tiene referentes en la tumba 17 de La Joya, donde se hallaron cuatro elementos similares relacionados con los arreos del carro depositado en la sepultura (Garrido y Orta, 1978: 81-83). Los cuatro pasadores de La Joya rematan por su parte trasera en sendas anillas (Fig. 19, n. ${ }^{\circ}$ 1), lo que permite inferir que el ejemplar del MNA se halla incompleto, y que contaría con un adita-

que buscar conexiones directas entre unos y otros. No obstante, las fuertes similitudes de los ejemplares de la zona de Sevilla -de cronología orientalizante- con los del Hallstatt B, podrían estar indicando otra cosa. Por otro lado, es más que posible que este sistema de cierre, fabricado sobre materiales menos nobles y más perecederos, como la madera, estuviese mucho más extendido en la Antigüedad, algo que veremos repetirse en el siguiente apartado. En cualquier caso, el tema requeriría de un análisis más detallado del que aquí podemos concederle, y quizá fuera conveniente una revisión funcional más completa de todos estos artefactos.

\subsubsection{Pasador sagital (cat. 12)}

También en relación con los procedimientos de cierres y uniones del sistema de tracción hay que situar esta pieza que, como la anterior, no ha sido mencionada en las referencias previas al conjunto del MNA.

Está formada por una barra de sección circular, ligeramente curvada, que concluye en una punta bien diferenciada de silueta y sección triangulares, por lo que se describe en los inventarios del museo como arpón (Fig. 17.12). Allí se la relaciona con cuatro fragmentos de barra de bronce de distinta longitud y sección que nosotros preferimos contemplar aparte, pues, con excepción de uno de mento similar. Otro pasador de análogas características se agrega a un conjunto de materiales resultado del saqueo de unas tumbas postorientalizantes en la zona de La Serena extremeña entre los que no se reconocen más elementos ecuestres (Fig. 19, n. ${ }^{\circ}$ 2), mientras que un último ejemplar de bronce aparece representado en la centenaria obra de $\mathrm{C}$. Cañal como procedente de las excavaciones de finales del siglo XIX en los túmulos de Acebuchal (Sevilla), de donde también reproduce un alamar, lo que, de cara a nuestros propósitos, acrecienta su interés (Fig. 19, n. ${ }^{\circ}$ 3). Además, entre el material inédito de la necrópolis de Setefilla se encuentra un objeto parecido fabricado en hierro (Fig. 19, n. ${ }^{\circ}$ ) con el que, hasta donde nosotros conocemos, concluiría todo el repertorio de estos pasadores sagitales en la Protohistoria ibérica. No obstante, en algunos conjuntos ecuestres publicados, como el de Alcurrucén, aparecen unas varillas metálicas aguzadas por un extremo y arrolladas por el contrario, que podrían haber desarrollado una funcionalidad similar a pesar de su mayor endeblez (Jiménez Ávila y Muñoz, 1997: fig. 10, n. 3-4). En este sentido, se pueden mencionar también algunas piezas incompletas e inéditas de Cancho Roano que podrían haber servido a los mismos propósitos, acercando, una vez más, la composición de nuestro equipo ecuestre al de este yacimiento extremeño

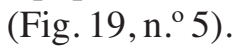



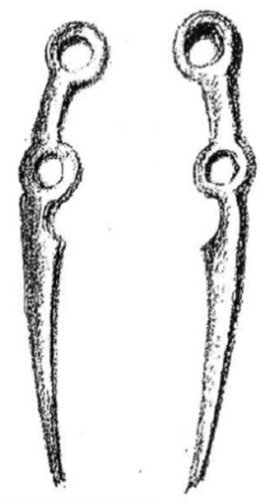

1

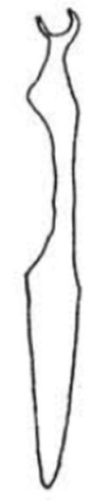

3

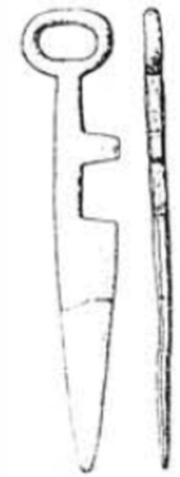

4
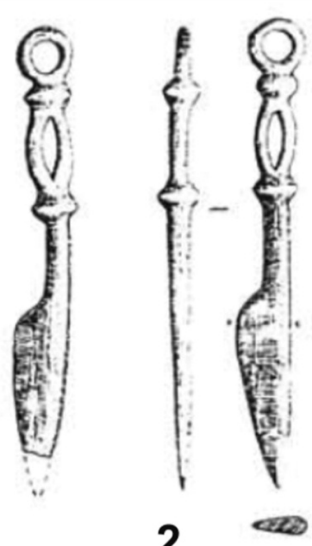

2

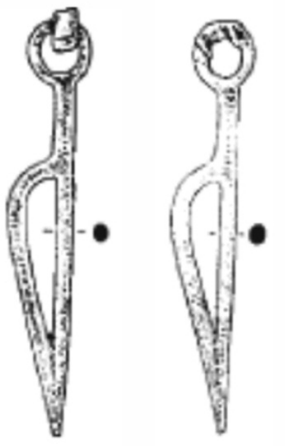

5
Figura 20. Pasadores sagitales de tumbas de carro hallstáticas del centro de Europa. 1. Vergosa, Italia; 2. Luisburgo, Alemania; 3. Herbertingen, Alemania; 4. Heuneburg, Alemania;

5. Hochdorf, Alemania (todos en Koch, 1999: láms. 12, 167 y 174).

En un ámbito más amplio, y al igual que sucede con los alamares, piezas similares, aunque menos numerosas, se encuentran en enterramientos hallstáticos de Europa Central y en el norte de Italia, donde son denominados "colgantes en forma de cuchillo" (Koch, 1999: 180-181: mapa 17). Hallazgos bien documentados como los de Herbertingen-Hundersingen, Sesto Calende, Vergosa o el propio Hochdorf, evidencian la relación de estos objetos con los sistemas de tracción de los carros depositados en las sepulturas de la I Edad del Hierro de estas zonas de Europa central (Ibidem) (Fig. 20).

El funcionamiento de estos pasadores debió de ser sencillo, usándose para ajustar correas de piel entre sí pasándolas por agujeros y trabillas trabajados a tal efecto. Sus extremos apuntados facilitarían la penetración y dificultarían el desprendimiento, al tiempo que las anillas traseras permitirían unirlos a cuerdas o cintas de cuero que impedirían su extravío, al quedar suspendidos de los talabartes cuando no estaban en uso. En la tradicional guarnicionería pastoril se usaban pasadores de madera de conformación similar para cierres de anchos correajes o collares, como los que sostienen los cencerros del ganado vacuno (Fig. 21).

La convivencia de alamares y pasadores dentro el mismo conjunto abre el problema del tipo de yugo que usarían estos vehículos. Si dos sistemas de cierre equivalen a dos sistemas de cinchos (uno pectoral y otro ventral) es posible que nos encontráramos ante un yugo dorsal (ver la problemática en Spruytte, 1979). Sin embargo, ambos procedimientos conviven también en el carro de La Joya, de fecha notablemente más antigua y al que, por analogía con los carros orientales se le ha atribuido un yugo de cuello (Jiménez Ávila, 2002; 2018b). Algunas representaciones plásticas peninsulares resultan poco esclarecedoras en este sentido (Jiménez Ávila e.p.).En suma, el actual estado de los datos no permite inferir que estos dos sistemas correspondan necesariamente a

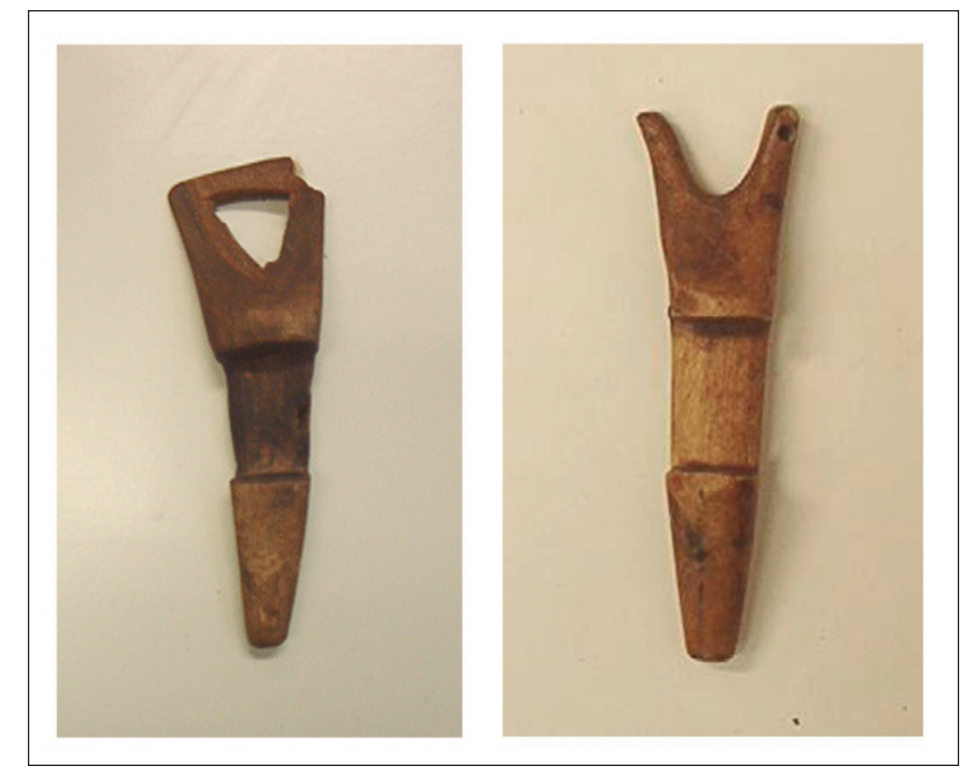

Figura 21. Chavetas de madera de uso tradicional de funcionamiento similar a los pasadores sagitales, Museu de Arte Popular, Lisboa. 


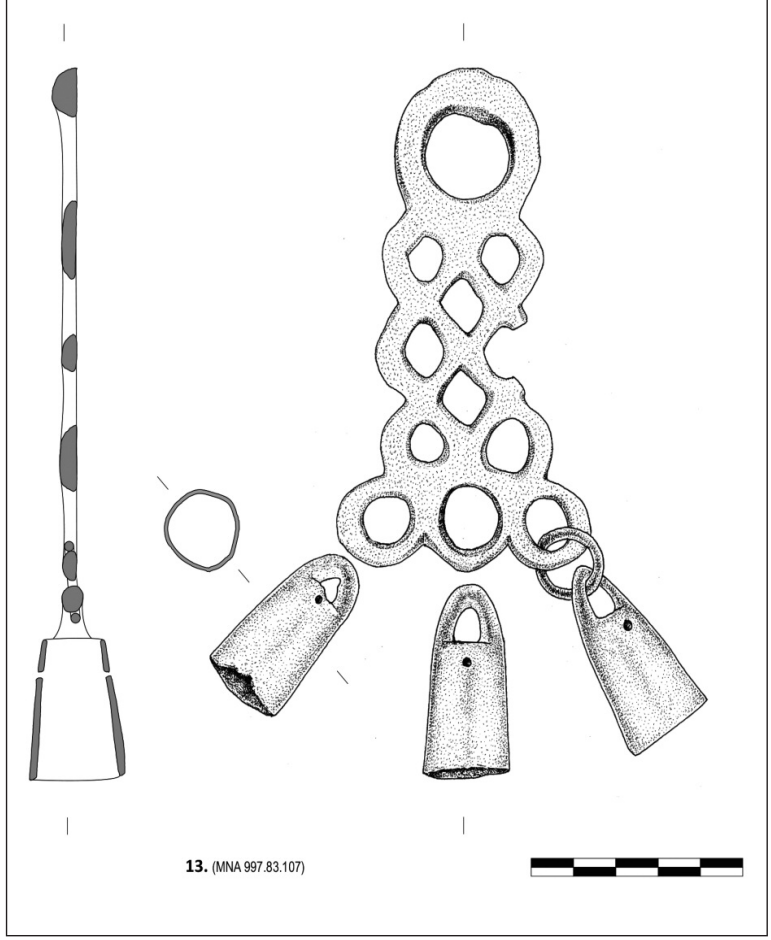

Figura 22. "Conjunto sepulcral de Guerreiro", cat. 13: colgante con campanillas. Museu Nacional de Arqueologia (Dibujos J.M. Jerez).

estos dos tipos de sujeciones, por lo que el tema solo puede ser apuntado como un problema más hacia el que avanzar en futuros trabajos.

Algo que sí puede señalarse, sin embargo, es que la relación que suele darse entre pasadores y alamares en los escasos ejemplos conocidos ( $\mathrm{La}$ Joya, el nuestro, tal vez Cancho Roano...) es también de 1 a 1 .

\subsubsection{Colgantes con campanillas (cat. 13, 14 y15)}

El conjunto de bronces en estudio, se complementa con una serie de adornos que pueden haberse situado indistinta y/o simultáneamente en la zona de la cabezada o en la parte del yugo y sus elementos de unión. Estos adornos son tres colgantes con campanillas, que estudiamos en este apartado, y una larga serie de botones de cúspide cónica que trataremos en el siguiente.

Los colgantes con campanillas son tres piezas de similar estructura, aunque de muy distinta factura y diferente grado de conservación. Están compuestos por una placa calada de tendencia rectangular que parte de una gran anilla proximal, que da paso a una zona media reticulada, donde se combinan varios registros de calados circulares y romboidales haciendo juegos geométricos, para desembocar en una base algo más ancha formada por tres anillas menores dispuestas en horizontal, una al lado de la otra. De estas tres anillas penderían tres campanillas unidas por sendas argollas circulares realizadas en fino alambre de bronce. Los ejemplares 13 y 14 debían ser prácticamente iguales. El n. ${ }^{\circ} 13$ se conserva casi completo y aún pende una campanilla de una de las anillas inferiores, conservándose las otras dos sueltas (Fig. 22). Del número 14 solo se conservan las anillas superior e inferiores y algunos restos del calado central, así como las tres campanillas sueltas y algún fragmento de las argollas de sujeción (Fig. 23). El n. ${ }^{\circ} 15$, aun manteniendo una estructura parecida, es muy diferente a los anteriores, mucho más tosco en su diseño y en su factura, pudiendo considerarse una burda imitación de los mismos (Fig. 24).

Desde el punto de vista técnico las placas están fundidas en molde abierto, percibiéndose también una clara diferencia entre los ejemplares 13 y 14 , que aparecen alisados por el reverso, con respecto

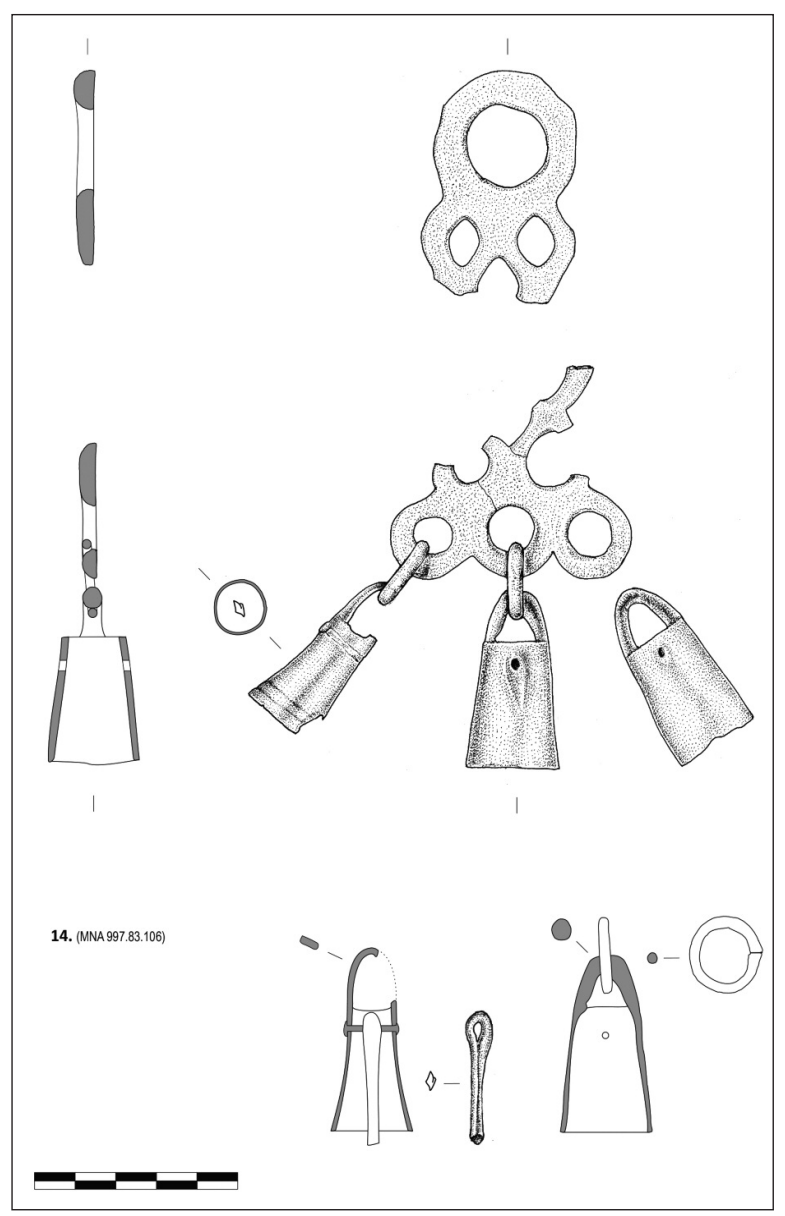

Figura 23. "Conjunto sepulcral de Guerreiro", cat. 14: colgante con campanillas. Museu Nacional de Arqueologia (Dibujo J.M. Jerez). 


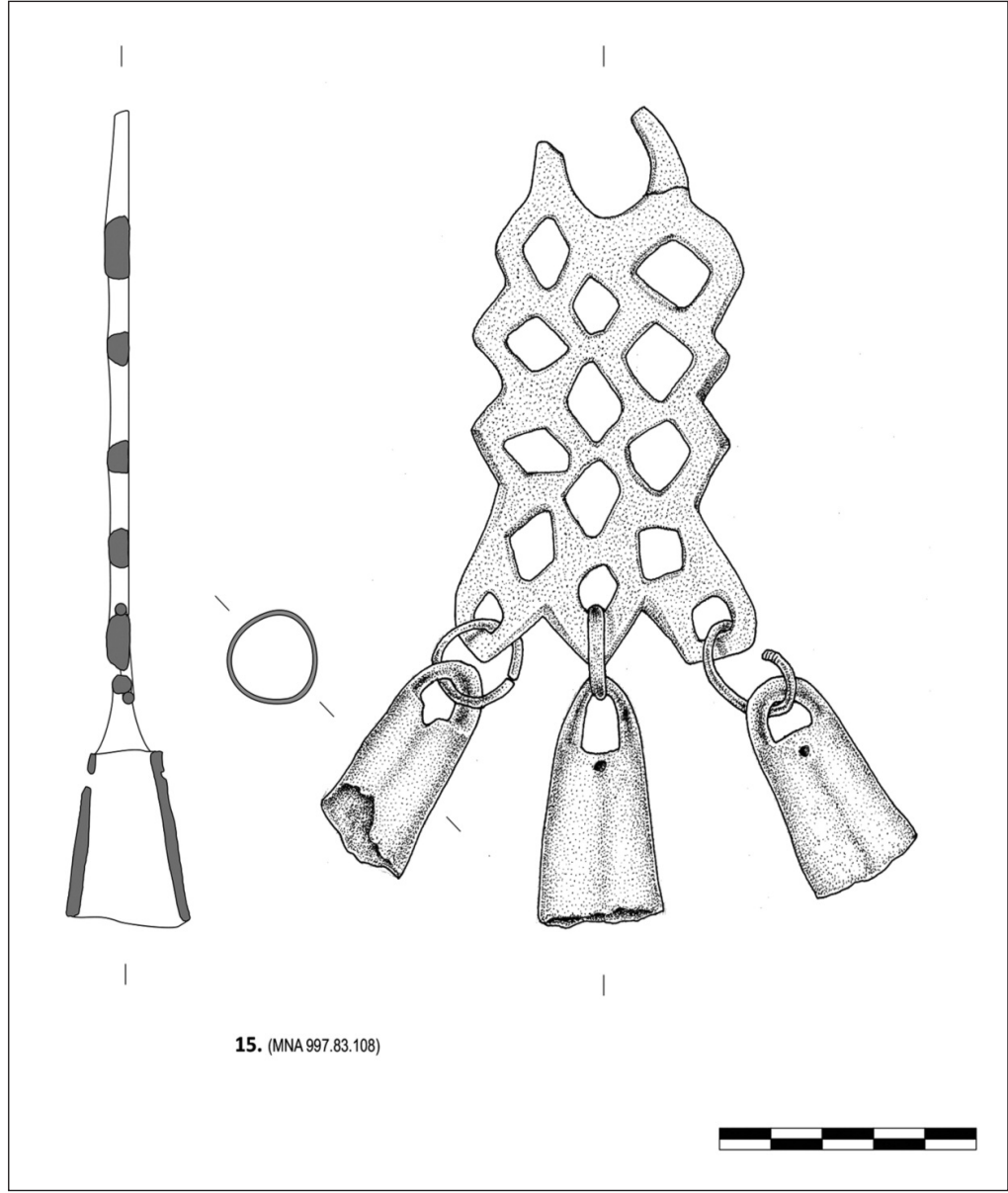

Figura 24. "Conjunto sepulcral de Guerreiro”, cat. 15: colgante con campanillas. Museu Nacional de Arqueologia (Dibujo J.M. Jerez). de Cancho Roano. Allí debemos fijarnos en dos objetos. Por un lado, en unos colgantes similares pero de más simple estructura, formados por una anilla superior y tres inferiores con sus correspondientes campanillas, todo ello unido a una cadena de eslabones de bronce (Maluquer de Motes, 1983: fig. 14). Por otro, en un fragmento de placa calada aparecida con anterioridad a las excavaciones que ha sido atribuida de manera poco convencida a una posible hebilla (Maluquer de Motes, 1981: fig. 14) y de manera muy poco convincente a un asa de jarro (Celestino y Zulueta, 2003: 25) y que corresponde, sin ningún género de dudas, a un colgante del tipo de los que aquí presentamos. Corregido este error, encontramos por tanto en Cancho Roano dos modalidades distintas de colgantes sonoros que podrían relacionarse con los dos tipos de juegos de bridas que se reconocen en el yacimiento a partir de los distintos tipos de bocados (Fig. 25).

Maluquer de Motes realizó un primer ensayo de reconstrucción de los colgantes de Cancho Roano uniéndolos a los extremos del bocado a través de una larga cadena (Maluquer de Motes, 1983: fig. 15), reconstrucción que ha sido argumentadamente contestada por F. Quesada (2002-03; 2005: 112). Bajo nuestro punto de vista, hay razones para pensar que los elementos de atalaje que van unidos a cadenas formarían parte del yugo, pues incluyen piezas, como las clavijas decoradas, que deben vincularse al sistema de tracción (Jiménez Ávila, 2002: 221) ${ }^{10}$. En este sentido $\mathrm{y}$, visto que los colgantes de Cancho Roano aparecen ligados a cadenas, su ubicación más creíble estaría en ambos extremos del yugo. La ausencia de cadenas en el conjunto del MNA no dificulta esta propuesta, pues las cadenas desarrollarían una función puramente ornamental, como también ha sido ya señalado en otras ocasiones a raíz de algunas evidencias arqueológicas (Jiménez Ávila, 2002: 221). Su función de unir distintos

\footnotetext{
${ }^{10}$ Tal vez el esquema presente en Cancho Roano sea similar al distribuidor de cadenas asociado a carros hallstáticos como el de Hochdorf (Koch, 1999: lám. 11).
} 


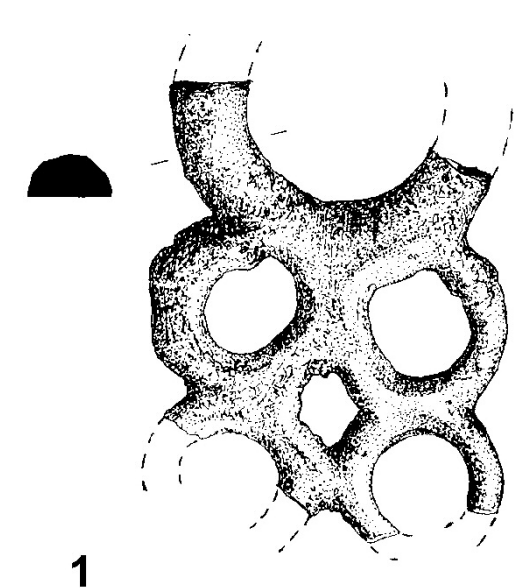

1

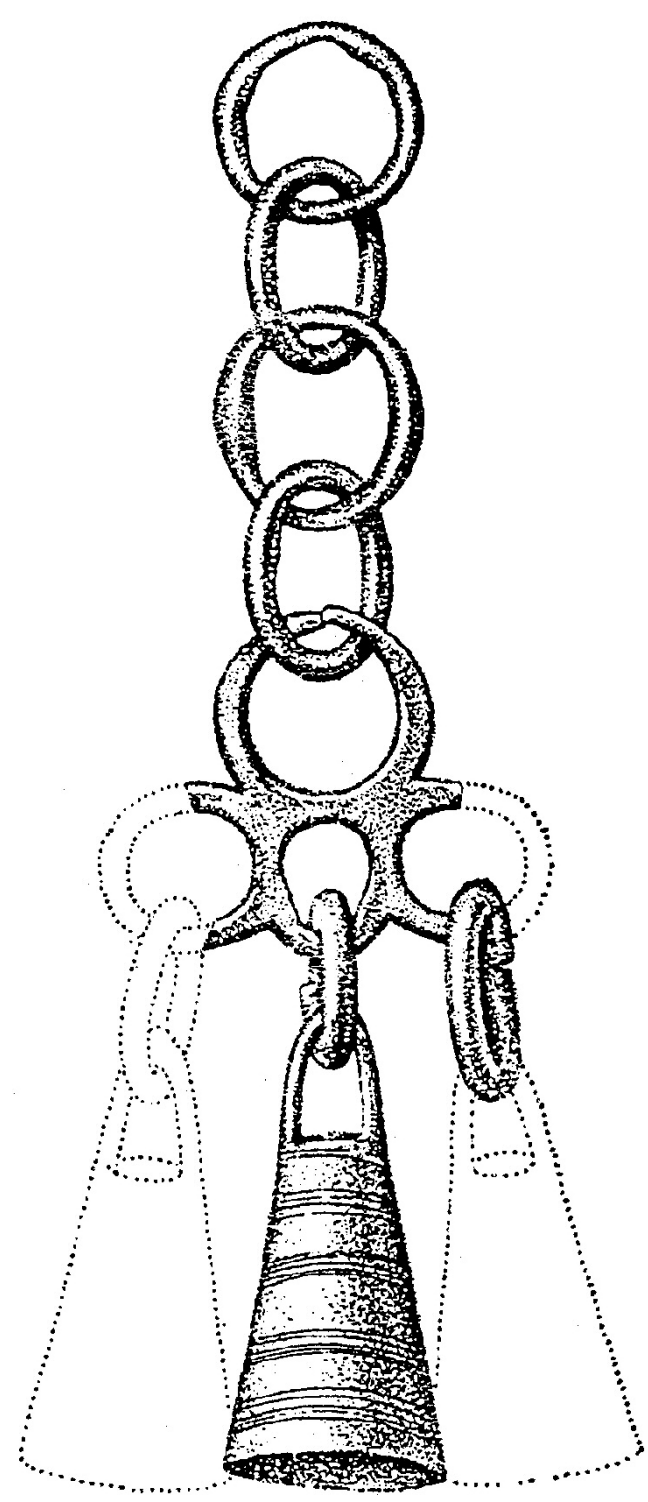

2

Figura 25. Cancho Roano: colgantes con campanillas (s. Maluquer 1981: fig. 14; 1983: fig. 14). elementos podría ser sustituida por correas de cuero. En cualquier caso, esta ubicación en el yugo solo es de utilidad para dos de los colgantes, quedando por ubicar un tercero (tal vez, no por casualidad, de factura muy diferente). El número impar de colgantes sugiere una situación central para este tercer ejemplar, que podría estar en medio del pretal o bien en la frontalera de la cabezada, siendo menos probables otras ubicaciones.

La reiteración de un mismo tipo de colgante con campanillas en dos hallazgos del suroeste peninsular (Cancho Roano y el nuestro) obliga a considerar esta variedad de ornamentos como la versión hispánica de un tipo de atalajes sonoros que fueron usuales en los carros de prestigio, tanto en Oriente como en Europa Central y mediterránea, a lo largo de la Edad del Hierro.

\subsubsection{Botones (cat. 16 - 100)}

Los objetos más numerosos del equipo ecuestre que estamos estudiando son los botones de cúspide cónica, de los que se han recogido 85 unidades, muchos de ellos en perfecto estado de conservación.

Corresponden todos al mismo tipo, compuesto por un disco de bronce, un remate cónico hueco situado en la parte central del lado visible y una presilla en forma de arco sobresaliendo por la cara opuesta, que serviría para coserlos o sujetarlos a la tira o a la prenda a que se desearan unir.

A pesar de estas analogías, pueden dividirse en tres grupos conforme a su tamaño: A) los más grandes, cuyos discos están en torno a $3,5 \mathrm{~cm}$ de diámetro y que suman un número de 10 unidades (Figs. 26 y 27); B) los intermedios, de $2,5 \mathrm{~cm}$ de diámetro con cinco unidades (Fig. 27) y C) los más pequeños, de alrededor de $2 \mathrm{~cm}$ de diámetro, grupo mayoritario al que se adscriben los 70 botones restantes (Figs. 28-31)

Aparte de las diferencias de tamaño (Fig. 32), existen también diferencias de fabricación entre estos grupos que resulta importante señalar. Así, los botones mayores y los más pequeños presentan por la parte inferior unas costuras que recorren diametralmente los discos y que afectan incluso a la depresión central y a las presillas, donde se observan las rebabas de fundición, tanto por el exterior del arco como por su interior (Fig. 33, n. ${ }^{\circ} 1$ y 3). Estas señales denuncian su fundición en moldes bivalvos. Sin embargo, en los botones del grupo B estas señales están completamente ausentes, pudiéndose observar, además, que sus presillas son considerablemente más robustas que las de los otros grupos, por lo que han debido de ser 

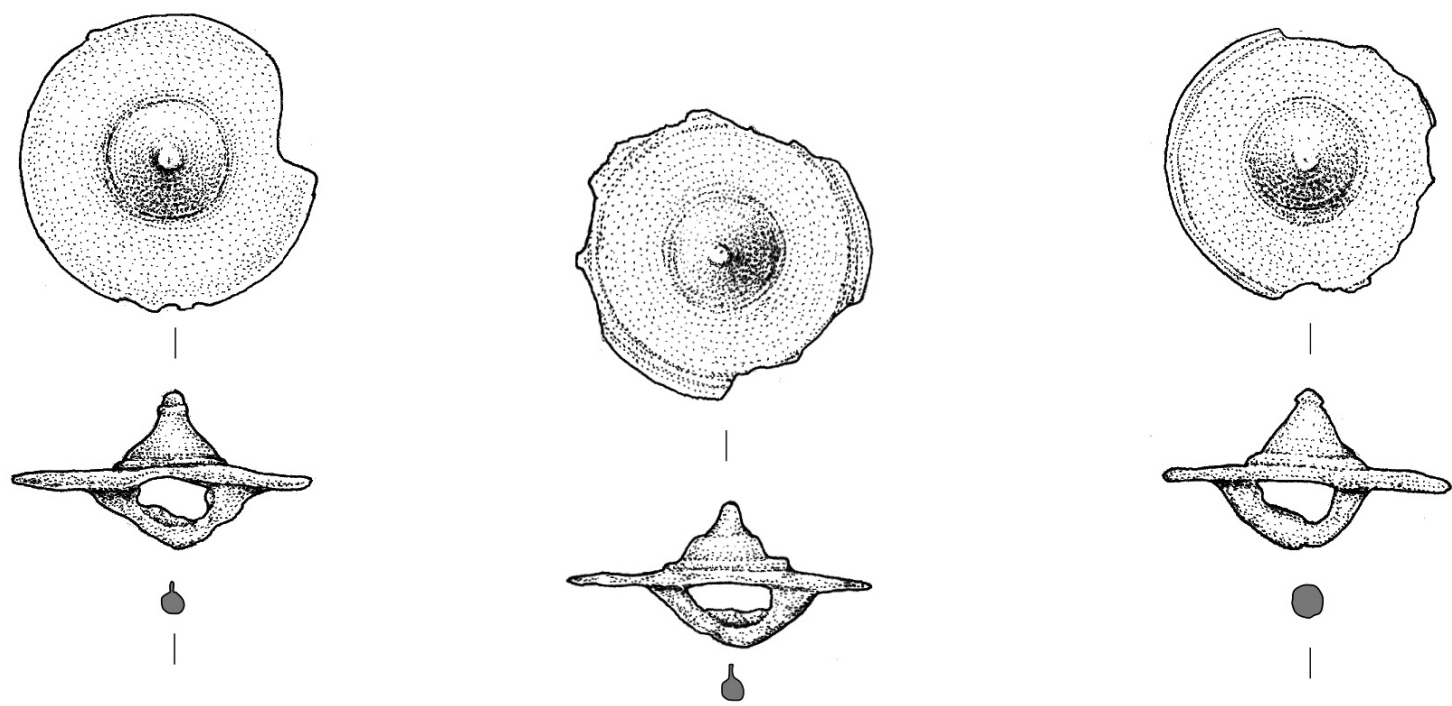

8

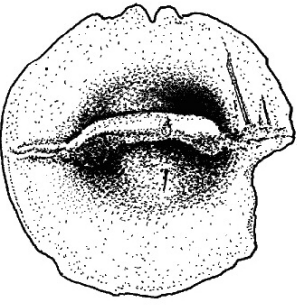

17. (MNA 997.83.2)

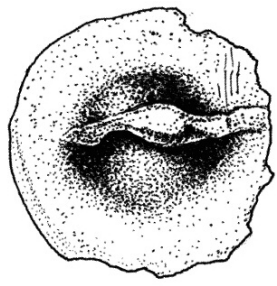

16. (MNA 997.83.1)
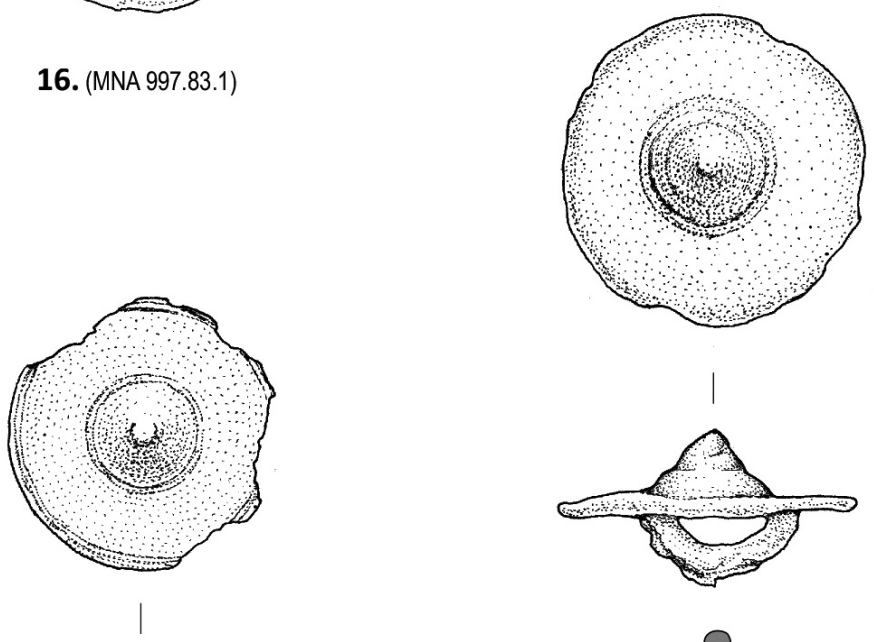

18. (MNA 997.83.3)
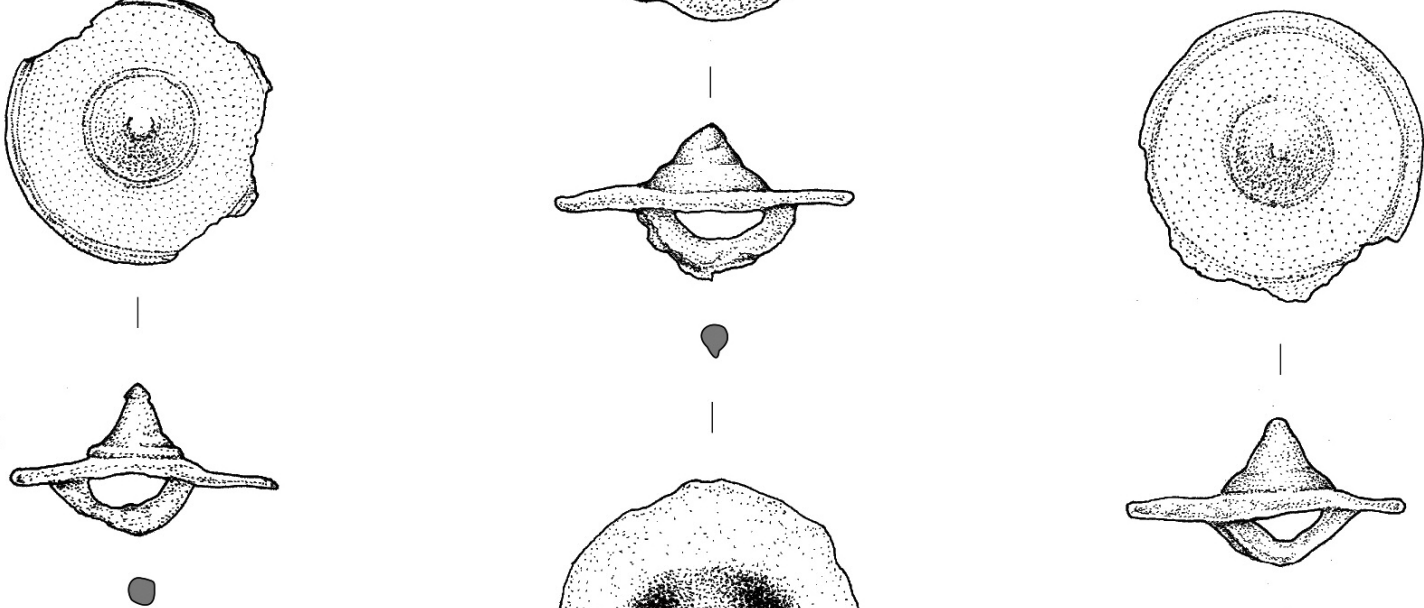

19. (MNA 997.83.4)
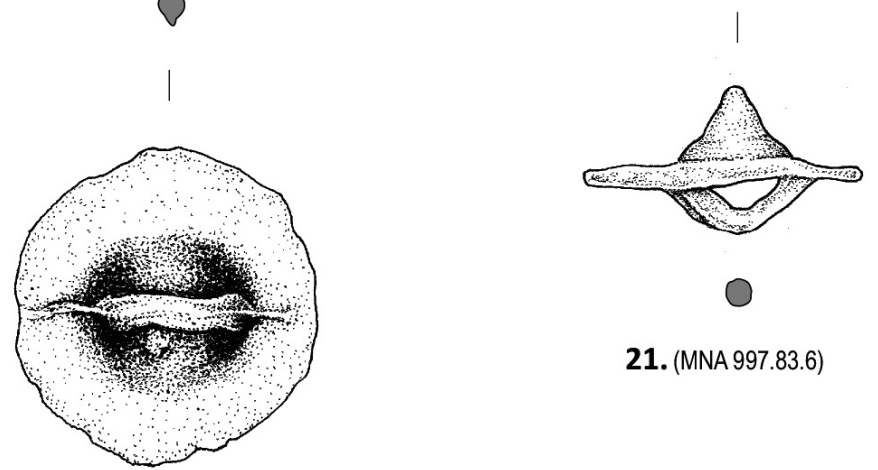

21. (MNA 997.83.6)

20. (MNA 997.83.5)

Figura 25. "Conjunto sepulcral de Guerreiro”, cat. 16-20: botones del grupo A. Museu Nacional de Arqueologia (Dibujo J.M. Jerez). 


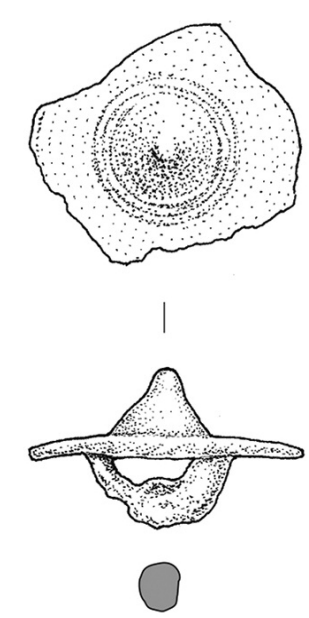

22. (MNA 997.83.7)
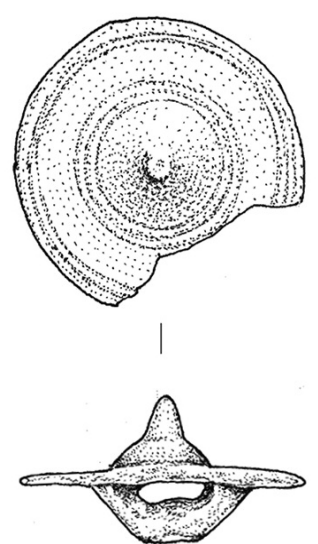

○

23. (MNA 997.83.8)
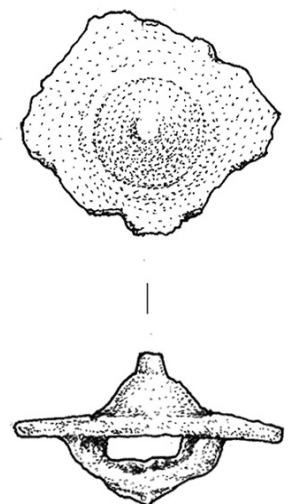

$\Omega$

24. (MNA 997.83.9)

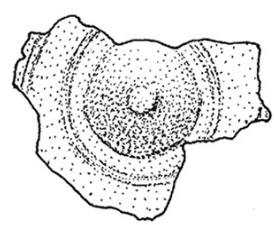

|

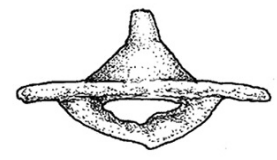

0

25. (MNA 997.83.10)

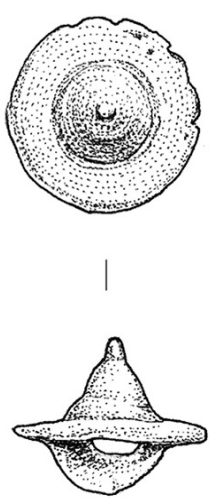

0

26. (MNA 997.83.11)
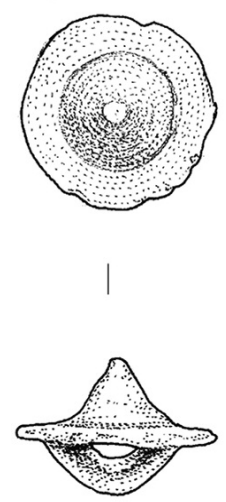

0

27. (MNA 997.83.12)
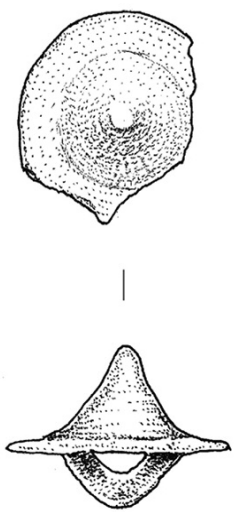

28. (MNA 997.83.13)
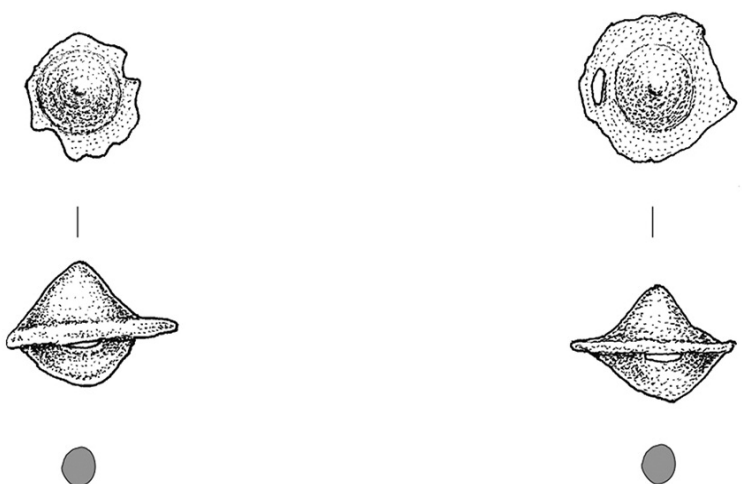

29. (MNA 997.83.25)

30. (MNA 997.83.67)

Figura 27. “Conjunto sepulcral de Guerreiro”, cat. 21-30: botones de los grupos A y B. Museu Nacional de Arqueologia (Dibujo J.M. Jerez). 


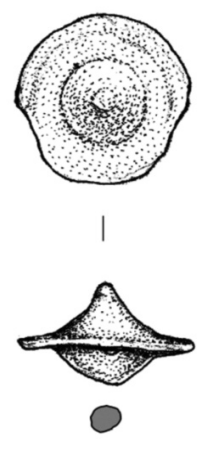

31 (MNA 997.83.14)
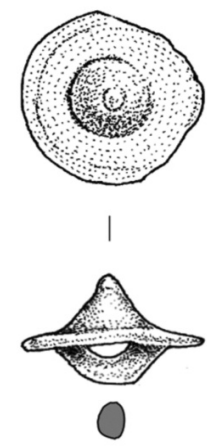

32 (MNA 997.83.15)
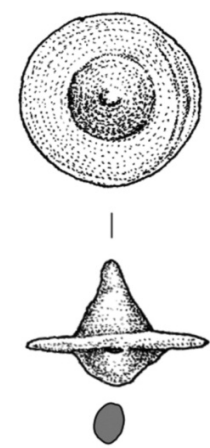

33 (MNA 997.83.16)
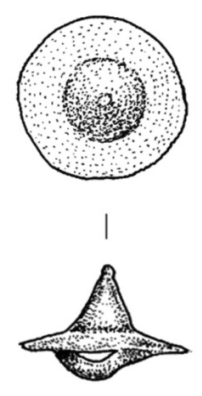

0

34 (MNA 997.83.17)
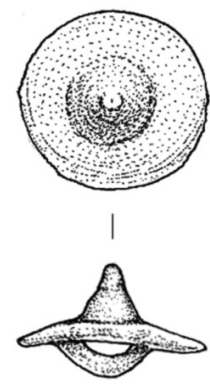

35 (MNA 997.83.18)
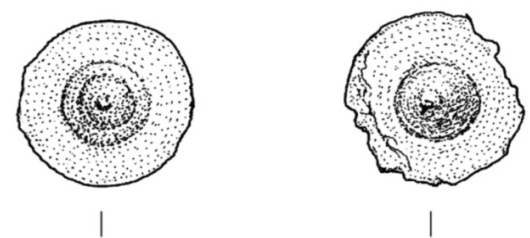

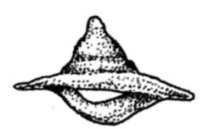

0

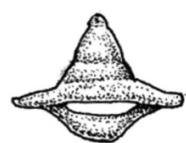

0

36 (MNA 997.83.19)

37 (MNA 997.83.20)

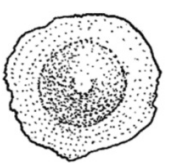

।

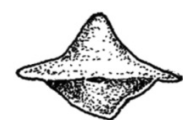

0

38 (MNA 997.83.21)
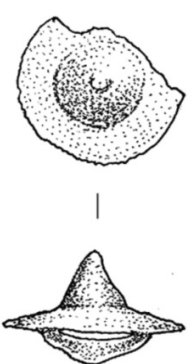

0

39 (MNA 997.83.22)
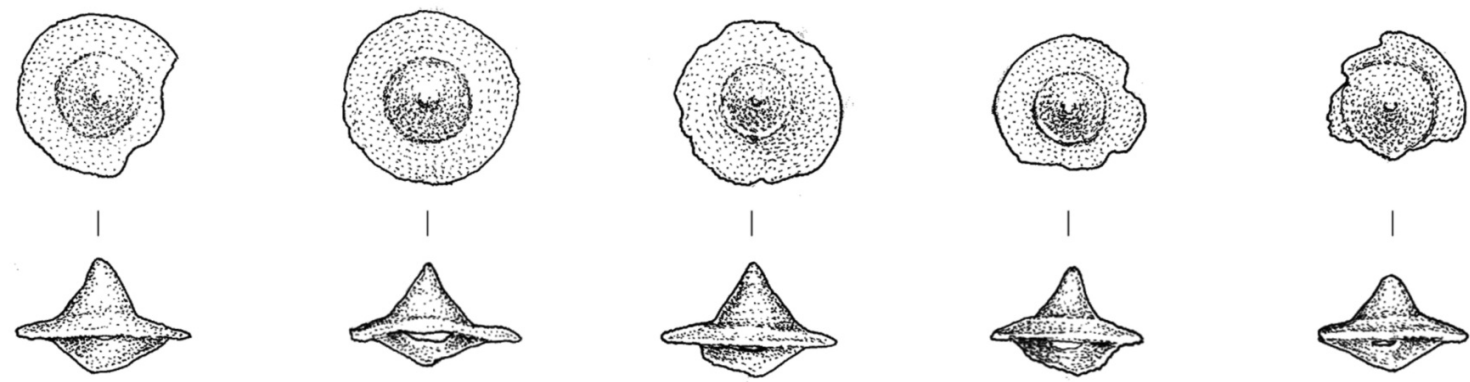

।
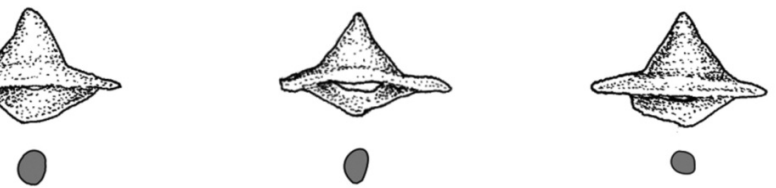

40 (MNA 997.83.23)

41 (MNA 997.83.24)

42 (MNA 997.83.26)

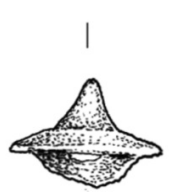

$\bigcirc$

43 (MNA 997.83.27)

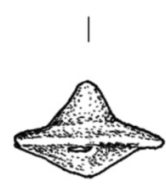

○

44 (MNA 997.83.28)
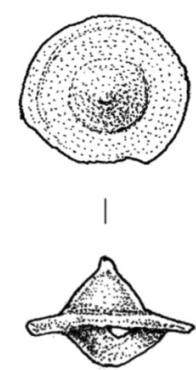

0

45 (MNA 997.83.29)

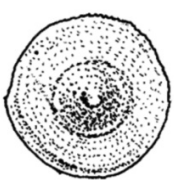

।

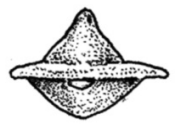

0

46 (MNA 997.83.30)
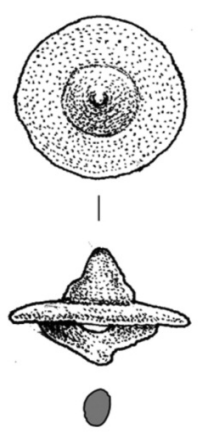

47 (MNA 997.83.31)
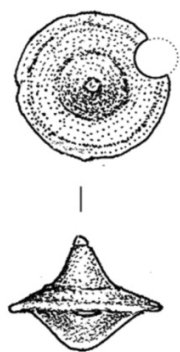

O

48 (MNA 997.83.32)

Figura 28. "Conjunto sepulcral de Guerreiro", cat. 31-48: botones del grupo C. Museu Nacional de Arqueologia (Dibujo J.M. Jerez). 


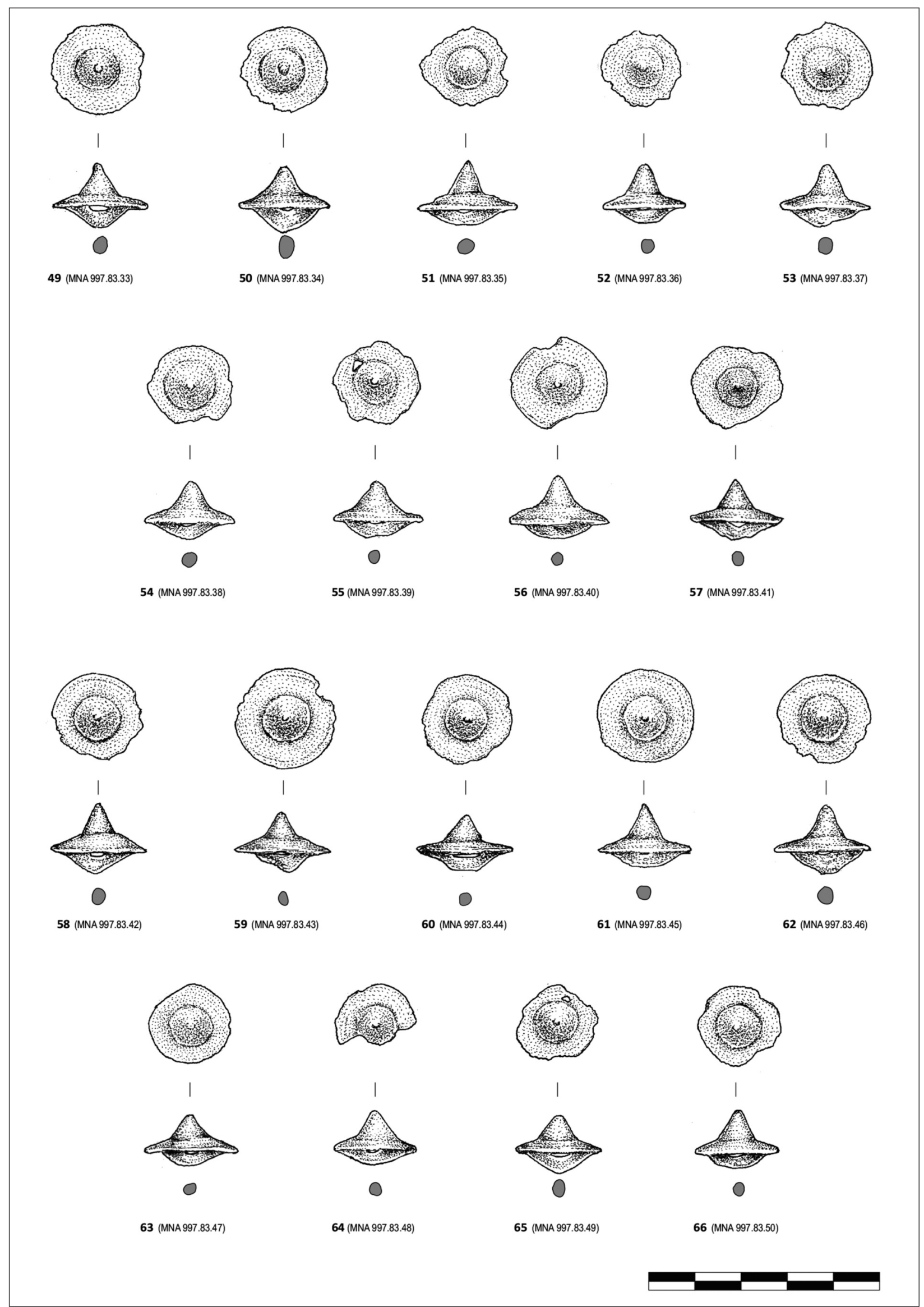

Figura 29. “Conjunto sepulcral de Guerreiro”, cat.49-66: botones del grupo C. Museu Nacional de Arqueologia (Dibujo J.M. Jerez). 

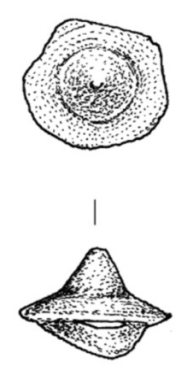

0

67 (MNA 997.83.51)
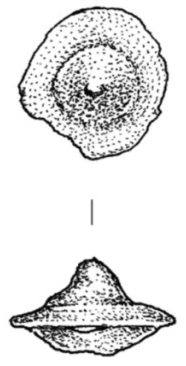

$\bigcirc$

68 (MNA 997.83.52)
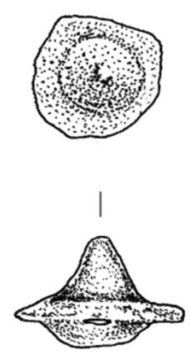

$\bigcirc$

69 (MNA 997.83.53)
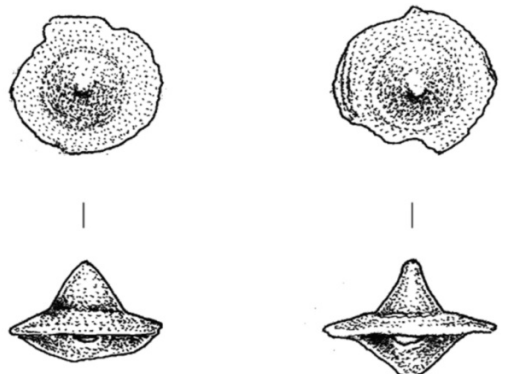

$\bigcirc$

70 (MNA 997.83.54)

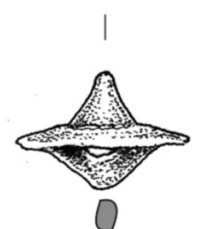

71 (MNA 997.83.55)
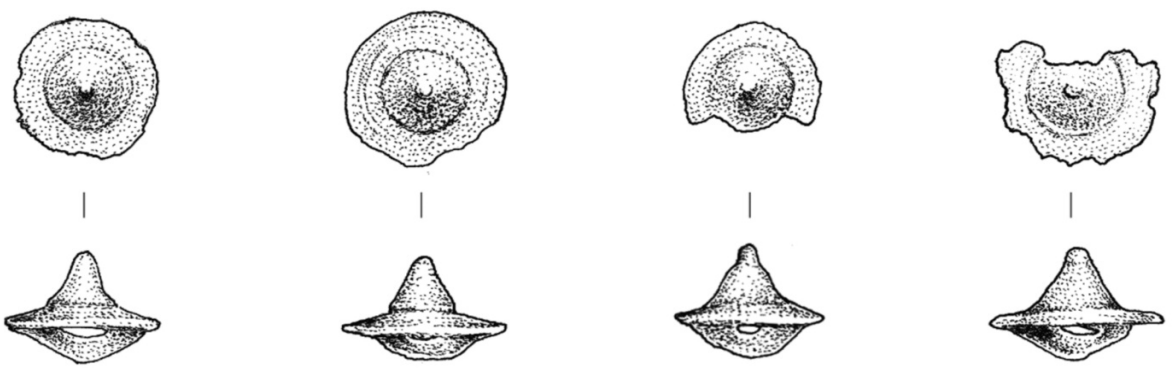

$\bigcirc$

73 (MNA 997. 83.57)
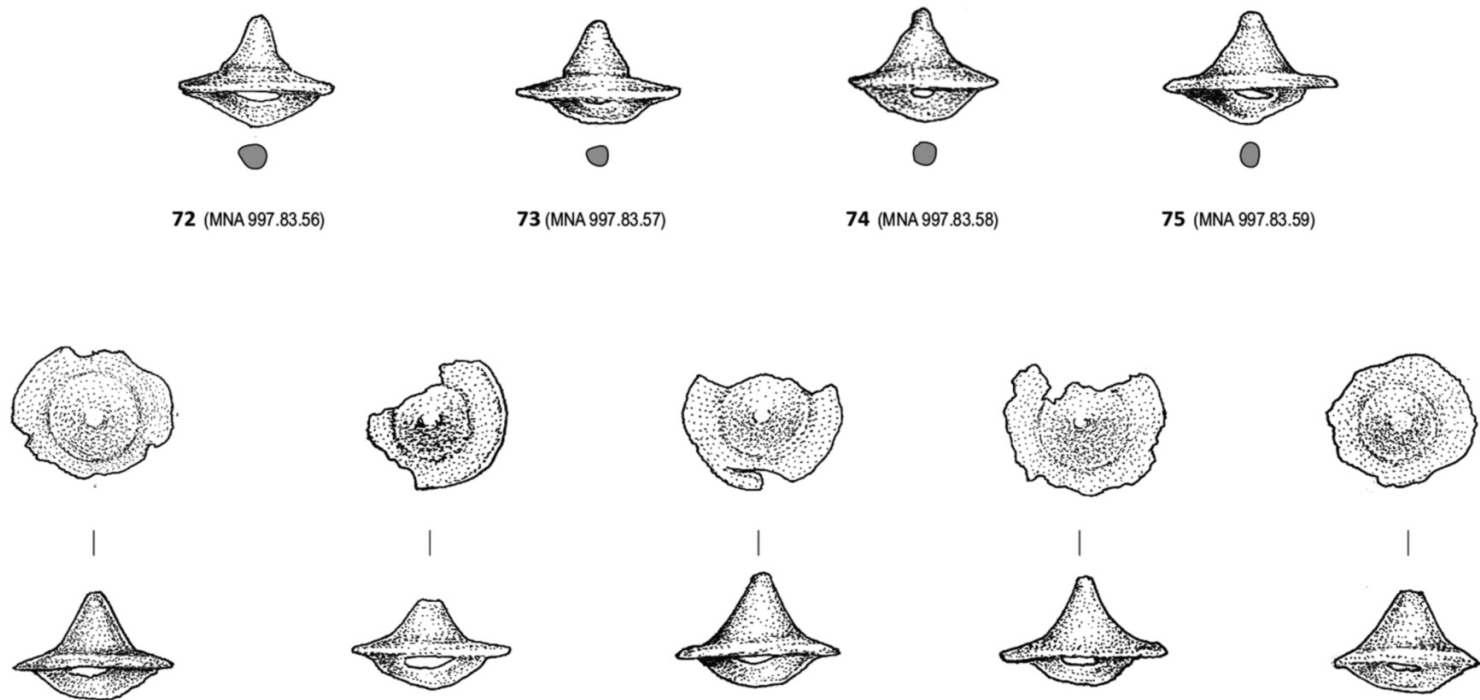

0

72 (MNA 997.83.56)

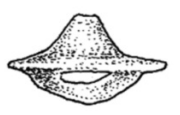

○

0

0

78 (MNA 997.83.62)

79 (MNA 997.83.63)

76 (MNA 997. 83.60)

77 (MNA 997.83.61)
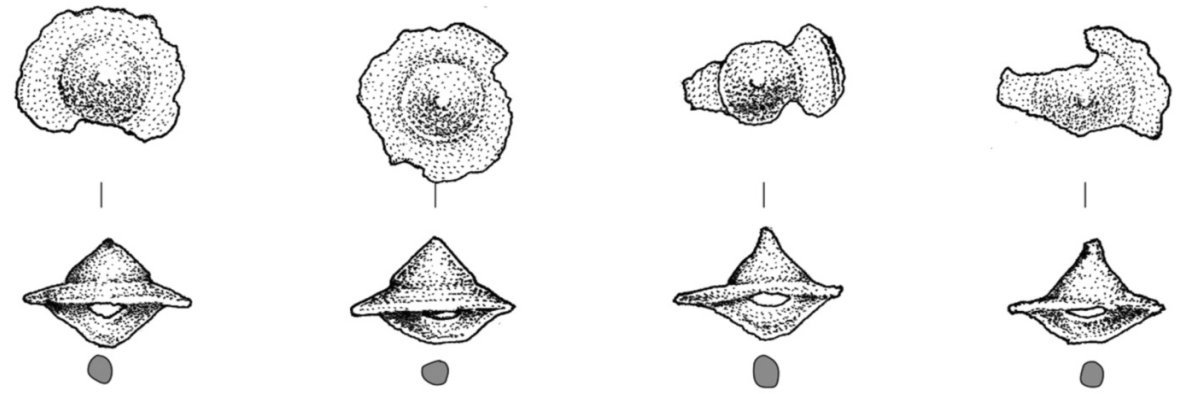

81 (MNA 997.83.65)

82 (MNA 997.83.66)

83 (MNA 997.83.68)

84 (MNA 997.83.69)

Figura 30. "Conjunto sepulcral de Guerreiro", cat. 67-84: botones del grupo C. Museu Nacional de Arqueologia (Dibujo J.M. Jerez). 


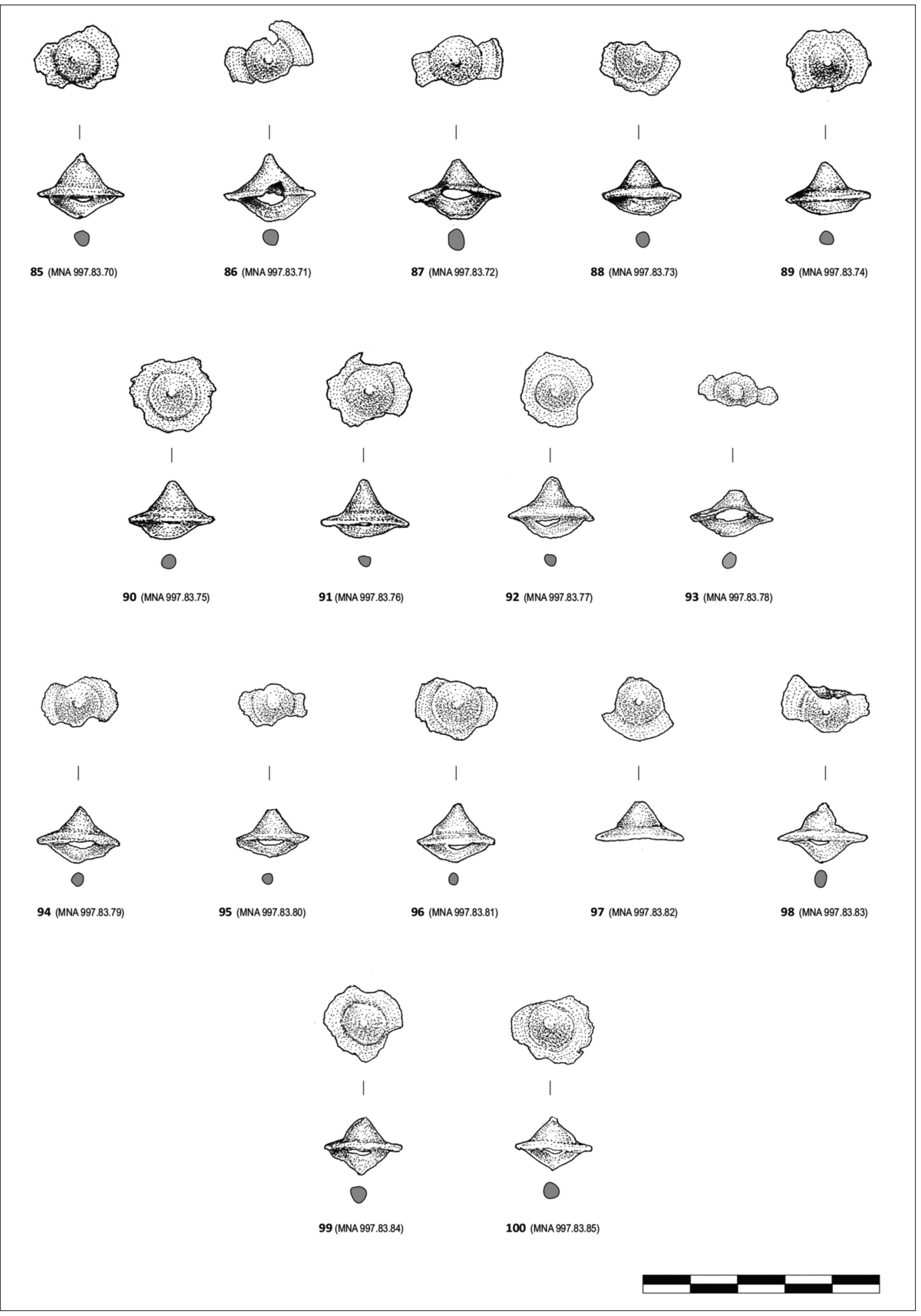

Figura 31. "Conjunto sepulcral de Guerreiro”, cat. 85-100: botones del grupo C. Museu Nacional de Arqueologia (Dibujo J.M. Jerez). 


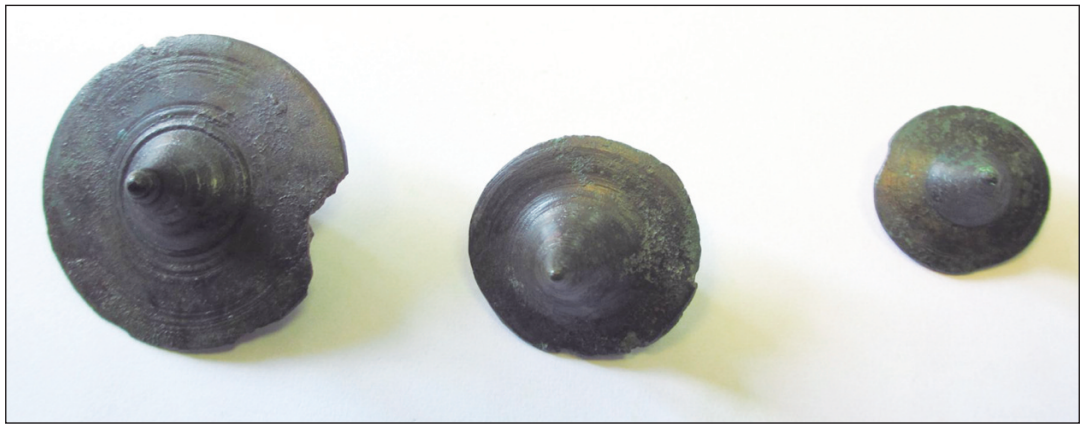

Figura 32. "Conjunto sepulcral de Guerreiro", comparativa de los tres tipos de botones (Fotos J. Jiménez Ávila).

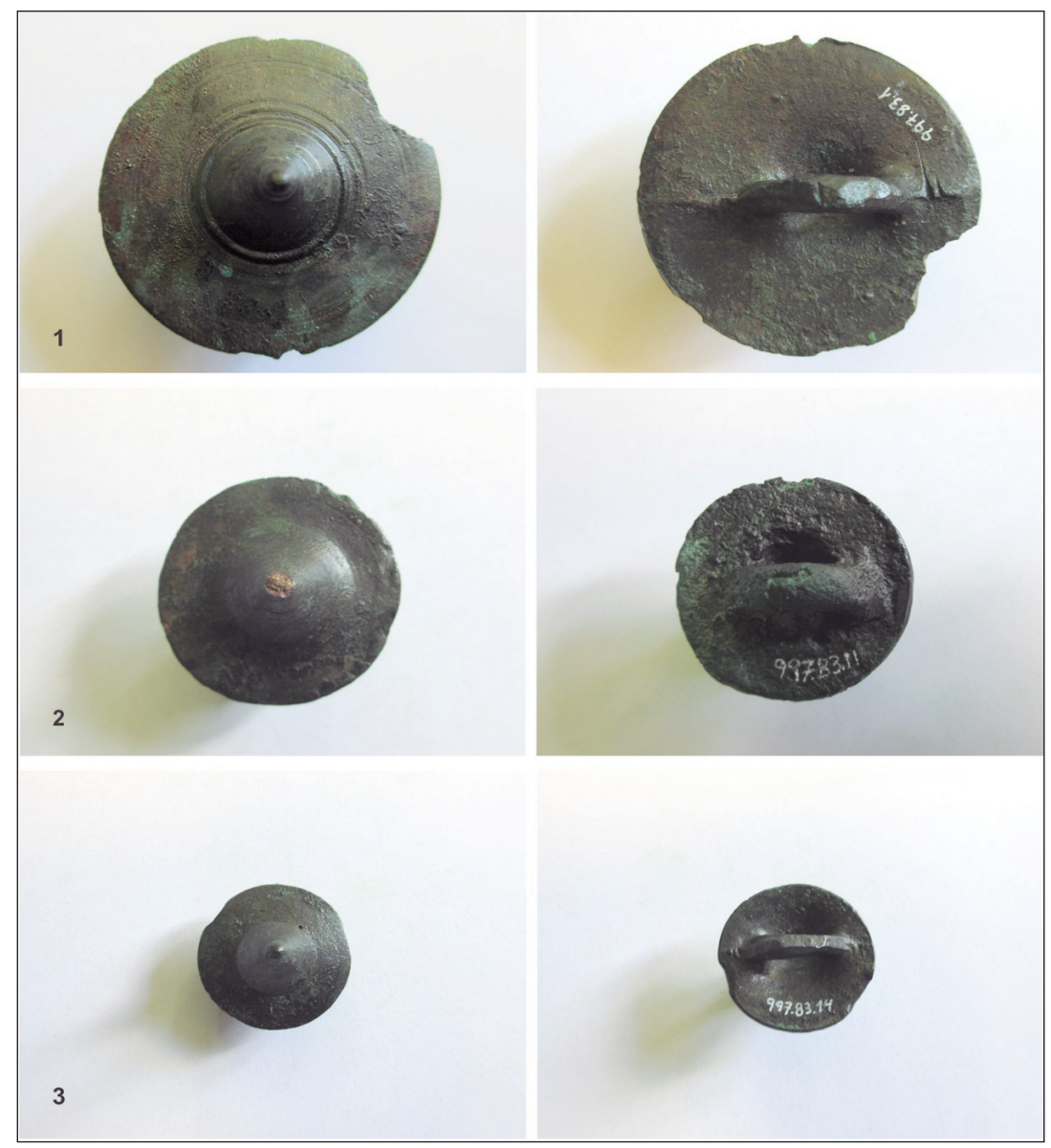

Figura 33. "Conjunto sepulcral de Guerreiro”, botones. 1. Botón del tipo A (cat.n. 16), obsérvese el pulido del anverso, los círculos conéntricos y las marcas de corte y rebabas del reverso. 2. Botón de tipo B (cat. $n .^{\circ} 26$ y 27),

obsérvese la ausencia de marcas en el reverso; 3 . Botón de tipo $C$ (cat.n. 31), (Fotos J. Jiménez Ávila).

fundidos conforme a otros procedimientos técnicos, seguramente la cera perdida (Fig. 33, n. ${ }^{\circ}$ $2)$. Estas diferencias se traducen también en los pesos (ver tabla 1).

Por sus caras visibles ni unos ni otros muestran huellas de fundición, porque todos ellos han sido sometidos luego a un proceso de fino pulido en frío a torno que es el responsable de los círculos y las molduras que muchos de ellos exhiben a modo de "decoración" (Fig. 33).

En el trabajo de M. Varela Gomes (2001: 115) y en los informes de restauración del Museo Nacional de Arqueología, figura el dato de que algunos ejemplares estaban sobredorados, pero en nuestro examen macroscópico no hemos podido verificar este extremo.

Una vez más, Cancho Roano es mejor yacimiento para referir este tipo de hallazgos. Entre las ruinas del complejo palacial se han hallado casi dos centenares de botones, no solo correspondientes a los tamaños que aquí hemos señalado, sino también algunos más grandes que requieren de dos presillas paralelas para su unión (Maluquer de Motes, 1983: 107: fig. 42; Celestino y Zulueta, 2003: 62 ss.). Pero el repertorio de botones cónicos resulta algo más amplio, habiéndose localizado unidades en varios yacimientos de la Edad del Hierro del Sur de Portugal -destacando por su proximidad los ejemplares de Azougada-, en necrópolis y poblados ibéricos e, incluso en alguna tumba del área vetona como la n. ${ }^{\circ} 52$ de El Raso de Candeleda. La cronología que parecen tener los botones cónicos en estos conjuntos gira en torno al siglo V a.C. (Fig. 34).

Desde que aparecieron estos botones en Cancho Roano vinculados por su proximidad a los elementos de tiro y cabezada, se ha señalado su funcionalidad como adornos de correajes (Maluquer de Motes, 1981: 107). Hallazgos como el que aquí presentamos, dominados por los objetos de atalajes, permiten confirmar esta utilidad -aunque se han planteado alternativas funcionales escasamente verosímiles y poco contrastadas (Celestino y Zulueta, 2003) - y existe una amplia gama de evidencias que apuntan en este sentido. En el ámbito peninsular se pueden señalar ejemplos en la escultura 
TABLA 1: CUADRO SINTÉTICO DE LOS BOTONES DE BRONCE DEL CONJUNTO

\begin{tabular}{|c|c|c|c|c|c|c|c|c|c|c|}
\hline \multirow{2}{*}{$\mathrm{INV}^{\circ}$} & \multirow{2}{*}{ MNA } & \multirow{2}{*}{ GRUPO } & \multicolumn{5}{|c|}{ DIMENSIONES (mm) } & \multirow{2}{*}{ Peso (g) } & \multirow{2}{*}{ CONSERVACIÓN } & \multirow{2}{*}{ OBSERVACIONES } \\
\hline & & & Long. & Anch. & Alt. & $\varnothing$ int. & Grosor & & & \\
\hline 16 & 997.83 .1 & $A$ & \multicolumn{2}{|c|}{$36,2 \varnothing$} & 18,9 & 13,2 & 1,1 & 12,46 & Casi completo & Costura diametral y cortes en el reverso del disco \\
\hline 17 & 997.83 .2 & $A$ & \multicolumn{2}{|c|}{$36,7 \varnothing$} & 17,8 & 13,0 & 1,5 & 10,20 & Casi completo & Costura diametral en el reverso del disco \\
\hline 18 & 997.83 .3 & $A$ & \multicolumn{2}{|c|}{$35,5 \varnothing$} & 19,8 & 14,0 & 1,1 & 11,96 & Casi completo & Costura lateral y cortes en el reverso del disco \\
\hline 19 & 997.83 .4 & $A$ & \multicolumn{2}{|c|}{$33,7 \varnothing$} & 17,9 & 12,0 & 1,2 & 10,04 & Casi completo, desgastado & Costura diametral y cortes en el reverso del disco \\
\hline 20 & 997.83 .5 & A & \multicolumn{2}{|c|}{$37,2 \varnothing$} & 17,5 & 13,4 & 1,5 & 14,36 & Casi completo, desgastado & Costura diametral en el reverso del disco \\
\hline 21 & 997.83 .6 & A & \multicolumn{2}{|c|}{$35,2 \varnothing$} & 18,5 & 13,4 & 2,0 & 11,16 & Casi completo & Costura diametral y cortes en el reverso del disco \\
\hline 22 & 997.83 .7 & A & 34,2 & 26,0 & 18,5 & 13,5 & 2,0 & 8,10 & Muy Fragmentado & Costura diametral y cortes en el reverso del disco \\
\hline 23 & 997.83 .8 & A & \multicolumn{2}{|c|}{$36,5 \varnothing$} & 18,0 & 16,0 & 1,0 & 10,47 & Fragmentado & Costura diametral y cortes en el reverso del disco \\
\hline 24 & 997.83 .9 & A & 34,0 & 26,0 & 17,8 & 13,7 & 1.2 & 8,9 & Muy Fragmentado & Costura diametral en el reverso del disco \\
\hline 25 & 997.83 .10 & A & 33,2 & 23,5 & 16,2 & 14,2 & 1,3 & 7,14 & Muy Fragmentado & Costura diametral en el reverso del disco \\
\hline 26 & 997.83 .11 & $\mathrm{~B}$ & \multicolumn{2}{|c|}{$25,2 \varnothing$} & 20.2 & 13.2 & 2.1 & 11,52 & Completo & Sin costuras \\
\hline 27 & 997.83 .12 & B & \multicolumn{2}{|c|}{$25,0 \varnothing$} & 17,5 & 14,7 & 1.5 & 11,52 & Completo & Sin costuras \\
\hline 28 & 997.83 .13 & B & \multicolumn{2}{|c|}{$26,2 \varnothing$} & 19,0 & 17,5 & 1,4 & 8,79 & Fragmentado & Sin costuras \\
\hline 29 & 997.83 .25 & B & 10,5 & 17,2 & 12,5 & 10,0 & 0,5 & 6.69 & Muy incompleto & Sin costuras \\
\hline 30 & 997.83 .67 & $\mathrm{~B}$ & 20,5 & 15,2 & 14,9 & 10,9 & 1,3 & 4,68 & Fragmentado & Sin costuras \\
\hline 31 & 997.83 .14 & $\mathrm{C}$ & \multicolumn{2}{|c|}{$20,0 \varnothing$} & 14,0 & 10.0 & 1.0 & 3.96 & Completo & Cortes en el reverso del disco \\
\hline 32 & 997.83 .15 & $\mathrm{C}$ & \multicolumn{2}{|c|}{$20,4 \varnothing$} & 13,7 & 12,0 & 1,6 & 4.83 & Completo & Costura diametral y cortes en el reverso del disco \\
\hline 33 & 997.83 .16 & $\mathrm{C}$ & & & 15,0 & 0,9 & 1,1 & 4.53 & Completo & Costura diametral y cortes en el reverso del disco \\
\hline 34 & 997.83 .17 & $\mathrm{C}$ & & & 14,5 & 10,0 & 1,1 & 4.34 & Completo & Costura diametral y cortes en el reverso del disco \\
\hline 35 & 997.83 .18 & $\mathrm{C}$ & & & 15,0 & 0,9 & 0,9 & 4.19 & Completo & Costura diametral y cortes en el reverso del disco \\
\hline 36 & 997.83 .19 & C & & & 14,0 & 15,0 & 1,5 & 5.21 & Completo & Costura diametral y cortes en el reverso del disco \\
\hline 37 & 997.83 .20 & $\mathrm{C}$ & & & 15,7 & 10,5 & 1,5 & 6.11 & Fragmentado & Costura diametral en el reverso del disco \\
\hline 38 & 997.83 .21 & $\mathrm{C}$ & & & 14,0 & 0,9 & 1,1 & 3.92 & Completo, desgastado & Costura diametral y cortes en el reverso del disco \\
\hline 39 & 997.83 .22 & $\mathrm{C}$ & & & 13,8 & 0,97 & 0,4 & 2.83 & Fragmentado & Costura diametral y cortes en el reverso del disco \\
\hline 40 & 997.83 .23 & C & & & 14,0 & 10,0 & 1,3 & 4.04 & Fragmentado & Costura diametral y cortes en el reverso del disco \\
\hline 41 & 997.83 .24 & $\mathrm{C}$ & & & 13,0 & 10,5 & 1,1 & 3.60 & Fragmentado & Costura diametral y cortes en el reverso del disco \\
\hline 42 & 997.83 .26 & $\mathrm{C}$ & & & 13,0 & 10,4 & 1,4 & 4,51 & Completo & Costura diametral y cortes en el reverso del disco \\
\hline 43 & 997.83 .27 & $\mathrm{C}$ & & & 14,5 & 0,9 & 1,7 & 3,38 & Fragmentado & Costura diametral y cortes en el reverso del disco \\
\hline 44 & 997.83 .28 & C & 15,0 & 17.2 & 12,5 & 10,0 & 0,5 & 2,07 & Fragmentado & Costura diametral y cortes en el reverso del disco \\
\hline 45 & 997.83 .29 & C & & & 14,0 & 10,5 & 1,0 & 3,70 & Fragmentado & Costura diametral y cortes en el reverso del disco \\
\hline 46 & 997.83 .30 & $\mathrm{C}$ & & & 11,5 & 8,8 & 1,3 & 3,78 & Completo & Cortes en el reverso del disco \\
\hline 47 & 997.83 .31 & $\mathrm{C}$ & & & 13,5 & 8,2 & 1,4 & 5,20 & Completo & Cortes en el reverso del disco \\
\hline 48 & 997.83 .32 & $\mathrm{C}$ & & & 14,5 & 8,9 & 1,0 & 3,59 & Completo & Costuras en el reverso. Troquel circular en el disco \\
\hline 49 & 997.83 .33 & $\mathrm{C}$ & & & 14,5 & 9,5 & 1,2 & 3,87 & Completo & Costura diametral en el reverso del disco \\
\hline 50 & 997.83 .34 & $\mathrm{C}$ & & & 14,4 & 10,0 & 1,0 & 3,68 & Casi completo & Costura diametral en el reverso del disco \\
\hline 51 & 997.83 .35 & $\mathrm{C}$ & & & 14,5 & 9,4 & 1,4 & 4,15 & Fragmentado & Costura diametral y cortes en el reverso del disco \\
\hline 52 & 997.83 .36 & C & & & 13,5 & 9,4 & 0,9 & 3,68 & Fragmentado & Costura diametral y cortes en el reverso del disco \\
\hline 53 & 997.83 .37 & C & & & 14,2 & 9,6 & 1,5 & 4,34 & Casi completo & Costura diametral y cortes en el reverso del disco \\
\hline 54 & 997.83 .38 & $\mathrm{C}$ & & & 12,8 & 10,1 & 1,5 & 3,37 & Completo & Costura diametral y cortes en el reverso del disco \\
\hline 55 & 997.83 .39 & $\mathrm{C}$ & & & 12,2 & 10,2 & 1,1 & 2,97 & Completo & Cortes en el reverso \\
\hline 56 & 997.83 .40 & $\mathrm{C}$ & & & 14,5 & 10,3 & 1,4 & 4,56 & Casi completo & Costura diametral y cortes en el reverso del disco \\
\hline 57 & 997.83 .41 & $\mathrm{C}$ & & $0 \varnothing$ & 13,5 & 10,0 & 1,4 & 3,54 & Casi completo & Costura diametral y cortes en el reverso del disco \\
\hline 58 & 997.83 .42 & $\mathrm{C}$ & & $5 \varnothing$ & 15,2 & 9,4 & 0,9 & 4,35 & Casi completo & Costura diametral y cortes en el reverso del disco \\
\hline 59 & 997.83 .43 & $\mathrm{C}$ & & $2 \varnothing$ & 13,2 & 9,2 & 1,3 & 4,88 & Completo & Cortes en el reverso del disco \\
\hline 60 & 997.83 .44 & C & & $0 \varnothing$ & 13,5 & 9,6 & 1,1 & 3,51 & Completo & Cortes en el reverso del disco \\
\hline 61 & 997.83 .45 & C & & $1 \varnothing$ & 14,4 & 8,9 & 1,5 & 4,26 & Completo & Costura diametral y cortes en el reverso del disco \\
\hline 62 & 997.83 .46 & $\mathrm{C}$ & & $5 \varnothing$ & 15,0 & 9,8 & 1,0 & 4,09 & Completo & Costura diametral y cortes en el reverso del disco \\
\hline
\end{tabular}


TABLA 1: CUADRO SINTÉTICO DE LOS BOTONES DE BRONCE DEL CONJUNTO

\begin{tabular}{|c|c|c|c|c|c|c|c|c|c|c|}
\hline \multirow{2}{*}{$\mathrm{INV}^{\circ}$} & \multirow{2}{*}{ MNA } & \multirow{2}{*}{ GRUPO } & \multicolumn{5}{|c|}{ DIMENSIONES (mm) } & \multirow{2}{*}{ Peso (g) } & \multirow{2}{*}{ CONSERVACIÓN } & \multirow{2}{*}{ OBSERVACIONES } \\
\hline & & & Long. & Anch. & Alt. & $\varnothing$ int. & Grosor & & & \\
\hline 63 & 997.83 .47 & $\mathrm{C}$ & \multicolumn{2}{|c|}{$18,9 \varnothing$} & 11,2 & 9,5 & 1,4 & 3,44 & Completo & Costura diametral y cortes en el reverso del disco \\
\hline 64 & 997.83 .48 & C & \multicolumn{2}{|c|}{$18,4 \varnothing$} & 11,4 & 9,7 & 1,1 & 3,53 & Fragmentado & Costura diametral y cortes en el reverso del disco \\
\hline 65 & 997.83 .49 & C & \multicolumn{2}{|c|}{$18,4 \varnothing$} & 13,8 & 9,4 & 1,0 & 2,88 & Casi completo & Cortes en el reverso del disco \\
\hline 66 & 997.83 .50 & C & \multicolumn{2}{|c|}{$18,3 \varnothing$} & 12,9 & 9,4 & 1,0 & 2,44 & Casi completo & Costura diametral y cortes en el reverso del disco \\
\hline 67 & 997.83 .51 & $\mathrm{C}$ & \multicolumn{2}{|c|}{$18,6 \varnothing$} & 14,7 & 9,4 & 1,0 & 3,25 & Casi completo & Costura diametral y cortes en el reverso del disco \\
\hline 68 & 997.83 .52 & $\mathrm{C}$ & \multicolumn{2}{|c|}{$20,1 \varnothing$} & 12,9 & 10,0 & 1,5 & 3,55 & Completo & Costura diametral y cortes en el reverso del disco \\
\hline 69 & 997.83 .53 & $\mathrm{C}$ & \multicolumn{2}{|c|}{$1,85 \varnothing$} & 13,5 & 9,4 & 1,3 & 3,44 & Completo & Cortes en el reverso del disco \\
\hline 70 & 997.83 .54 & $\mathrm{C}$ & \multicolumn{2}{|c|}{$1,91 \varnothing$} & 12,6 & 9,5 & 1,4 & 3,37 & Casi completo & Costura diametral y cortes en el reverso del disco \\
\hline 71 & 997.83 .55 & $\mathrm{C}$ & \multicolumn{2}{|c|}{$2,14 \varnothing$} & 14,6 & 11,0 & 1,3 & 3,56 & Casi completo & Cortes en el reverso del disco \\
\hline 72 & 997.83 .56 & $\mathrm{C}$ & \multicolumn{2}{|c|}{$1,8 \varnothing$} & 14,0 & 9,8 & 1,3 & 3,61 & Completo & Cortes en el reverso del disco \\
\hline 73 & 997.83 .57 & $\mathrm{C}$ & \multicolumn{2}{|c|}{$20,0 \varnothing$} & 13,6 & 9,5 & 1,8 & 4,13 & Completo & Costura diametral y cortes en el reverso del disco \\
\hline 74 & 997.83 .58 & $\mathrm{C}$ & \multicolumn{2}{|c|}{$17,8 \varnothing$} & 14,3 & 10,3 & 1,0 & 3,08 & Fragmentado & Costura diametral y cortes en el reverso del disco \\
\hline 75 & 997.83 .59 & $\mathrm{C}$ & 20,5 & 14,0 & 14,0 & 10,5 & 1,2 & 1,72 & Fragmentado & Costura diametral y cortes en el reverso del disco \\
\hline 76 & 997.83 .60 & $\mathrm{C}$ & \multicolumn{2}{|c|}{$19,5 \varnothing$} & 12,6 & 10,7 & 1,1 & 3,03 & Fragmentado & Costura diametral y cortes en el reverso del disco \\
\hline 77 & 997.83 .61 & $\mathrm{C}$ & 19,1 & 15,2 & 11,5 & 9,4 & 1,3 & 2,64 & Fragmentado & Costura diametral y cortes en el reverso del disco \\
\hline 78 & 997.83 .62 & $\mathrm{C}$ & \multicolumn{2}{|c|}{$20,0 \varnothing$} & 14,4 & 10,0 & 1,1 & 3,33 & Fragmentado & Costura diametral y cortes en el reverso del disco \\
\hline 79 & 997.83 .63 & $\mathrm{C}$ & \multicolumn{2}{|c|}{$20,6 \varnothing$} & 13,8 & 10,4 & 1,0 & 2,63 & Fragmentado & Cortes en el reverso del disco \\
\hline 80 & 997.83 .64 & $\mathrm{C}$ & 17,9 & 16,3 & 13,4 & 9,4 & 1,3 & 3,34 & Casi completo & Costura diametral y cortes en el reverso del disco \\
\hline 81 & 997.83 .65 & $\mathrm{C}$ & \multicolumn{2}{|c|}{$20,0 \varnothing$} & 13,5 & 9,8 & 1,2 & 3,12 & Fragmentado & Cortes en el reverso del disco \\
\hline 82 & 997.83 .66 & $\mathrm{C}$ & 20,7 & 13,2 & 13,0 & 9,8 & 1,6 & 3,59 & Fragmentado & Cortes en el reverso del disco \\
\hline 83 & 997.83 .68 & $\mathrm{C}$ & 18,5 & 11,5 & 14,9 & 9,7 & 0,8 & 2,05 & Fragmentado & Costura diametral y cortes en el reverso del disco \\
\hline 84 & 997.83 .69 & $\mathrm{C}$ & 19,1 & 15,3 & 12,5 & 11,0 & 1,0 & 2,16 & Muy fragmentado & Costura diametral y cortes en el reverso del disco \\
\hline 85 & 997.83 .70 & $\mathrm{C}$ & 17,5 & 15,0 & 14,4 & 10,9 & 1,0 & 2,91 & Fragmentado & - \\
\hline 86 & 997.83 .71 & $\mathrm{C}$ & 18,3 & 14,2 & 15,0 & 10,0 & 0,8 & 2,39 & Fragmentado & Costura diametral y cortes en el reverso del disco \\
\hline 87 & 997.83 .72 & $\mathrm{C}$ & 19,2 & 10,1 & 11,7 & 9,7 & 0,9 & 2,13 & Muy fragmentado & Costura diametral y cortes en el reverso del disco \\
\hline 88 & 997.83 .73 & $\mathrm{C}$ & 17,8 & 14,2 & 11,9 & 9,0 & 1,0 & 2,64 & Fragmentado & Costura diametral en el reverso del disco \\
\hline 89 & 997.83 .74 & $\mathrm{C}$ & 17,9 & 14,3 & 11,0 & 9,5 & 1,5 & 2,32 & Fragmentado & Costura diametral y cortes en el reverso del disco \\
\hline 90 & 997.83 .75 & C & 18,2 & 14,1 & 12,2 & 9,5 & 1,4 & 2,59 & Fragmentado & Cortes en el reverso del disco \\
\hline 91 & 997.83 .76 & C & 19,6 & 15,1 & 13 & 9,3 & 1,5 & 2,22 & Fragmentado & Costura diametral y cortes en el reverso del disco \\
\hline 92 & 997.83 .77 & $\mathrm{C}$ & 77,4 & 15,2 & 13,7 & 9,4 & 1,4 & 3,01 & Casi completo & Cortes en el reverso del disco \\
\hline 93 & 997.83 .78 & $\mathrm{C}$ & 16,5 & 16 & 10,5 & 8,7 & 1 & 1,15 & Muy fragmentado & Costura diametral y cortes en el reverso del disco \\
\hline 94 & 997.83 .79 & $\mathrm{C}$ & 15,7 & 11,3 & 11,2 & 9,5 & 1,5 & 1,80 & Fragmentado & Costura diametral y cortes en el reverso del disco \\
\hline 95 & 997.83 .80 & $\mathrm{C}$ & 15,4 & 9,9 & 11,5 & 10,9 & 1,4 & 1,82 & Muy fragmentado & Costura diametral y cortes en el reverso del disco \\
\hline 96 & 997.83 .81 & $\mathrm{C}$ & 15,9 & 11 & 13,1 & 10,6 & 1,4 & 2,40 & Fragmentado & - \\
\hline 97 & 997.83 .82 & $\mathrm{C}$ & 15,6 & 16,4 & 9,5 & 9,9 & 1,5 & 2,03 & Muy fragmentado & Costura diametral en el interior del cono \\
\hline 98 & 997.83 .83 & $\mathrm{C}$ & 18,5 & 12,4 & 12,8 & 9,5 & 1,3 & 2,56 & Muy fragmentado & Costura diametral en el reverso \\
\hline 99 & 997.83 .84 & $\mathrm{C}$ & 16,3 & 13,2 & 12,6 & 9,5 & 1,1 & 2,43 & Fragmentado & Cortes en el reverso del disco \\
\hline 100 & 997.83 .85 & C & 16,3 & 10,9 & 11,9 & 8,2 & 1,3 & 1,48 & Fragmentado & Costura diametral en el reverso \\
\hline
\end{tabular}

ibérica ecuestre, como los ya aludidos caballos de Alcantarilla o La Covatilla (Bandera, 1979-80; Jiménez Ávila, e.p.) o también una de las caras del cipo de Jumilla (Fig. 35) como ejemplos de representaciones plásticas que sugieren este uso. Y muy próxima a las fronteras ibéricas se halla la bien conocida tumba 99 de Cayla, donde las ristras de botones (aunque de otra tipología) aparecían formando las líneas de la cabezada (Louis et al., 1958). En el ámbito centroeuropeo los ejemplos de tumbas de carros que incluyen adornos de este tipo se multiplican (Pare, 1992).

Sí es cierto, no obstante, que existen hallazgos individuales de botones peninsulares, como el de la 
tumba 52 de E1 Raso de Candeleda o el de Lapa da Cova, en ámbito portugués que, por su carácter unitario, resultan más arduamente vinculables con juegos completos de arreos, que están ausentes en sus respectivos contextos. Pero nada impide pensar que los botones de bronce tuvieran un uso simultáneo como complementos de vestido: capas, cinturones, talabartes o coletos, y que con estas funciones encuentren su justificación los hallazgos individuales que aparecen en tumbas y otros contextos cerrados. De hecho, los botones más antiguos de la Península Ibérica, los del horizonte de la Ría de Huelva, aparecen en un momento donde aún no es evidente que existieran caballos enjaezados con adornos de bronce.

Aparte de las comparaciones tipológicas, el material de Cancho Roano permite hacer algunas valoraciones de orden numérico. Los botones

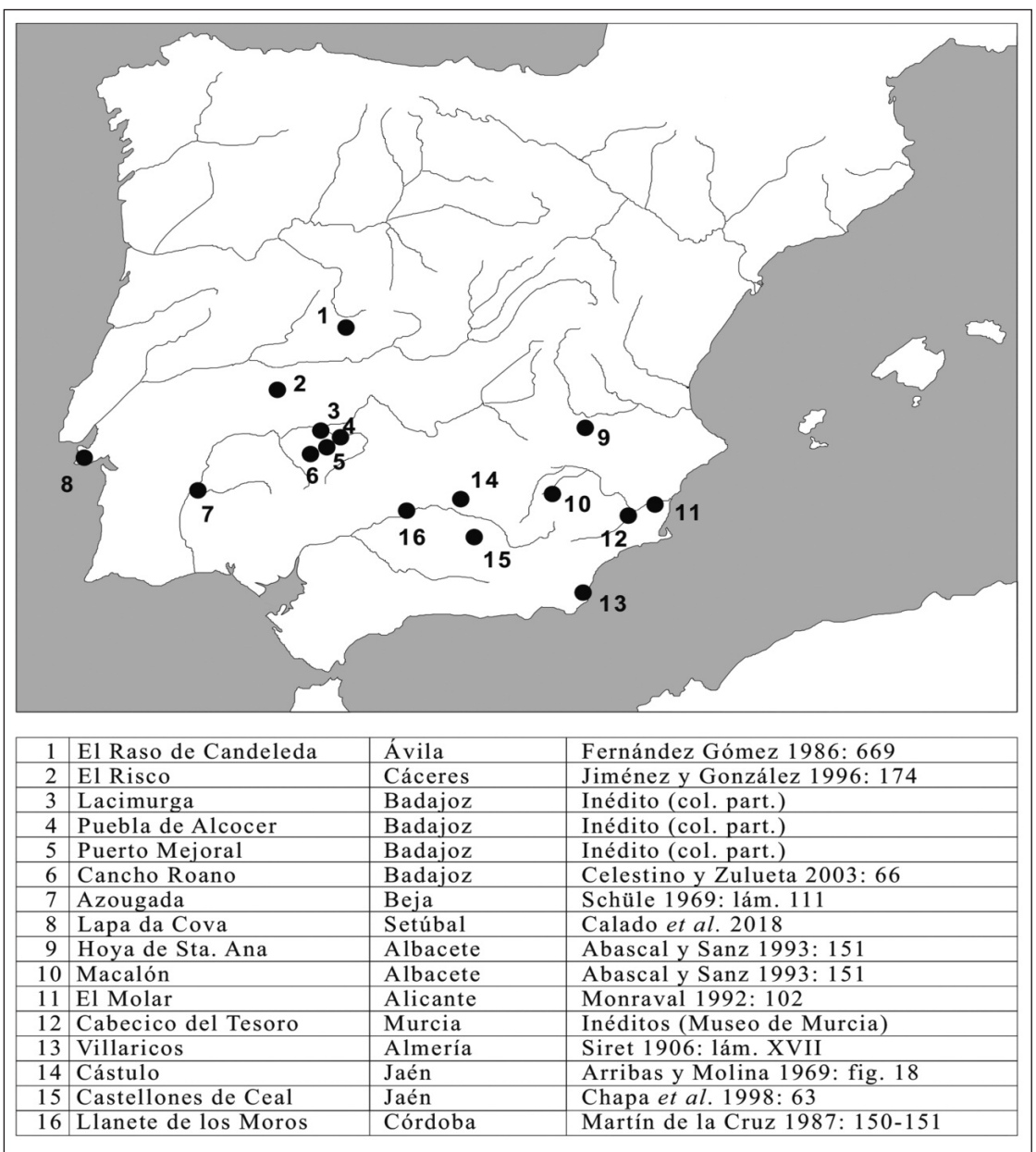

Figura 34. Distribución de los botones cónicos de época postorientalizante en la Península Ibérica. recogidos en Cancho Roano suman unos 200, lo que, de admitir que en el palacio se contenían cuatro juegos de bridas, implicaría que en cada una de ellas se aplicaran unos 50 botones (en el improbable caso de que la distribución fuera homogénea). El número de botones que presenta el conjunto del MNA para una sola brida es de 80 botones, cifra considerablemente superior. No obstante, como hemos adelantado, la distribución de unidades por arreo debió de haber sido sustancialmente diversa y caprichosa.

\subsubsection{Reconstrucción del equipo ecuestre}

El conjunto ecuestre que hemos estudiado es enormemente coherente desde el punto de vista de la funcionalidad y parece orientado a enjaezar y engalanar un solo caballo, sin que falte ni sobre ninguno de los elementos necesarios destinados a tal propósito. De este modo, encontramos todas las piezas de una única cabezada (dos camas, un filete, dos faleras) y los elementos de un yugo y sus sistemas de unión, junto a un número importante

de adornos de bronce para las riendas y correajes en forma de botones y colgantes, que también encuentran coherencia numérica. La relación de estos elementos con una única cabezada es clara, y coincide con lo que conocemos para otras situaciones de enterramientos de carros: dos pasarriendas (uno a cada lado de la gamella del yugo) y dos cierres diferentes para el enganche de las cinchas (Fig. 36).

Conviene recordar que en la mayoría de las situaciones en que se han hallado restos de carro en contextos "cerrados" de Edad del Hierro hispánica, corresponden casi siempre a la zona del yugo, sugiriendo que estos elementos eran objeto de un tratamiento especial (pars pro toto) que excluía al resto del vehículo en las sepulturas (Jiménez Ávila y Muñoz, 1997). Y también parece suceder así en otros contextos no funerarios, como demostrarían los restos de Cancho Roano, donde no hay restos de caja ni de ruedas. De este modo, contrastando con una cierta abundancia de elementos de yugo, adolecemos de una enorme escasez de otros 


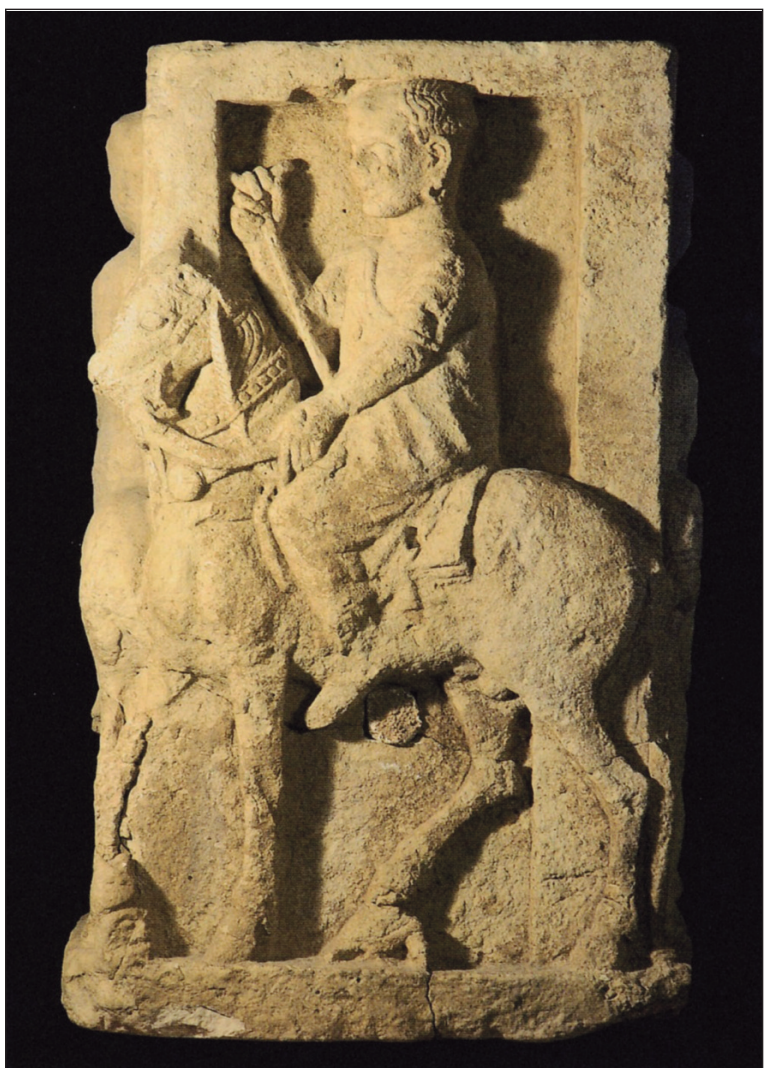

Figura 35. Cipo de Jumilla (Murcia) en el que aparece un jinete con arreos decorados con botones (Foto Museo de Jumilla).

componentes de carro en la Protohistoria ibérica. Por tanto, la ausencia de piezas de otras partes del carro no debe disuadirnos de considerar como un hallazgo completo este conjunto del MNA.

La posibilidad de que en una actividad de saqueo o en una obra de remoción se hubiera recuperado solo la mitad de un equipo de jaeces resulta escasamente creíble, vista la organicidad del conjunto y su perfecta estructura.

Por todo ello, parece adecuado plantear que nos hallamos ante un equipo completo destinado a enjaezar y unir a un solo caballo a través de un yugo de una única gamella y de una sola cabezada.

Aunque la forma en que fue recogido el conjunto dista mucho de las privilegiadas condiciones tafonómicas de algunos depósitos peninsulares y europeos, donde los componentes ecuestres se hallaban prácticamente in situ, facilitando así la restitución de los elementos en las bridas y en los sistemas de tracción, se puede ensayar una primera reconstrucción del mismo (Fig. 37).

El bocado, de decorativas camas, iría unido a la cabezada a través de dos tiras en "Y" invertida, como se deduce de las dos sujeciones laterales que presentan las "grupas" de los prótomos de caba- llos, en forma de argollas semicirculares. En dos camas similares de Cancho Roano se hallaron los remaches aún fijados a sujeciones equivalentes (Fig. 38), pero su ausencia en nuestro conjunto nos lleva a sugerir la posibilidad de sistemas de agarre alternativos (tal vez mediante costuras) aunque puede que los remaches, simplemente, se hayan extraviado. De la zona de unión de las tiras del bocado quizás partieran una muserola y una sobraba, aunque estos elementos son minoritarios en los repertorios ibéricos cuando contamos con grupos numéricamente significativos, como el de El Cigarralejo (Cuadrado, 1950), tal y como refleja alguna de las reconstrucciones que se han realizado para equipos próximos, donde estos elementos están ausentes (Quesada, 2002-03; 2005: fig. 17).

La cabezada se decoraría con dos faleras a la altura de la sien que se agarrarían en las quijeras, en el ahogadero, en el frontal y en la testera. Aunque no se conservan todos los remaches, en la reconstrucción hemos optado por la solución más canónica, que contempla cinco agarres. No obstante, la presencia de solo cuatro remaches por disco podría explicarse por diversos motivos (aparte del recurrente extravío), como que en la parte central se situara algún elemento de pasamanería o, incluso, que las faleras fueran elementos reutilizados y que en su montaje secundario quedara libre alguna perforación.

La presencia de dos faleras laterales sugiere la posibilidad de un elemento frontal, como sucede en la mayoría de las cabezadas ibéricas dotadas de discos que hemos examinado. En este sentido, hemos valorado la posibilidad de que se instalara en el frontal uno de los colgantes calados con campanillas, aunque, finalmente, por proximidad a los otros dos, lo hayamos situado en la zona del pretal en la reconstrucción gráfica.

Es bastante posible que una parte de los 85 botones cónicos que componen el conjunto se instalara en la cabezada. Así se desliga de la relación entre bocados y botones que aparece en Cancho Roano (Maluquer de Motes, 1981: 22: fig. 37), o de modelos conocidos más o menos próximos, como los ya referidos de Alcantarilla, Marchena o Mailhac. Sin embargo, a partir de ahí, todas las reconstrucciones que se puedan hacer (como la que aquí proponemos en el dibujo) son puramente especulativas.

En cuanto a los sistemas de unión entre el bocado y las riendas, estando ausentes las anillas que se encuentran en otros bocados contemporáneos, como los de Cancho Roano, y vistas las características de nuestra embocadura, hay que 


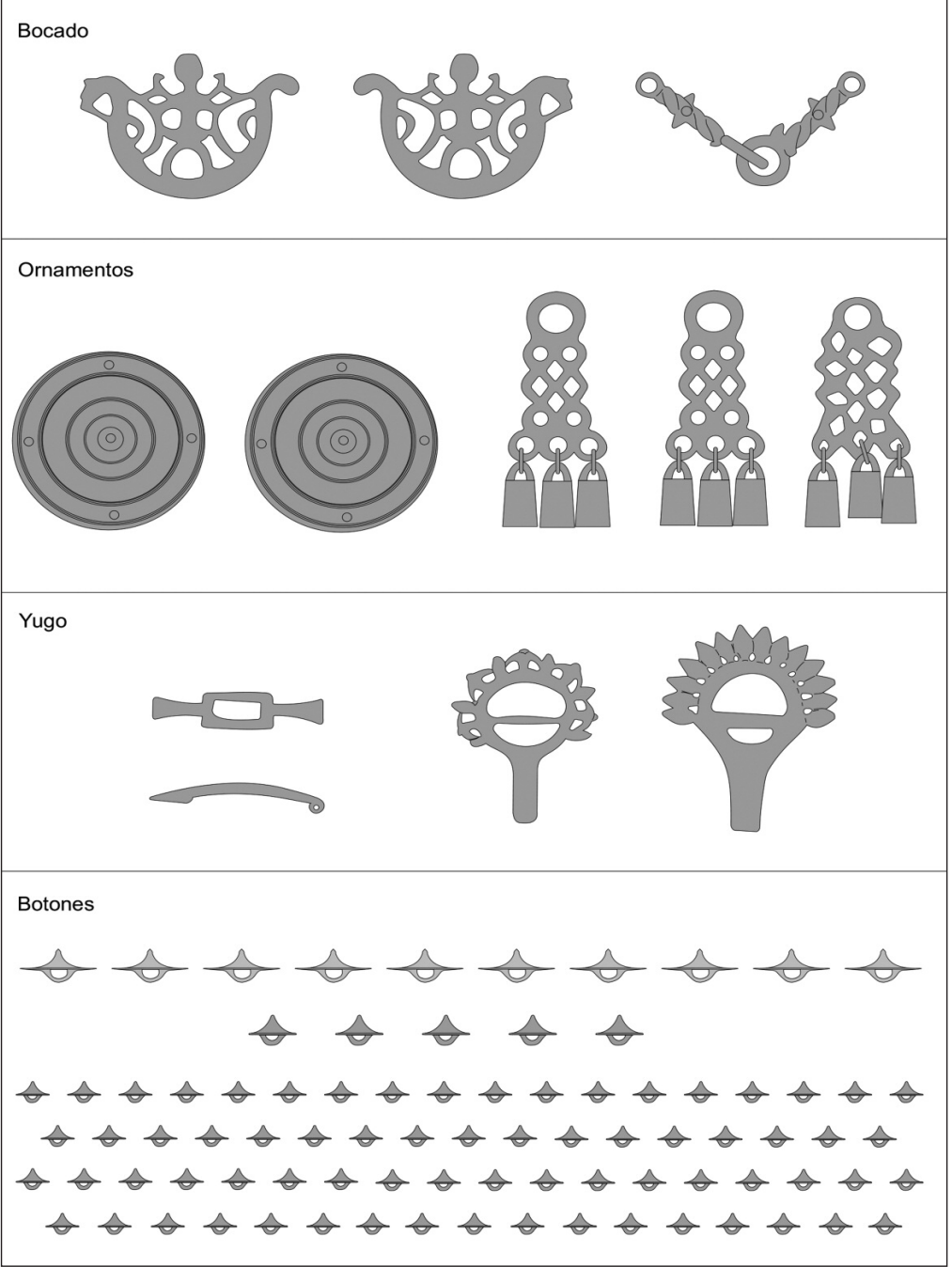

estar ante la presencia de yugos dorsales, que parecen documentarse para periodos algo más tardíos (Jiménez Ávila, 2015b; e.p.).

En el yugo se instalarían los dos pasarriendas y se uniría al caballo mediante un correaje pectoral, a modo de pretal, unido con cierre de alamar. Y si aceptamos su condición de yugo dorsal -tal y como reproduce el dibujo- un segundo cierre de pasador uniría la cincha ventral. Ambos tipos de abrochaduras cuentan con exponentes en la tradición de los carros orientalizantes peninsulares y, al mismo tiempo, con buenas relaciones entre los carros coetáneos de Europa central.

Al igual que los correajes de la cabezada, es muy posible que las del sistema de tracción también fueran decoradas con botones y otros adornos de bronce. Los colgantes con campanillas y algunos de los botones podrían haber ejercido esta función, como aquí reconstruimos, y como se observa en muchos caballos engalanados del Mediterráneo y arcaico y de la Europa hallstática. No obstante, tal y como sucede con los adornos de la

Figura 36. Cuadro-resumen con la composición del equipo ecuestre del "Conjunto sepulcral de Guerreiro" en el Museo Nacional de Arqueología.

arbitrar sistemas diferentes. Hemos optado por un sistema de lazos combinados de cordón y cuero con cierres de botón, aunque las posibilidades serían múltiples.

Pasando a la zona del yugo, conviene empezar señalando nuestro casi absoluto desconocimiento de todo lo que se refiere a los carros de este periodo en la Península Ibérica. Para los carros del Periodo Orientalizante, a partir de las analogías con sus homólogos orientales, se han reconstruido yugos de cuello (Jiménez Ávila, 2002: fig. 116; 2018b: figs. 11 y 13), y la pervivencia de pasarriendas de la misma clase hasta época avanzada (como es nuestro caso) puede sugerir el uso de este mismo tipo. Pero ya hemos señalado que, si de la presencia de dos sistemas de cierre (pasadores y alamares) se deducen dos cinchos distintos -algo que tampoco tendría que ser necesariamente así- podríamos

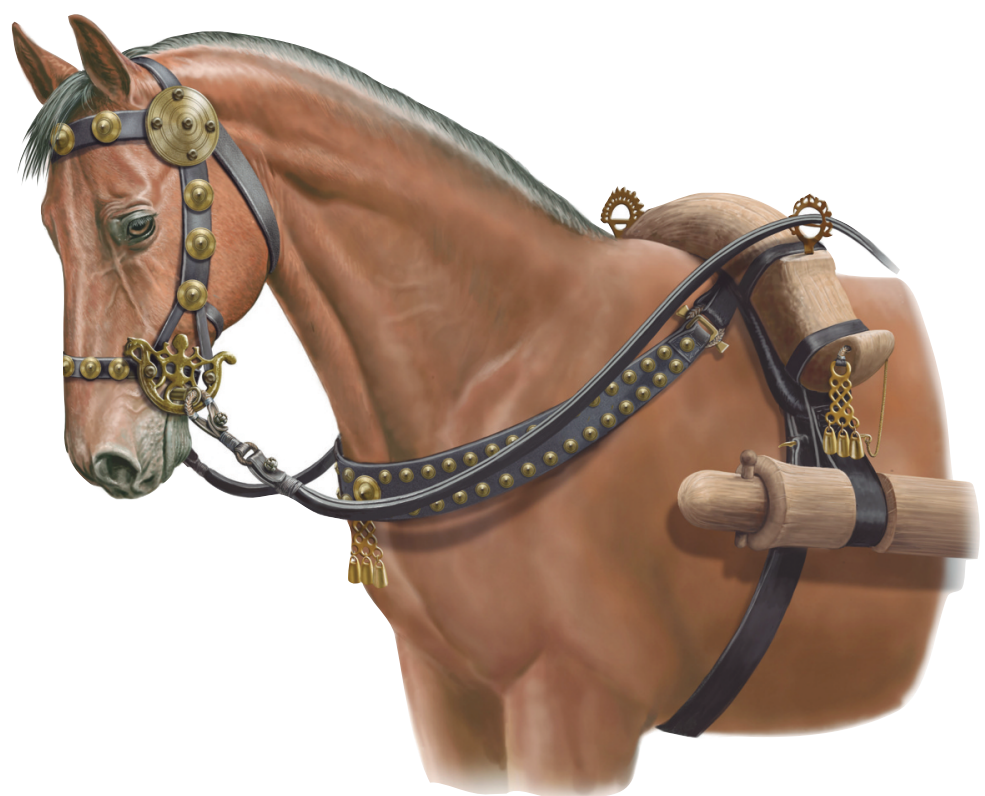

Figura 37. Reconstrucción del equipo ecuestre a partir de los materiales del "Conjunto sepulcral de

Guerreiro" con yugo dorsal

(Dibujo infográfico A. Grajera). 


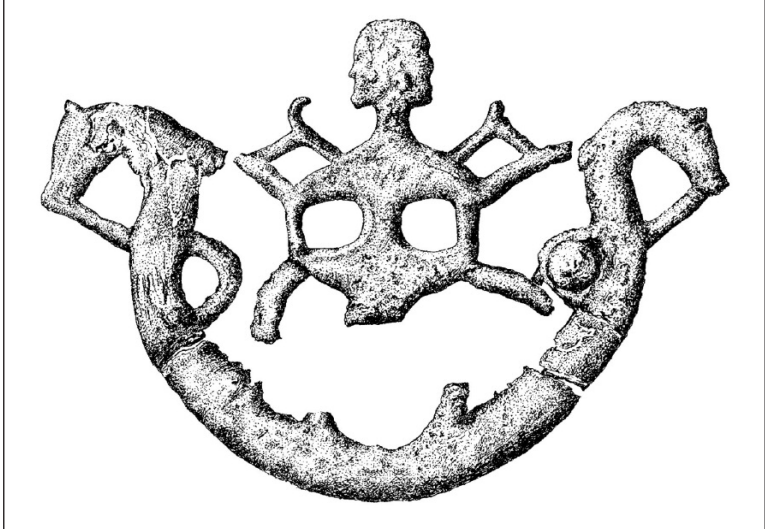

Figura 38. Cancho Roano. Cama lateral de bocado con uno de los agarres in situ (s. Maluquer 1981: fig. 37).

cabezada, cualquier intento de reconstrucción concreta resultaría puramente hipotético.

Como tantas veces sucede en los equipos ecuestres hallados en la Edad del Hierro de la Península Ibérica, el "Conjunto sepulcral de Guerreiro" no incluye elementos de la parte posterior al yugo, lo cual, al margen de las significaciones ideológicas y culturales que se puedan derivar, y a las que ya hemos aludido, dificulta no poco el conocimiento y las posibles reconstrucciones de los vehículos de prestigio de esta época.

\subsection{Fragmentos amorfos (cat. 101)}

Cuatro pequeños fragmentos en forma de barra maciza completan el catálogo (Fig. 39). Su vincu- lación con elementos de tipo pasador sagital, como se hace con alguno de ellos en los inventarios del museo, debido a su perfil ligeramente curvado, o con otro tipo de objetos - como asadores - resulta dudosa.

\section{ESTUdio de CONJUNTO Y PROBLEMAS DEL HALLAZGO}

Aparte del estudio por tipos, conviene hacer algunas valoraciones de conjunto sobre aspectos generales como la cronología, las técnicas de fabricación, la producción, etc. de cara a obtener una visión global del hallazgo y facilitar así su integración en nuestro actual conocimiento de la Edad del Hierro postorientalizante del sur de Portugal. Por otro lado, es conveniente plantear algunas cuestiones que quedan abiertas o sujetas a debate debido a nuestro desconocimiento del lugar y de las circunstancias del hallazgo.

\subsection{Aspectos generales}

\subsubsection{Cronología}

En su estudio de los santuarios púnicos del sur de Portugal, donde se recogen algunos datos sobre este conjunto de metales, M. Varela Gomes señala que, a instancias del Museo Nacional de Arqueología, se realizó un análisis radiocarbónico sobre restos de carbón entregados junto con los bronces. El análisis (Gif A-99 119) ofreció una fecha de $2500 \pm$ 100, y tras una calibración de $2 \sigma$ un intervalo de entre el 808 y el 397 a.C. (Gomes, 2001: 117). El dato, si bien confirma la situación del conjunto en tiempos protohistóricos, es demasiado impreciso como para resultar de utilidad.

En su lugar, debemos recurrir a criterios tipológicos que, de manera global, permiten situar el conjunto en el siglo V a.C., como se desliga de la presencia de la mayoría de estos mismos bronces en el momento del incendio de Cancho Roano, bien datado por la cerámica griega. El seguimiento que se puede hacer de algunos elementos concretos, como los asadores, los colgantes amorcillados o los
Figura 39. "Conjunto sepulcral de Guerreiro", cat. 101: fragmentos en forma de barra. Museu Nacional de Arqueologia (Dibujo J.M. Jerez). 
botones cónicos, también apunta en la misma dirección, y es en esta misma época cuando se debieron realizar las versiones en bronce de vasos con asas rematadas en cabeza de anátida, como sugieren tanto la datación de la mayor parte de las importaciones de su género localizadas en la Península como las propias imitaciones de vasos hispánicos que las portan.

Algunos elementos pueden presentar una cronología algo anterior, como los pasarriendas, que -en particular el n. ${ }^{\circ} 10$ - ostentan una decoración más propia de los siglos VII y VI. Pero ya hemos señalado que debe tratarse de pervivencias más antiguas, como denuncia su propio dimorfismo, extraño dentro de un mismo set. Por otro lado, la presencia de pasarriendas de la misma especie, aunque sin decorar (modalidad 2a), también está verificada en el sitio de Cancho Roano a través de un único ejemplar (Maluquer de Motes, 1981: lám. XL), y la misma fecha del siglo $\mathrm{V}$ se ha propuesto para los de Talavera la Vieja (Jiménez Ávila y González Cordero, 2012). Por tanto, su uso en siglo V debía estar bastante extendido.

En cuanto a la cronología algo más antigua que algunos autores han señalado para las camas caladas de tipo despotes, ya hemos apuntado que raramente se aportan argumentos que así lo justifiquen y que, en su lugar, la proliferación de hallazgos homogéneos que pueden fecharse en el siglo V (Cancho Roano, con dos equipos, y ahora el nuestro) anima a considerar que sea en esta centuria cuando se usaran y se fabricaran de modo preferencial.

\subsubsection{Aspectos técnicos}

A la espera de la realización de los análisis químicos de los componentes del conjunto, se pueden señalar algunas características técnicas referidas a los procedimientos de fabricación, que pueden contribuir a su mejor interpretación y encuadre cultural.

Si hay algo que destaca dentro de este grupo de bronces es la variedad de técnicas que se han aplicado en su elaboración, contrastando con lo que conocemos para momentos inmediatamente anteriores, donde el uso de la cera perdida y el sobrefundido constituían la mayor parte del bagaje tecnológico, al menos para el tipo de bronces que aquí estamos tratando (Jiménez Ávila, 2002: 331 s.).

En este caso se ha aplicado la fundición en molde abierto, en moldes bivalvos, a la cera perdida y el pulido en frío a torno. Esta última técnica, practicada para el acabado de los discos y botones, no se empleaba con anterioridad en el trabajo de los bronces peninsulares. Para su uso posiblemente se haya aplicado un torno de violín y, en el caso de los botones, es posible que se haya mantenido el bebedero, a modo de barra de sujeción, en la parte más sobresaliente de la presilla de agarre, pues muchos ejemplares tienen en esta zona la huella del corte de la tenaza o el cincel que se aplicó a tal efecto (Fig. 40).

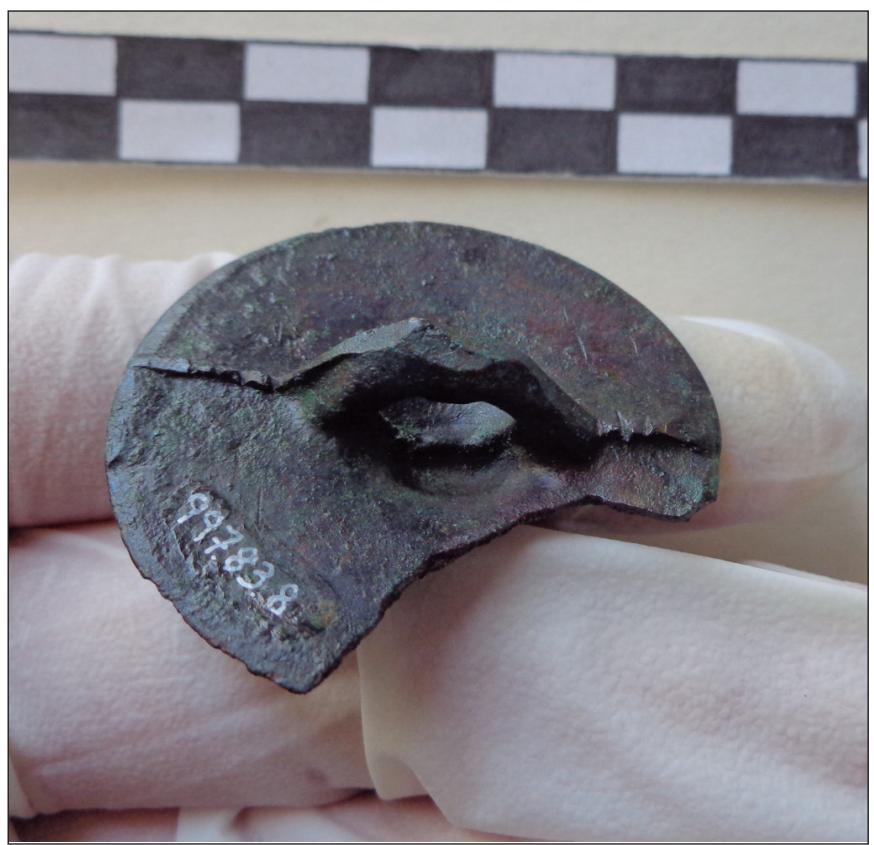

Figura 40. "Conjunto sepulcral de Guerreiro": botón n. 23. Detalle del reverso mostrando huellas de corte en la presilla y en el disco. Museu Nacional de Arqueologia

(Foto A.S. Antunes).

El análisis de las técnicas aporta otros datos de interés, pues el grupo de botones de tamaño intermedio no se ha realizado aplicando las técnicas de molde bivalvo como los de sus homólogos de los grupos A y C, sino que se han fundido a la cera perdida. Estos elementos presentan, además, diferencias morfológicas, como el mayor grosor de sus presillas, sugiriendo su procedencia de un taller diferente.

Igualmente dignas de destacar son las diferencias de calidad entre las placas caladas de los colgantes sonoros, debidas a artesanos con unos niveles de pericia muy distintos.

Resulta también ilustrativo comparar las diferentes calidades de algunos objetos con lo que conocemos de otros conjuntos tipológicamente próximos, en particular las camas laterales con sus paralelos de Cancho Roano, que presentan un trabajo de representación de los detalles escultóricos 
mucho mejor acabado y una fundición mucho más lograda. Esta diferencia de tratamientos, que hace parecer las camas del conjunto del MNA como productos más descuidados o de inferior categoría, es importante también de cara a determinar la existencia de uno o varios centros de producción.

Lo que se desliga del estudio del conjunto del MNA es la existencia de talleres distintos, no solo para este equipo respecto de otros conocidos sino, incluso, para los distintos componentes del mismo conjunto, como señalan las distintas categorías de botones, los colgantes, los pasarriendas, etc.

Esto es importante porque se ha venido afirmando que todos estos conjuntos procedían, posiblemente, de un único taller suroccidental. Lo que los datos parecen avalar es que este equipo no se constituyó con un set fundido unitariamente, sino que se formó con productos salidos de distintos talleres y, a veces, de muy variado aspecto, calidades e, incluso, cronologías, denunciando un modo de adquisición diversificado y algo errático que se ajusta a lo que conocemos para la circulación de bronces y otros bienes de prestigio en el Periodo Postorientalizante (Jiménez Ávila, 2006-07).

En el caso concreto de los arreos, resulta útil recordar, además, que este tipo de utillaje ecuestre pasa por dos esferas artesanales sucesivas que no tienen por qué estar necesariamente coordinadas: por un lado los broncistas y, por otro, los talabarteros. Los modos de operar, de abastecerse unos a otros y de abastecer después a los últimos destinatarios de los productos es algo que apenas se ha planteado.

\subsubsection{Producción}

La localización de un conjunto de objetos que encuentran referentes tan próximos en yacimientos peninsulares y, más concretamente, del suroeste ibérico, viene a reforzar la idea de que todos los objetos de bronce que integran este conjunto sean una producción peninsular situable -con alguna poco significativa excepción- en el Periodo Postorientalizante. Las referencias y similitudes que se pueden encontrar tanto con bronces europeos como del resto del Mediterráneo, tropiezan con la reiteración de unas tipologías y unas decoraciones concretas que no se constatan fuera del ámbito peninsular.

Así contribuye a pensar, sobre todo, el conjunto ecuestre, pero también los elementos adscribibles a otras categorías, como el asador de tipo andaluz o el colgante amorcillado, todos ellos de indudable fabricación peninsular. Basándonos en el mismo tipo de razonamientos, hemos propuesto una filia- ción peninsular para el fragmento de asa zoomorfa, posiblemente correspondiente a un colador que imita o recrea las series coetáneas de Grecia o Italia, aunque en este caso, al contrario de lo que sucede con los demás elementos, se trate de una pieza sin parangones directos.

La distribución geográfica de algunos de los objetos es netamente suroccidental, lo que, a priori, animaría a situar en el Suroeste los talleres de dichas producciones. Pero hemos de tener cautela en una fase tan incipiente del conocimiento de estas cuestiones como esta en la que actualmente nos encontramos para la broncística postorientalizante. Por ejemplo, todos los discos y faleras de bronce que hemos documentado hasta la fecha están en el entorno del Guadiana medio y bajo, pero es evidente que en el mundo ibérico, donde hasta ahora no han aparecido, también se usaron, como evidencia su presencia en la escultura en piedra. Y si contamos con que algunos elementos de atalajes, como las camas y los botones, estaban extendidos por todo el mediodía peninsular (sureste y suroeste), es más que probable que los talleres también participaran de una cierta dispersión o que, al menos, la comercialización de sus productos alcanzara una amplia zona. Cabe esperar que la realización de análisis de composición química y la comparación de resultados venga a ampliar nuestra base argumental de cara a matizar, fortalecer o rebatir todas estas opiniones acerca de la broncística postorientalizante e ibérica de la que tan poco sabemos.

Excepciones a la consideración como bronces postorientalizantes peninsulares, que hemos señalado para la mayor parte del conjunto serían, probablemente, los pasarriendas, que podrían corresponder a una cronología algo anterior, adscribiéndose, por tanto, a las producciones hispano-fenicias o propiamente orientalizantes. Esta presencia de elementos antiguos en contextos postorientalizantes parece ser un hecho frecuente, como demuestran contextos bien conocidos como el de Cancho Roano, donde junto a cerámicas griegas de finales del siglo $\mathrm{V}$ se encuentran infundíbulos etruscos o productos cerámicos griegos del delta del Nilo de la centuria anterior; u otros similares como el de El Turuñuelo de Mérida que, junto al mismo tipo de material, proporcionó un fragmento de marfil griego arcaico (Jiménez Ávila, 2008: fig. 14.2)

\subsubsection{Iconografía}

Habida cuenta de que, como hemos señalado, los escasos objetos que ostentan elementos figurativos proceden de distintos talleres y de épocas diferentes, es poco lo que se puede añadir en un apar- 
tado de conjunto a lo ya dicho al comentar los aspectos iconográficos de cada uno de ellos, pues no es esperable, en semejantes circunstancias, que los diferentes elementos simbólicos guarden una relación entre sí demasiado estrecha.

Los componentes figurados son el fragmento de asa, las camas del bocado y los pasarriendas. En cuanto a la primera, decorada con una cabeza de anátida, ya hemos indicado que se trata de un motivo recurrente en las vajillas de lujo de la Antigüedad y que de su frecuente utilización en los infundíbulos y otras vasijas de similar estructura griegas y etruscas debió pasar a las imitaciones ibéricas, como la que aquí nos ocupa. En esta tesitura podría haber desarrollado una función esencialmente decorativa.

Mayor contenido simbólico debían tener las imágenes representadas en las camas de la brida, que fueron sometidas a una serie de modificaciones formales sobre los modelos originales que ya hemos comentado y que se traducen en la transformación de los caballos bifrontes en animales de una sola cabeza, perdiendo así la simetría de la composición. La escasa definición de las formas hace que el resultado sea difícil de reconocer y, por tanto, de comentar. Pero no debe pasar desapercibida la intencionalidad de todos estos cambios que, a pesar de la baja calidad de la representación, difícilmente pueden atribuirse a lectura incorrecta de los modelos originales pues, como ya hemos señalado, esta disparidad implica una multiplicación de moldes y un incremento sustancial de las tareas previas al trabajo de fundido.

Por último, las cresterías de los pasarriendas reproducen las típicas sucesiones florales de origen oriental que se siguen realizando sobre objetos de esta época e, incluso, posteriores, aunque en la forma en que aquí se presentan quizá debían tener un aspecto ya algo arcaico en la época en que se amortizaron, a finales del siglo V a.C.

\subsection{Problemáticas derivadas del hallazgo}

Las desconocidas circunstancias del hallazgo suscitan una serie de problemas que es necesario tener en cuenta a la hora de valorar su estudio de conjunto y su integración en el panorama de la arqueología postorientalizante del Sur de Portugal. Estos problemas afectan a la zona de procedencia, al contexto y a algunos aspectos concernientes a las

\footnotetext{
${ }^{11}$ Actualmente estamos estudiando los bronces de Azougada.
}

posibles reconstrucciones que se pueden realizar a partir del registro recuperado.

\subsubsection{El problema de la procedencia}

El primer problema sujeto a discusión es el del lugar de origen del conjunto. Los datos publicados señalan su posible procedencia de Azougada, en Moura (Gomes, 2001), pero en el MNA se le atribuye un origen en los alrededores de Alcácer do Sal, en función de la localidad del comprador del lote y de su zona de actividad habitual. Probablemente Azougada y Alcácer do Sal sean dos de los yacimientos que mayor cantidad de bronces protohistóricos hayan proporcionado de todo el Sur de Portugal (pues de lo que no parece haber dudas es de que el conjunto tiene un origen en la mitad meridional del país). Por lo tanto, ambos sitios serían $a$ priori buenos candidatos.

Una ojeada a los bronces de estos dos yacimientos pone de manifiesto señaladas conexiones entre nuestro conjunto y lo que conocemos de ellos: los colgantes amorcillados, por ejemplo, son especialmente abundantes en Alcácer, donde además se halló un pasarriendas de crestería similar al n. ${ }^{\circ}$ 10; pero también hay colgantes en Azougada y en otros yacimientos próximos como Mértola y Terras Frias (Schüle, 1969: 215). Por todo ello, y por el criterio por el que se ha elegido este sitio como lugar de procedencia, no nos parece que Alcácer do Sal sea una procedencia muy verificable.

Azougada, por su parte, cuenta con una significativa colección de elementos de atalaje, destacadamente un objeto en forma de rueda, faleras, campanillas, botones cónicos... un perfil de objetos de bronce más próximo al del mundo postorientalizante $^{11}$. No obstante, varios de estos utensilios se apartan por su morfología de los nuestros (algunos de los botones de Azougada, por ejemplo, son de doble presilla).

Tampoco debemos olvidar que en las cercanías de Azougada se encuentra el yacimiento del Cabeço Redondo, parcialmente destruido a principios de los años noventa (Soares, 2012; Soares y Soares, 2017) y que, por sus características, debe haber albergado una edificación monumental similar a la de Cancho Roano, referente fundamental en el estudio de estos bronces. La relativa proximidad de la destrucción de este yacimiento a la fecha de entrada del conjunto en el MNA también ha sido un criterio para marcar este punto como posible origen del conjunto.

Por último, las indagaciones que nosotros 
mismos hemos realizado acerca de la procedencia de este lote permitieron recoger algunas informaciones que apuntan a su hallazgo en un yacimiento arqueológico localizado en las márgenes del río Degebe, afluente del Guadiana. Intentar precisar más este sitio constituye un ejercicio especulativo que resultaría, de momento, poco fructífero, aunque sea tentador, en este sentido, referir la existencia del Castelo Velho do Degebe, situado en las márgenes de este río. Este yacimiento fue destruido en la década de los noventa del siglo pasado y era frecuentado por usuarios de detectores de metales. Sin embargo, su ocupación situada entre los siglos IV y I a.C. (Mataloto, 2014: 371), no parece concordar con el encuadre cronológico que hemos propuesto para el conjunto de bronces del MNA, que hemos situado en el siglo $\mathrm{V}$ a.C.

Con todos estos elementos, y sin que ninguno de ellos sea determinante, la zona del Bajo Guadiana, principalmente entre los valles del Degebe y el Ardila, nos parece actualmente la más verosímil como el posible origen de este hallazgo. La presencia de un asador de tipo andaluz en el conjunto resulta coherente con esta propuesta y con el área de distribución habitual de estos bienes situada, mayoritariamente, en territorio actualmente español.

\subsection{2 ¿Un conjunto funerario?}

El segundo problema a debatir es si estamos ante un hallazgo de signo funerario, como se desliga de la denominación de "Conjunto sepulcral de Guerreiro" con que se reconoce el conjunto en los archivos e inventarios del MNA. Los datos publicados por M. Varela permiten deducir la convivencia de los bronces con carbones, aunque ninguno de los elementos presenta huellas de haber sido afectado por el fuego. Pero en época postorientalizante este dato no es garantía del carácter funerario del conjunto, pues complejos arquitectónicos como el de Cancho Roano, Cabeço Redondo, o el propio de Azougada, están amortizados por estratos de cenizas y carbones entre los que se encuentran los restos arqueológicos.

La composición y el estado de conservación del conjunto tampoco son determinantes. Sorprende, para un conjunto funerario, que solo se hayan recogido elementos de bronce (no hay hierros, ni cerámicas, ni huesos...) pero podría haberse procedido a una recogida selectiva o una venta selectiva al MNA $^{12}$. Sin embargo, en las zonas de hábitat -incluidos los espacios palaciales- raramente se encuentran depósitos tan orgánicos como el nuestro, siendo lo habitual que los objetos estén mucho más mezclados, aunque el modelo de Cancho Roano no fuera objeto de una excavación modélica. La presencia de elementos fragmentados de antiguo, como el asa de símpulo, también son extraños en una tumba, pero nada obliga a pensar que se haya recuperado todo el contenido (aunque el equipo ecuestre es bastante completo y unitario, como ya hemos señalado).

Hay elementos que suelen ser característicos de depósitos funerarios, como la inclusión de un yugo aislado sin más restos del carro; pero otros, como los asadores, son raros en las sepulturas, como ya hemos señalado. Por otro lado, parece que la separación simbólica de los yugos no solo se hace de cara a su depósito en las tumbas, pues en Cancho Roano sucede lo mismo: solo se documentan elementos de yugo, mientras que el resto de los componentes metálicos del carro están completamente ausentes, lo que quizá indique que se utilizara esta decorada y decorativa parte del vehículo como elemento exhibitorio en espacios áulicos y de representación aristocrática.

Otras opciones, como que se trate de un depósito de bronces para refundir o para tesaurizar (lo que podría venir avalado por la naturaleza monoespecífica de la muestra conservada) vienen contestadas por el carácter completo de la mayor parte de los elementos, y por su unidad funcional. Pero, sobre todo, por el componente simbólico que exhibe el equipo, ya que al no incluirse piezas del resto del carro, este conjunto parece asumir los presupuestos ideológicos y rituales que se han descrito para los hallazgos de yugos aislados en el panorama de la Protohistoria peninsular (Jiménez Ávila y Muñoz, 1997).

Por tanto, y en ausencia de un contexto conocido, la posibilidad de que se trate del ajuar de una sepultura de un personaje diferenciado (de las que tan poco conocemos para el Periodo Postorientalizante en el Suroeste) parece menos probable que su procedencia de las ruinas de un yacimiento singularizado de tipo,Azougada o Cabeço Redondo, aunque en el estado de nuestro conocimiento, ambas hipótesis puedan permanecer abiertas. Pero, en cualquier

\footnotetext{
${ }^{12}$ Algunas informaciones apuntan, no obstante, a la existencia de otros elementos en el conjunto que no fueron entregados al MNA. Entre ellos, una falcata (que habría acabado en Nueva York), un fragmento de borde de un cuenco de cerámica gris y fragmentos de borde y de pared de una olla con asa de cesta.
} 
caso, hay que concederle una intencionalidad ritual a la conformación del conjunto tal y como ha llegado hasta nosotros, lo que permite descartar $a$ priori otro tipo de situaciones.

\subsection{3. ¿Carros de prestigio de un solo caballo?}

La propuesta que hemos formulado, acerca de que los arreos de este conjunto del MNA correspondieran a un vehículo de un solo caballo reviste cierta novedad, pues en el mundo antiguo son inhabituales los vehículos de prestigio o de parada (modalidad a la que sin duda debemos adscribir el carro en cuestión) tirados por un único animal. En su lugar, los carros coetáneos de Oriente, el Mediterráneo y Europa central, avalados tanto por hallazgos reales como por representaciones iconográficas, eran tirados por dos, raramente tres, o cuatro caballos (Littauer y Crouwel, 1979; Crouwel, 1992; Crouwel, 2012; Pare, 1992).

El esquema de un vehículo de un solo tiro se aproxima más al ideal de la carreta, dotada de dos lanzas laterales, modalidad que no suele relacionarse con contextos de preeminencia social ni con herrajes de bronce, y que no suele estar tiradas por caballos con embocaduras y atalajes ornamentados.

De cara a enfocar este problema tenemos que realizar algunas observaciones de distinta naturaleza. 1) En primer lugar, la propia composición del conjunto que aquí tratamos, que parece una compilación de objetos muy diversos, algunos de baja calidad, si los comparamos con sus paralelos -como las camas laterales-o recuperados de distintos lotes y procedencias -como los pasarriendas o los colgantes-, algo que podría estar en relación con la capacidad adquisitiva y el marco de relaciones sociales del personaje que ostentara estos símbolos de prestigio. En este sentido, cabría cuestionarse si esta menor calidad de los arreos, reunidos de modo algo oportunista, podría relacionarse con la cantidad de ganado disponible para su uso. 2) En segundo lugar podemos señalar la existencia de algunos otros conjuntos hispánicos que podrían apuntar en la misma dirección de carros de parada de un solo tiro, como el de Alcurrucén, que reúne solo dos pasarriendas de tipo Cancho Roano, aunque las condiciones de este hallazgo no sean las más propicias para certificar este dato (Jiménez Ávila y Muñoz, 1997). 3) En tercer lugar podemos apuntar algunos paralelos extrapeninsulares, como en conocido carrito fenicio de Tartús, en el Museo del Louvre, que presenta dos divinidades sobre un vehículo incompleto dotado de dos lanzas laterales y que, a falta de espacio para acoger dos caballos en el hueco que estas dejan libre, podría estar representando un tiro único (Littauer y Crouwel, 1979: fig. 83). 4) Finalmente, podemos señalar la posición periférica en el extremo Occidente del Mediterráneo de este hallazgo como criterio recurrente de la menor excelencia de las aristocracias sidéricas de esta parte liminar del mundo conocido, aunque es cierto que la mayoría de los conjuntos ecuestres hasta ahora documentados en el Hierro peninsular apuntan hacia tiros de dos caballos. En cualquier caso, se trata también de un tema que requeriría de mejores contextos para poder traspasar de manera decidida la frontera del debate.

\section{LOS BRONCES DEL "CONJUNTO SEPULCRAL DE GUERREIRo" y LA Aroueología Postorientalizante Del Alentejo Interior}

El panorama de la Edad del Hierro postorientalizante en el Alentejo Interior, en el territorio articulado con el Bajo Guadiana, se nos presenta aún bastante incompleto, a pesar de los esfuerzos realizados por la investigación y de algunos trabajos desarrollados en los últimos años. Sin embargo, es posible elaborar un intento de lectura global basado en los datos existentes.

Las escasas evidencias de poblamiento en el interior del Alentejo entre las postrimerías de la Edad del Bronce -que se pueden situar a fines del siglo VIII a.C. (Mataloto et al., 2013)- y el Periodo Postorientalizante, desde finales del siglo VI, revelan una cierta continuidad con el Bronce Final en lo que se refiere a la implantación de sitios, que ocupan tanto lugares destacados en el paisaje como ubicaciones en el llano.

Esta última modalidad ha sido recientemente documentada en el Bajo Alentejo, en las comarcas de Serpa y Beja, donde se excavaron varias estaciones en llano situables entre los siglos VIII y VI a.C. tales como Monte do Bolor 3 (Antunes et al., 2017a; Borges et al., 2012), Torre Velha 3 (Antunes et al., 2017a; Estrela et al., 2012) y Salsa 3 (Antunes et al., 2012b; Antunes et al., 2017a; Deus et al., 2010).

Estos sitios exhiben una cultura material y una arquitectura de marcado cuño indígena basadas en la tradición del Bronce Final, pero incluyendo ya algunos elementos exógenos, como la cerámica pintada de tipo carambolo de Monte do Bolor 3 y de Salsa 3 o el pithos de Torre Velha 3, donde apareció, además, una fíbula de doble resorte cuya presencia se podría justificar por contactos comerciales con el área bajoandaluza, sin que podamos hablar todavía de un verdadero proceso de aculturación (Antunes et $a l ., 2017$ a). Por este motivo, la inserción de estos 
testimonios en el Periodo Orientalizante viene realizándose únicamente a efectos cronológicos, ya que no existen indicadores culturales y sociales que los integren dentro de ese ámbito.

Un escenario semejante se registra en el Alentejo Central, a través de pequeñas instalaciones rurales como Miguens 10, datado entre finales del siglo VIII y parte del siglo VII a.C. (Calado, 2002; Calado, et al., 2007: 141-143; Calado y Mataloto, 2008; Mataloto, 2009); Monte da Estrada 2 (Calado, 2002; Calado, et al., 2007: 145-147) o Moinho da Cinza, donde se recogió un pithos importado y un vaso à chardon de producción local (Calado, 2002; Calado, et al., 2007: 143-145; Calado y Mataloto, 2008) y para el que se obtuvo una datación radiocarbónica de $2577 \pm 31 \mathrm{BP}$, que corresponde al intervalo de 820590 cal BC (Mataloto, 2009: 285). Para estaciones posteriores como la del Espinhaço de Cão, cuya ocupación, a través de diversas fases constructivas, se prolonga a lo largo del siglo VI, se observan ya elementos de filiación mediterránea en la organización del espacio y en la implantación de posibles espacios áulicos y rituales (Calado, 2002; Calado et al. 2007: 147-151; Calado y Mataloto, 2008: 204; Mataloto, 2009; Jiménez Ávila, 2009a).

Junto a estas estaciones en llano, también contamos con ejemplos de poblados situados en la cima de elevaciones destacadas controlando importantes vías de comunicación. Es el caso, en el Alentejo Central, de Corôa do Frade, en Évora (Arnaud, 1979), Castelo de Arraiolos (Fabião, 1996) que han proporcionado sendas fíbulas de doble resorte; el Alto do Castelinho da Serra, en Montemor-o-Novo (Gibson et al. 1998) y el Alto de São Gens (Redondo), implantado en la parte superior de uno de los picos más destacados de la Serra d'Ossa y que se encuadra cronológicamente entre el siglo VII a.C. (quizá ya en su primera mitad) y los inicios de la siguiente centuria. En este emplazamiento se documentó un único nivel de ocupación donde coexistía un conjunto cerámico de tradición del Bronce Final regional con recipientes exógenos, de filiación fenicia, destacadamente ánforas de tipo R-1, junto a otros de fabricación local-regional inspirados en producciones mediterráneas como los pithoi o los vasos que reproducen formas situadas a medio camino entre las ánforas y los pithoi y que se encontraban revestidas de engobe rojo, así como algunas formas cerradas con decoración digitada en los hombros (Mataloto, 2004a).

Los datos del Alentejo Central deben relacionarse, principalmente, con el escenario orientalizante organizado en torno al valle del Tajo, con importantes reflejos en sitios como Talavera la Vieja
(Jiménez Ávila, 2006) o la Alcáçova de Santarém (e.g. Arruda, 1999-2000) y, en la zona del estuario, en Almaraz (Barros y Sabrosa, 1993) o en la propia Lisboa (e.g. Arruda, 1999-2000; Sousa, 2014), siendo de destacar que tanto la cultura material como las dataciones radiométricas de la Alcáçova de Santarém, corroboradas por las de Almaraz, permiten retrasar hasta finales del siglo IX o inicios del siglo VIII a.C. la cronología de los primeros contactos de esta zona con las poblaciones fenicias (Arruda, 2005a; 2005b).

En el Bajo Alentejo, en la margen izquierda del Guadiana, se pueden referir como ejemplos de sitios destacados en el paisaje Passo Alto en Serpa y el Castro dos Ratinhos en Moura. En Passo Alto (Serpa) tras una fase del Bronce Final que termina a fines del siglo VIII a.C. se registra una ocupación de la I Edad del Hierro situada en el siglo VI y que viene evidenciada por construcciones de planta ortogonal y cerámica gris a torno, así como vasos decorados con digitaciones, mamelones verticales e incisiones (Antunes et al., 2017b; Soares et al., 2009).

En Serpa se identificó una estructura negativa, de sección en V, excavada en la roca, interpretada como un foso y posiblemente construida en el Bronce Final, en cuyos depósitos de colmatación se recogieron fragmentos de ánfora de tipo R1/10.1.2.1 y cerámicas de producción local que permiten afirmar que el lugar estaba ocupado, al menos, en el siglo VI a.C., habiendo sido sellado el foso, muy probablemente, a fines de esta centuria o inicios de la siguiente, para dar lugar a una nueva fase constructiva (Antunes et al., 2012a; 2017b).

En la "acrópolis" de Ratinhos (Moura), un importante poblado del Bronce Final, se identificó un edificio ortogonal de planta en "L" con una longitud de 10,92 $\mathrm{m}$ y una anchura de 7,80. El edificio estaba segmentado modularmente y contaba con bancos adosados revestidos de arcilla roja, a semejanza de los pavimentos y de los alzados de las paredes. Este edificio fue interpretado como un santuario de influencia fenicia posiblemente dedicado al culto de Astarté y de Baal (Berrocal y Silva, 2007; 2010; Prados, 2010) justificándose esta atribución cultural en la arquitectura, a pesar de la escasez de objetos de origen oriental $u$ orientalizante (aunque hay algunos recipientes de barniz rojo, vasos de tipo 8 y 11 de Tiro y ánforas de los tipos 710 de Ramon) y de la ausencia del uso del torno en la producción local, así como de la inexistencia de metalurgia de hierro. En su lugar se apela a la utilización de un sistema métrico semita en la construcción del edificio, concretamente el "codo de Ezequiel" o "codo fenicio", de 0,52 m, evidenciando la exis- 
tencia de un proyecto planificado y de un arquitecto con un conocimiento específico del sistema utilizado, aunque la mano de obra fuese local. Además, se pone de manifiesto el uso de técnicas constructivas sin parangón en el Bronce Final regional, no solo en el referido santuario sino en dos edificios de planta circular y en la línea de murallas que circundaba a esta "acrópolis" y que son todos coetáneos (Berrocal y Silva, 2007; 2010; Prados, 2010).

La función sacra se halla evidenciada-siempre de acuerdo con los autores- no solo en la planta de tipo sirio o Langbau (que tiene paralelos en edificios cultuales del Próximo Oriente y particularmente en el área nuclear fenicia) que se desarrolla a lo largo de tres compartimentos que corresponderían con el ulum, el hekal y el debir (vestíbulo, antecámara y cámara, respectivamente), cuya entrada se orienta en la dirección del solsticio de verano; sino también en la ausencia de cultura material doméstica y en la alineación del eje longitudinal del edificio de un conjunto de elementos de particular significado simbólico al que se añaden algunos objetos (Berrocal y Silva, 2007; 2010; Prados, 2010).

Las dataciones radiométricas realizadas permiten situar esta fase de ocupación de Ratinhos (1a) entre 830 y 760 a.C. marcando su fin la destrucción del santuario por causa de un incendio (que inutilizó también una parte de la muralla que delimitaba la acrópolis). Los restos del santuario fueron utilizados en un nuevo edificio (fase 1b) construido, de nuevo, conforme a las técnicas edilicias propias del Bronce Final y en el que ya no se reconoce ninguna vocación sagrada, aunque pueda haber mantenido una función de prestigio. Esta última fase de ocupación fue de corta duración y concluiría en torno al 730 a.C. (Berrocal y Silva, 2007; 2010).

Según los autores, la construcción de una estructura de características tan marcadas desde el punto de vista funcional y cultual en un poblado del Bronce Final de gran importancia regional, ocupado al menos desde el siglo XIII a.C., debe relacionarse con planteamientos estratégicos asumidos por los propios indígenas, en función de intereses comerciales motivados por la exploración de nuevas vías por parte de las comunidades orientales u orientalizadas del litoral peninsular que, de este modo, promueven la "re-sacralización" de la "acrópolis" de Ratinhos (Berrocal y Silva, 2007; 2010: 434-435).

En cualquier caso, a pesar de que existieran colonos fenicios instalados en la costa meridional desde el siglo IX a.C. (Aubet, 2008; González de Canales et al., 2004; Arancibia et al., 2011: 130), la escasez de la cultura material orientalizante en Ratinhos pone de manifiesto la inexistencia de vías de comercio o de contactos regulares con las comunidades del litoral a lo largo del Guadiana y, consecuentemente, con el Alentejo Interior, lo que obliga a caracterizar como episódica la presencia orientalizante en este territorio durante los siglos IX y VIII a.C. (Antunes, 2014) y, de alguna manera, a traer a colación la discusión sobre una "precolonización", no ya en el Mediterráneo, sino más internamente, a escala peninsular.

Las dificultades de navegación que presenta el considerado en Portugal como "gran río del Sur" -el Guadiana-, sobre todo por el bloqueo que provoca el estrangulamiento topográfico del Pulo do Lobo, han constituido uno de los factores que limitaron un comercio más dinámico y más regular con el litoral sur peninsular y en concreto con la desembocadura del río, donde se localiza Castro Marim, cuya primera ocupación orientalizante se sitúa en el siglo VII a.C. (e.g. Arruda, 1999-2000, 2003a; 2005a; Arruda et al. 2007). Esto establece un fuerte contraste con el territorio ribereño situado al sur del Pulo do Lobo, como evidencia Mértola, último punto navegable del tramo meridional del Guadiana, cuya cultura material sugiere el establecimiento de un eje comercial con el litoral andaluz, destacando las urnas cruz del negro, las ánforas de tipos 10.1.1.1 y 10.1.2.1 y algunas cerámicas de barniz rojo (Barros, 2007; 2008).

Pero aún en esta fase y revelando la manera progresiva con que las influencias orientalizantes se instalan en este territorio, interesa reseñar elementos como el timiaterio de Safara, en Moura o el toro de Mourão, ya en el Alentejo Central y que también pertenecería a un quemaperfumes (Jiménez Ávila, 2002 , cat. n. 69 y 82).

A partir del siglo VII se asiste en el interior del Alentejo a una progresiva alteración en el modelo de poblamiento relacionada con el abandono de los poblados de altura, que no parecen pervivir más allá de mediados del siglo VI a.C.Así, se constata en esta época un proceso que empieza a ser visible en el Alentejo Central y que ya había sido bien documentado en la Extremadura española: la consolidación de las implantaciones en llano y el advenimiento del postorientalizante, con fuertes influencias meridionales y mediterráneas que ahora se observan en la asimilación plena y perdurable de plantas ortogonales y de un urbanismo regularizado, si bien la cultura material siempre mantendrá un fuerte componente local.

En el Alentejo Central este fenómeno se documenta en sitios como Herdade da Sapatoa (Mataloto, 2004a; 2005; 2007; 2008; 2009), Malhada das Taliscas 4 (Calado, 2002; Calado et al., 2007; 
Calado y Mataloto, 2008; Jiménez Ávila, 2009; Mataloto, 2009), Fonte da Calça, Forno da Cal, Chaminé 18, Gato, Musgos 10, Malhada dos Gagos y Casa da Moinhola 3 (Calado, 2002; Calado et al., 2007).

Igualmente, en el Bajo Alentejo (en el área correspondiente a los municipios de Castro Verde y Ourique y parte de los de Odemira y Almodôvar) se reconoce una plena ocupación de los valles entre los siglos VI y V a.C. que se traduce en la concentración de pequeños locales de hábitat concebidos, desde sus fundamentos, con una arquitectura de plena inspiración mediterránea (ortogonal), implantados en cotas bajas, sin preocupaciones defensivas y de aparente vocación agro-pecuaria.

Esta realidad aparece, sin embargo, más vinculada al mundo orientalizante del litoral del Alentejo. De hecho, el territorio donde se implantan estos sitios se sitúa en el punto de encuentro de dos importantes cuencas hidrográficas, la del Mira y la del Sado, cuyos afluentes generan pequeñas riberas en torno a las cuales se articula el poblamiento. Esta área constituye también una zona de elevada riqueza minera, insertándose en la "faja pirítica ibérica" aunque la capacidad de sus suelos es más limitada, exhibiendo un paisaje de relieves ondulados y suaves de cotas bajas.

Entre los 23 sitios de hábitat identificados (Beirão, 1986; Beirão y Correia, 1991; 1994; Correia, 1993; 1996; 1997; 2007; Arruda, 2001) destaca el de Fernão Vaz (Ourique) por la calidad de la cultura material (a pesar de no estar íntegramente publicada) y por el mayor desarrollo arquitectónico, con los espacios distribuidos en torno a un patio central que da acceso, hacia el oeste, a una construcción de cuatro estancias alargadas, formando una planta que presenta similitudes con las de La Mata y Cancho Roano (Correia, 2007; Jiménez Ávila, 2009). La investigación ha señalado para Fernão Vaz una función de "lugarcentral" o de centro palacial, que desempeñaría un papel a la vez sacro y político (Arruda, 2001; Correia, 2007; Jiménez Ávila, 2009b).

Fernão Vaz ha permanecido en el centro de un largo debate, no solo sobre su función, sino también sobre su cronología ya que su cultura material, encuadrada en los siglos VI y V a.C. (Arruda, 2001; Jiménez Ávila, 2001) entre la que destaca la cerámica de barniz rojo, una copa cástulo, la cerámica gris fina, un pithos y un asador de tipo andaluz con caracteres en escritura del Suroeste, no parece concordar con las tres fechas radiocarbónicas obtenidas para el nivel de incendio que puso fin a la ocupación del sitio que, en conjunto, apuntan hacia el segundo cuarto del siglo VII a.C. (Beirão y Correia, 1991; Correia, 2007).

En el municipio de Castro Verde, los trabajos arqueológicos realizados en el coto minero de Neves-Corvo permitieron identificar varios sitios en los cuales las influencias orientalizantes aparecen de modo más intenso que en el área de Ourique. Inicialmente considerados como necrópolis -Neves I y Neves IV-y poblados -Neves II, Corvo I y Corvo II- (Maia, 1985-86; 1986; 1987; 1996; 2008), su funcionalidad ha sido discutida con posterioridad, interpretándose Neves I, Corvo I y Corvo II como espacios de culto (Arruda, 2001: 273; 2005) o, a semejanza de Fernão Vaz, como ejemplos de arquitectura áulica postorientalizante que, sin embargo, no habría alcanzado la monumentalidad de sus congéneres de la Extremadura española, principalmente Cancho Roano y La Mata (Jiménez Ávila, 2001; 2009a; 2009b).

El sitio de Neves II fue excavado íntegramente, evidenciándose la existencia de dos núcleos arquitectónicos separados por cerca de siete metros. Ambos núcleos presentan construcciones de planta rectangular, antecedida en uno de los núcleos por un pequeño patio, elevadas con muros de barro o adobe sobre zócalo de piedras que se superponen a estructuras de planta circular encuadradas en el Bronce Final (Maia, 1985-86; 2008; Correia, 1995; Arruda, 2001: 274).

En Corvo I, situado frente a Neves II, se localizó un conjunto de compartimentos de planta rectangular dispuestos en torno a un espacio enlosado que probablemente actuaría como un patio descubierto (Maia, 1998; Maia y Maia, 1986; 1996; 2008). El mobiliario recogido, entre el que destacan las copas cástulo, las ánforas de tipo 11.2.1.4 de Ramon, algunos recipientes de vidrio polícromo, cuentas de pasta vítrea (algunas de ellas oculadas) y terracotas zoomorfas, apunta hacia un periodo entre el segundo y el tercer cuarto del siglo V a.C. (Arruda, 2001: 278-279). Aunque inicialmente se interpretó como un poblado, la existencia de un espacio consagrado al culto, así como la presencia de terracotas, consideradas exvotos, y de un asador de bronce asociado a una estructura con evidencias de combustión, parecen indicar un componente sacro para este espacio (Arruda, 2001: 282; Correia, 1995; Jiménez Ávila, 2009; Maia, 2008).

La presencia de dos larnacas de terracota - una de las cuales consistía en un cofre lleno de cenizas y carbones- superpuestos en el centro de un compartimento de Neves I, reproduciendo ambas la forma de "lingote chipriota" o de piel de buey 
extendida, así como los paralelos que guarda esta forma en altares como los de Cancho Roano o Coria del Río, han llevado también a revisar la propuesta funcional de este sitio como necrópolis planteada originalmente por sus excavadores (Maia, 1985-86; 1987; Maia y Maia, 1996; Maia, 2008). En su lugar se reinterpreta Neves I como un espacio áulico con elementos de culto ancestral evidenciados por el depósito de las larnacas (Arruda, 2001: 279-282; Jiménez Ávila, 2001; 2009a).

La ocupación de los sitios de Castro Verde debe centrarse en torno a mediados-finales del siglo $\mathrm{V}$ a.C., a partir de las copas cástulo y de las ánforas de tipo Mañá Pascual A4, si bien se ha propuesto retrasar el inicio de la ocupación de algunas de estas estaciones a finales del siglo VI (Arruda, 2001: 273 s.).

Es posible que el modelo de abandono de los poblados de altura también haya tenido lugar en esta región donde el Castro da Cola, destacado poblado situado en una elevación y ocupado en el Bronce Final, parece no tener presencias antrópicas a partir de los siglos VII y VI a.C. Así parece indicarlo el conjunto artefactual recogido en la excavación arqueológica realizada por Abel Viana (1961), en el que se reconocen formas semejantes a las de la ocupación de la Edad del Hierro de Ratinhos y de las de la necrópolis de Nora Velha 2, que son más antiguos (Vilhena, 2006; 2008: 383 s.).

Finalmente, el mismo escenario se habría producido en la margen izquierda del Bajo Guadiana, donde se detectan ocupaciones postorientalizantes en llano en las cuencas de los afluentes del río como la ribera del Enxoé, con el sitio de Casa Branca 11, en Serpa (Antunes y Cosme, e.p), o la ribera del Alcarrache, con sitios como Serros Verdes 4, Moura (Albergaria y Melro, 2002: 130; Albergaria et al., 2013), por referir solo yacimientos que han sido objeto de excavación arqueológica.

Interesa destacar que el escenario que se presenta en la margen izquierda del Bajo Guadiana se asemeja al del Guadiana Medio, donde la expansión del poblamiento rural entre los siglos VI y V a.C. está asociada al fenómeno de los Complejos Monumentales que, por su calidad constructiva y por su función áulica, asociados a una cultura material de prestigio, permiten reconocer la presencia de aristocracias rurales como elemento social predominante y protagonista de este momento (Jiménez Ávila, 1991; 2008; Rodríguez Díaz, 2009; 2010). En este ámbito se puede incluir el yacimiento de Cabeço Redondo, en Moura (Soares, 2012; Soares y Soares, 2017), que, a pesar de la escasez de datos disponibles sobre su arquitectura, pero atendiendo a la morfología del yacimiento antes de su destrucción (un montículo) y a su implantación en el llano, habría constituido muy probablemente un complejo monumental similar a los ya referidos.

En esta región adquiere también relevancia el sitio de Azougada (Moura) que se implanta en una pequeña elevación en la desembocadura del Ardila que destaca cuando se accede desde el Guadiana, lo que hace plausible atribuirle un papel esencial en relación con el río y con la navegación -aunque sea en tramos específicos- del Guadiana, destacando el segmento entre el Ardila y el Degebe o el Bajo Ardila, ya que hacia el sur, el Pulo do Lobo constituye un accidente topográfico insuperable, a no ser que se efectúe un transbordo terrestre. Atendiendo a la presencia en Azougada de elementos sacros (por ejemplo, el llamado smiting god); a su arquitectura, a base de compartimentos de planta ortogonal distribuidos en torno a un patio central, y a su implantación, que evoca algunos sitios tartésicos considerados santuarios en el Bajo Guadalquivir, es posible que Azougada pueda haber actuado como un sitio guía (tal vez un santuario guía) de navegación en el área del Guadiana-Ardila. Aunque la orientación y la protección de la navegación por parte de la(s) divinidad(es) a las que se rendía culto fuese un factor relevante, no menos importante era la función económica que se les asociaba, ya que constituiría, al mismo tiempo, un punto neutro, donde podrían efectuarse transacciones comerciales al amparo de los dioses (Antunes, 2008; 2009a y 2009b). Azougada sería así, al mismo tiempo, un importante centro regulador de los intercambios y de la economía local y, posiblemente, también regional, lo que queda evidenciado por la presencia de platillos de balanza de bronce y numerosos ponderales de bronce y de plomo que evidencian la existencia de dos patrones metrológicos basados en un siclo ligero, de 7,83 g. y un siclo pesado, de 9,4 g, relacionados con los contactos tanto con el litoral como con el interior, y que reflejan el uso de un sistema común en el Bajo Alentejo y en el Guadiana Medio. Podríamos postular que Azougada adquiere un cariz a la vez sacro y áulico o aristocrático y que habría funcionado como una entidad rural superior gestora del territorio y de los recursos de los alrededores.

En Azougada, la presencia de componentes de atalaje ecuestre, así como de objetos de prestigio - entre los que destaca un vaso de alabastro de reciente valoración (Antunes, e.p.) - y otros ítems asociados a rituales lustrales (los "braseros"), al banquete (asadores), o al consumo de vino (copas cástulo y viena-116) parece confirmar la existencia 
de grupos aristocráticos en la región, lo que confiere un encuadre social coherente a nuestro "Conjunto sepulcral de Guerreiro". Un panorama que, en un marco más amplio, señalan también los elementos de Fernão Vaz y de Corvo I referidos más arriba.

El mismo escenario parecen plantear las necrópolis, que reflejan la presencia de elementos destacados en la sociedad. Esta premisa puede inferirse de la documentación de espacios sepulcrales diferenciados y específicos destinados a algunos individuos, especialmente en las regiones de de Beja y de Pedrogão, que se traducen en la disposición de una sepultura de inhumación (a veces dos) en el interior de amplios recintos (de cerca de $7 \mathrm{~m}$ de longitud en los casos de Palhais y Carlota) delimitados por profundos fosos de planta rectangular o cuadrangular, en el interior de los cuales se realizan rituales de carácter votivo. Algunos de estos recintos se presentan adosados, como se observa, por ejemplo, en Palhais (Santos et al., 2009; 2017), Vinha das Caliças (Arruda et al., 2017; Barbosa, inédito) o Carlota (Salvador y Pereira, 2012; 2017), lo que permite presumir la existencia de lazos familiares entre los inhumados que, eventualmente, pueden sugerir la presencia de linajes.

Los individuos de las sepulturas centrales de estos recintos están acompañados de objetos personales de prestigio, sobre todo armas y elementos de adorno, que incluyen cuentas de vidrio, de fayenza egipcia, de plata y de oro; colgantes de cornalina y también de metales preciosos; escarabeos y escaraboides; pendientes de oro y plata; anillos de plata y pulseras de bronce; broches de cinturón, fíbulas (de tipo alcores y acebuchal, en algunos casos) y sets de tocador de bronce tal y como se observa en Palhais (Santos et al. 2012; 2017), en Vinha das Caliças (Arruda et al., 2017; Barbosa, 2010), en Monte do Bolor 1-2 (Soares et al., 2017), en Quinta do Estácio 6 (Pereiro et al., 2017), en Carlota y Cinco Reis 8 (Salvador y Pereira, 2012; 2017), en Quinta do Castelo 5 (Calvo y Simão, 2017), en Pisões (Bargão y Fernandes, 2017), en Pardieiro, en Poço Novo 1, en Fareleira 2, en Fareleira 3 y en Poço da Gontinha1 (Figueiredo y Mataloto, 2017) que parecen confirmar su papel destacado en la sociedad. Además, es importante referir en este ámbito, por la exclusividad del ritual, los "braseros" de Fareleira (Figueiredo y Mataloto, 2017: 379, fig. 12) y Évora (Teichner, 2000).

En un área más meridional del Bajo Alentejo, en la región de Ourique, también hallamos sepul- turas de la Edad del Hierro encuadradas en recintos delimitados por estructuras, aunque debamos señalar diferencias de planteamientos arquitectónicos y, quizá también, culturales y cronológicas. De hecho, en alguna de las pocas necrópolis excavadas completamente se registró un murete de planta ortogonal con una entrada marcada que delimitaba un recinto que integraba una o más estructuras tumulares que cubrían las sepulturas excavadas en la roca. Estos conjuntos son designados por algunos autores como "monumentos rodeados por un temenos" (Correia, 1993: 359), documentándose en torno al túmulo 2 del Sector A de Chada, que constituye un monumento escalonado en tres gradas (Beirão, 1986: 83) y a las sepulturas 3, 5 y 6 (al menos) de Fonte Santa (Beirão, 1986: 68 y 70). V.H. Correia incluye también Fernão Vaz y, com menos certeza, Pardieiro (Odemira) entre este tipo de necrópolis con monumentos delimitados por temenos (Correia, 1993: 359), algo que, sin embargo, no se evidencia en las plantas (Beirão, 1990: 110; Correia, 1993: 371). En la necrópolis de Nora Velha (Ourique) se registró también una parte de un muro -estructura 3- (Arnaud et al., 1994: 200 y 207), que podría haber cumplido, probablemente, esa misma función, aunque la confirmación de esta hipótesis tropiece con su deficiente preservación (Santos et al., 2017: 251).

Hay que recordar, por otro lado, que en ninguna de las necrópolis protohistóricas excavadas en el interior del Alentejo se ha registrado la presencia de elementos de atalaje ecuestre, lo que constituye un argumento de peso para descartar una procedencia funeraria del mal llamado "Conjunto sepulcral de Guerreiro" que, por el contrario, encuentra plena contextualización en la esfera aristocrática que reflejan sitios que habrían tenido un papel relevante en la gestión del territorio, como Azougada o Fernão Vaz.

\section{Conclusiones}

El conjunto artefactual que hemos estudiado en este trabajo constituye una de las más importantes colecciones de bronces de la Edad del Hierro del territorio actualmente portugués, tanto por la cantidad de elementos que incorpora cuanto por su coherencia funcional. Los objetos de atalaje ecuestre, mayoritarios en su composición y vinculados tanto con el control del caballo como con la unión al carro (limitados, en este caso, al yugo y sus componentes), deben relacionarse con la presencia de aristocracias postorientalizantes en el sur de Portugal y se fecharían en el siglo $\mathrm{V}$ a.C. 
$\mathrm{Al}$ igual que ocurre en otros hallazgos peninsulares donde han aparecido conjuntos ecuestres (como sucede en el palacio de Cancho Roano y en numerosas sepulturas del área ibérica y del Suroeste), también en este caso se debe señalar la total ausencia de objetos relacionados con otras partes del vehículo, como la lanza, las ruedas y la caja. Este fenómeno confiere un especial significado simbólico al yugo y al tratamiento que este elemento recibe, tanto en ambientes funerarios como en espacios áulicos, a lo largo de la I Edad del Hierro.

Al mismo tiempo, esta constatación permite verificar que los elementos de atalaje del "Conjunto sepulcral de Guerreiro" constituyen un conjunto completo, concebido para un tiro de un solo caballo engalanado con una única cabezada y un yugo de una sola gamella.

La presencia de un vehículo de prestigio de estas características, tirado por un solo caballo, constituye un recurso original, con escasos paralelos conocidos en Oriente, en el Mediterráneo y en Europa, donde lo habitual es que los carros estén traccionados por dos, cuatro o, más raramente, tres animales. Tal vez, esta circunstancia sea debida a la situación periférica o extrema de este hallazgo en los confines del mundo conocido.

Junto a los arreos, son igualmente importantes los objetos relacionados con el banquete (un recipiente asociado al consumo del vino y un pincho asador) que se vinculan también con una esfera simbólica y de prestigio reforzada por la propia decoración y la iconografía presente en estos y otros elementos del conjunto. Efectivamente, estos bienes serían usados, prioritaria o exclusivamente, en ceremonias que tendrían lugar en espacios rituales de signo religioso o, conforme a sus contextos de hallazgo, más frecuentemente áulicos o palaciales. Serían, en todo caso, contextos de representación social, siempre asociados a las élites, que empiezan a constatarse desde el Bronce Final, como pone de manifiesto la presencia de un asador, que continúa la tradición que evidencian los pinchos de esta época.

Finalmente, como parte del conjunto, un único objeto se refiere a la esfera del adorno personal: un colgante amorcillado.

Las incertidumbres que afectan a este conjunto en lo que se refiere a su procedencia constituyen, sin duda, una importante limitación a la hora de abordar su análisis histórico y cultural. Sin embargo, una revisión a los contextos de hallazgo donde aparecen elementos de similar naturaleza en la Península Ibérica permiten cuestionar (sin descartarlo de manera absoluta) un contexto funerario que justificaría la denominación de "Conjunto sepulcral de
Guerreiro" con que figura en los inventarios del MNA. Por el contrario, conjuntos de atalajes ecuestres similares al que aquí nos interesa han aparecido en sitios que debieron desempeñar un importante papel en la gestión del territorio en el que se encuentran y en los cuales la presencia de elites sacras de carácter aristocrático se revela con especial pujanza. Son sitios como Cancho Roano o La Mata en la Extremadura española o Azougada y Cabeço Redondo en el Alentejo.

La diversidad funcional que se contrasta en el estudio de este conjunto, por tanto, no es óbice para considerar su procedencia de un único espacio. Los elementos consignados, correspondientes a arreos ecuestres, banquetes conviviales y boato personal coinciden con algunas de las principales actividades representativas constatadas para la aristocracia postorientalizante del suroeste peninsular en otros yacimientos clave como Cancho Roano, con cuyos bronces, tantas concomitancias muestra este conjunto.

A pesar de que se ha señalado, de manera algo intuitiva, la posibilidad de que este conjunto de bronces sea originario de Alcácer do Sal -en virtud de la localización en esa zona de algunas propiedades del vendedor del lote-, o de Azougada, por el hecho de proceder de este yacimiento otros elementos de atalaje, algunas informaciones recogidas por los autores, señalan una posible procedencia en el valle del río Degebe, uno de los afluentes más importantes del Guadiana en la región del Alentejo. Con cierta cautela podemos asumir, por tanto, una procedencia en el territorio del Bajo Guadiana, posiblemente en el área del Degebe o, ampliando el círculo, entre el Degebe y el Ardila.

Desde el punto de vista de la producción nos encontramos, en su práctica totalidad, ante creaciones peninsulares. Algunas de ellas reproducen prototipos típicamente mediterráneos, como el recipiente con asas rematadas en cabeza de anátida o las camas caladas; otras tienen resonancias en la Europa hallstática, como los sistemas de cierre de los correajes; otras, por último, parecen genuinamente ibéricas, tal y como sucede con los asadores o los colgantes amorcillados, que carecen de referentes fuera del ámbito peninsular. No obstante, resultaría conveniente acompañar el estudio tipológico con una buena batería de análisis arqueometalúrgicos para poder fundamentar mejor todas estas premisas y para caracterizar mejor la metalurgia postorientalizante del Suroeste.

Pero, a pesar de las limitaciones que impone esta falta de datos arqueométricos, el estudio de los elementos del conjunto ha permitido también 
extraer algunas inferencias acerca de la organización artesanal y las formas de distribución de los distintos elementos que lo componen. Así, las diferencias morfotécnicas observadas en los pasarriendas, en los botones, en las camas caladas, etc. sugiere la existencia de distintas técnicas y de distintos centros artesanales, en modo similar a como se ha descrito para la generalidad del mundo postorientalizante, sobre todo a partir de lo observado en el complejo palacial de Cancho Roano.

Esta es una observación fundamental, toda vez que resulta contraria a la sostenida creencia de que todos estos conjuntos provendrían de un único taller situado en el suroeste peninsular. De hecho, el "Conjunto sepulcral de Guerreiro" conjuga elementos no solo de diferentes procedencias y distinta calidad sino, incluso, de distinta cronología, como sucede con los pasarriendas, que son más antiguos que el resto. Esta multicidad en las vías de abastecimiento se subraya, por tanto, como una de las características básicas del funcionamiento de la broncistica postorientalizante del Suroeste y a ella responde, de nuevo, este conjunto. Es necesario tener en cuenta, además, que estos procesos se multiplican en conjuntos como el nuestro, dominado por los elementos ecuestres, que implican la actuación de broncistas y talabarteros, dos esferas tecnológicas que no tienen que estar necesariamente secuenciadas ni coordinadas.

Al finalizar este trabajo constatamos que son muchas las cuestiones que quedan aún abiertas, desde la procedencia del conjunto hasta algunas peculiaridades técnicas concernientes a los procesos de producción, sin olvidar la funcionalidad concreta de algunas piezas. Sin embargo, entendemos que, a pesar de todas sus limitaciones, el estudio y publicación de este conjunto era ineludible y que constituye una contribución fundamental para el conocimiento de los bronces del postorientalizante peninsular y para el estudio del utillaje ecuestre en la Iberia prerromana, así como para su inclusión en los debates sobre las sociedades aristocráticas que los utilizaron.

\section{Agradecimientos}

Nos gustaría mostrar nuestro agradecimiento a António Carvalho, Director del MNA y a Ana Isabel Santos, conservadora de esta misma institución, así como a todo el personal del museo que nos atendió durante nuestro trabajo de campo, por las facilidades dadas para el estudio del conjunto; a Pedro Barros por las fotografías; a Antonio Grajera y José Manuel Jerez por los dibujos; a Rodrigo

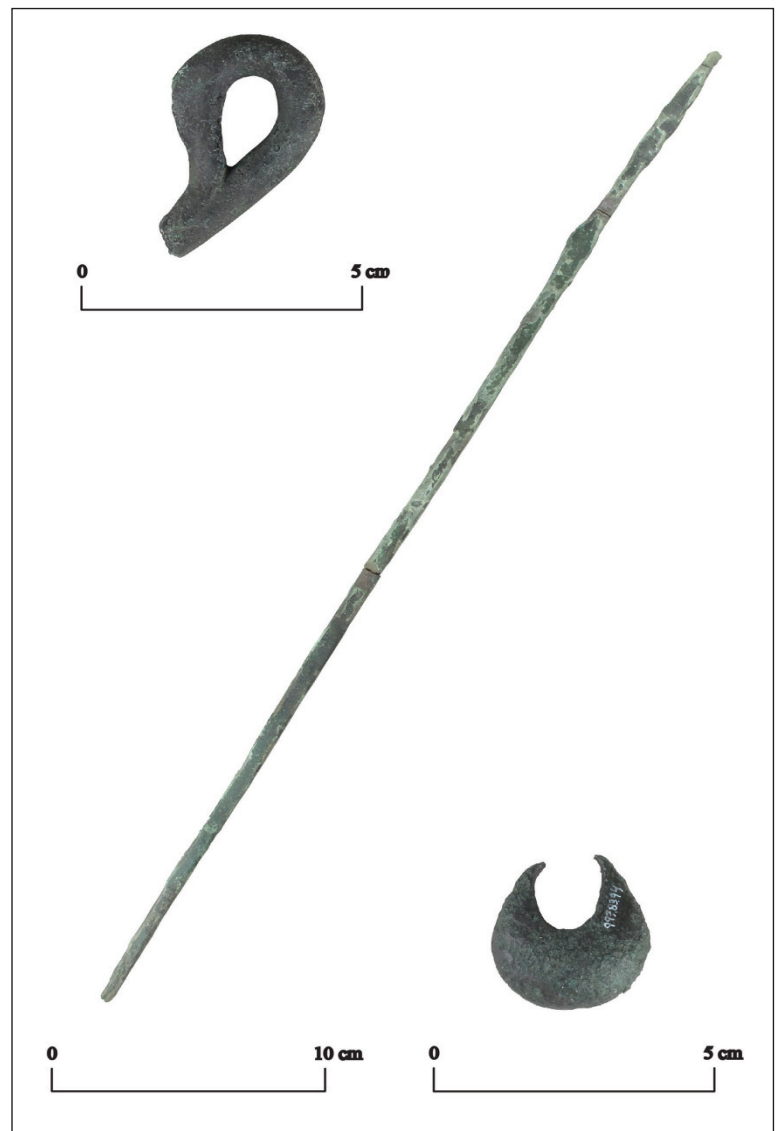

Figura 41. "Conjunto sepulcral de Guerreiro". Mango de recipiente (cat. 1), asador (cat. 2) y colgante amorcillado (cat.3), Museu Nacional de Arqueologia de Lisboa (Fotos P. Barros).

Banha da Silva por las informaciones sobre el hallazgo original en el valle del Degebe y sobre su contexto; a Susana Correia, Raimon Graells, Rui D. Jesuino, Guillermo Kurtz, Rui Mataloto, Samuel Melro e Isabel Pinto por las noticias y las informaciones aportadas sobre algunos de los objetos que se estudian aquí.

\section{Catálogo}

1.- Asa de recipiente (fragmento). MNA 997.83.95. Bronce fundido. $4,45 \times 2,8 \times 0,8 \mathrm{~cm} ; 30,33 \mathrm{~g}$.

Extremo proximal del asa de un recipiente metálico que se vuelve sobre sí mismo adoptando la forma de cabeza de anátida de la que solo se reconoce el pico. Sección circular en la zona de la fractura y de tendencia triangular en la parte donde la pieza adquiere su configuración zoomorfa. El pico contacta con el enmangue, con el que está solidariamente fundido.

Figs. 3.1 y 41 . 
2.- Asador.

MNA 997.83.99.

Bronce fundido y martilleado.

$44 \times 1 \times 0,39 \mathrm{~cm} ; 57,64 \mathrm{~g}$. (peso total).

Tres fragmentos que casan entre sí y que permiten reconstruir un asador de bronce al que le falta únicamente la zona de la punta. El enmangue se diferencia por el adelgazamiento de la sección de la barra y un ligero ensanchamiento oval típico de estas producciones. En esta zona el bronce aparece mellado y carcomido.

Figs. 3.2 y 41 .

3.- Colgante amorcillado.

MNA 997.83.94.

Bronce fundido en hueco.

3 x 2,7 x $1,3 \mathrm{~cm} ; 16,6 \mathrm{~g}$.

Colgante amorcillado en forma de bolsa de paredes gruesas $(1,5 \mathrm{~mm})$ ahuecado al interior. Ha perdido las láminas de cierre en la parte superior.

Figs. 3.3 y 41 .

4.- Cama lateral de bocado de caballo.

MNA 997.83.104

Bronce fundido en molde abierto.

13,2 x 9,4 x $0,5 \mathrm{~cm} ; 119,41 \mathrm{~g}$.

Cama lateral de bocado ecuestre trabajada en una placa calada que forma una composición figurativa de carácter simbólico en disposición simétrica. La pieza se estructura a partir de un sector de segmento circular algo mayor a la media circunferencia, que discurre por la parte inferior y cuyos extremos se vuelven en sentido opuesto al centro. El extremo de la izquierda adquiere la forma de una cabeza ecuestre muy sumariamente tratada que incluye la representación de una brida, que se une a la estructura principal de la cama generando un espacio abierto. El lado derecho concluye en un simple apéndice vuelto de extremo redondeado. La parte central está ocupada por una figura de estructura antropomorfa muy estilizada que se presenta en una antinatural posición simétrica, con las piernas exageradamente abiertas y arqueadas, apoyando los pies en el marco curvado que sirve de base a la pieza. La figura descansa, como si tomara asiento, en un anillo ojival que cumple la función de sujetar el filete del bocado. Los brazos, igualmente abiertos y doblados, unen con el marco a la altura de la nuca del prótomo equino, ligándose los codos y las rodillas con unos listones verticales que fortalecen la estructura de la pieza. La cabeza, exageradamente grande, no presenta rasgos anatómicos fácilmente identificables, aunque se averigua una posible nariz y labios que hacen aventurar su disposición en perfil mirando a la izquierda, en coincidencia con la posición de la cabeza equina. Aprovechando la doblez de los brazos se instalan sendas figuritas, muy perdidas, que por paralelos iconográficos pueden identificarse como dos aves muy estilizadas orientadas hacia la cabeza del personaje central. La de la derecha está fragmentada. La pieza se complementa con dos anillas semicirculares situadas entre los pies y los brazos de la figura humana, adheridas a la zona interior del marco curvado que enmarca la composición. Tanto la sección planoconvexa del objeto como el aspecto de la superficie trasera apuntan a una fundición en molde abierto univalvo.

Figs. 5.4 y 42.

\section{5.- Cama lateral de bocado de caballo.}

MNA 997.83.105.

Bronce fundido en molde abierto.

$$
13,2 \text { × } 9,4 \text { × } 0,5 \mathrm{~cm} ; 89,72 \mathrm{~g} \text {. }
$$

Placa similar a la anterior pero fragmentada en tres trozos que permiten reconstruirla solo parcialmente, pues faltan parte del brazo derecho, de la anilla ojival y de la pierna izquierda, así como las dos figuritas en forma de aves. Los tres fragmentos corres-

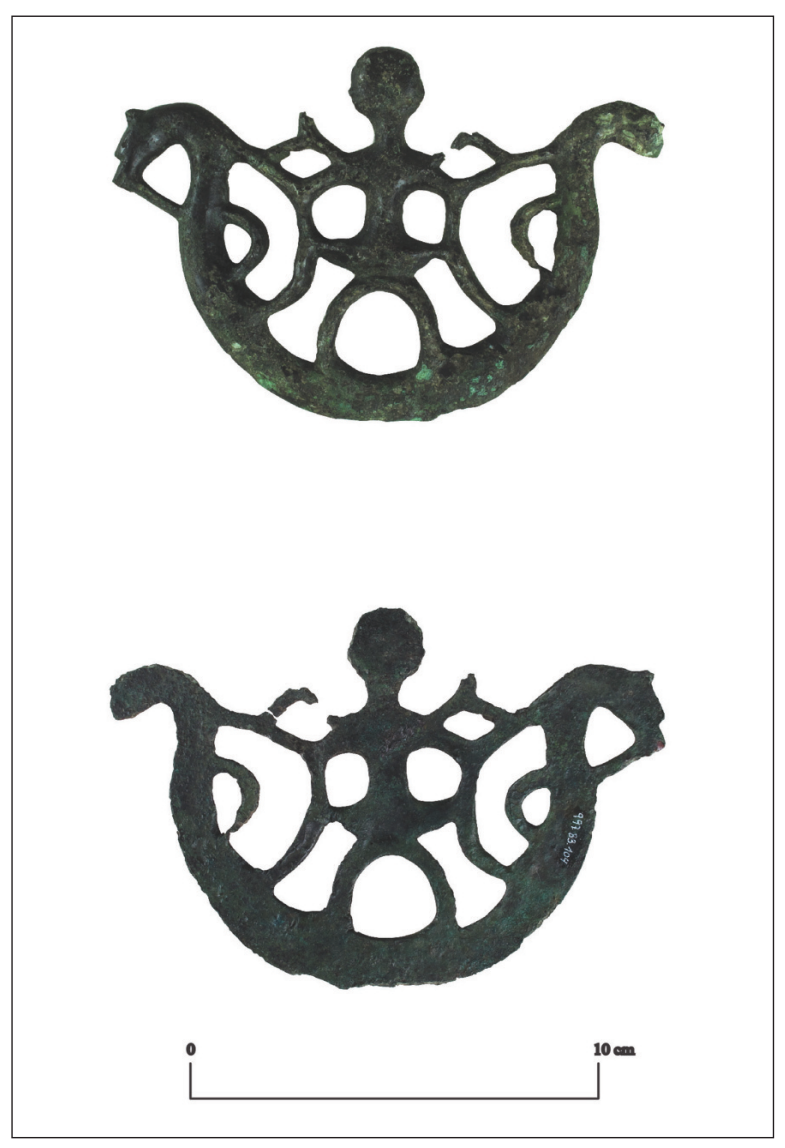

Figura 42. "Conjunto sepulcral de Guerreiro". Cama lateral de bocado (cat. 4), anverso y reverso, Museu Nacional de Arqueologia de Lisboa (Fotos P. Barros). 
ponden, básicamente, con las dos mitades del bastidor semicircular y con la figura central que contacta independientemente con cada uno de los dos fragmentos anteriores que no casan entre sí. La diferencia fundamental con la placa anterior es la disposición contraria de los extremos de modo que, en este ejemplar, la cabeza de caballo queda a la derecha del espectador y el remate curvado a la izquierda. La cabeza del personaje presenta la misma escasez de rasgos sin que, como en el caso anterior, sea imposible proponer el trabajo de un perfil en el lado derecho, coincidiendo de nuevo con la cabeza del caballo, aunque en este caso su definición es aún menor. Por tanto, las dos camas estarían trabajadas en disposición especular. Sin embargo, cuando se superponen las dos placas en la misma dirección se observa la coincidencia de perfiles en todo el recorrido salvo en los extremos, lo que denuncia el uso de las mismas matrices para la confección de los moldes originales excepto en la zona de los prótomos.

En el MNA se adscriben a este número de inventario dos fragmentos (997.83.105.D y 997.83.105.E) que no corresponden a esta placa calada sino a los objetos nos. 14 y 15 de nuestro catálogo que coinciden con dos colgantes de campanillas cuyo número de inventario en el MNA es 997.83.106 y 997.83.108, respectivamente.

Figs. 5.5 y 43.

6.- Bocado articulado.

MNA 997.83.96. Bronce fundido a la cera

perdida y sobrefundido.

$17,9 \times 3,1 \times 3,1 \mathrm{~cm} ; 127,74 \mathrm{~g}$.

Filete de bocado ecuestre articulado en dos piezas semejantes formada cada una de ellas por una argolla anular de sección circular de unos $3 \mathrm{~cm}$ de diámetro por donde se unen entre sí; un cañón torsionado en forma de cordón de dos guías y una argolla proximal de estructura tubular de $1,6 \mathrm{~cm}$ de diámetro $\mathrm{x} 1 \mathrm{~cm}$ de longitud. En el centro de los cañones y en la unión de estos con cada argolla mayor se dispone una serie de tres púas radiales de algo más de $1 \mathrm{~cm}$ cada una, si bien estas últimas están dobladas y anuladas. Las argollas de uno de los cañones están trabajadas en el mismo plano mientras que las de su homólogo lo hacen en planos diédricos de manera que, al estar montada la pieza, las argollas proximales quedan, de nuevo en un mismo plano.

Fundido a la cera perdida en dos partes, primero uno de los cañones y después, por sobrefundido sin contacto, el otro.

Figs. 9 y 43.

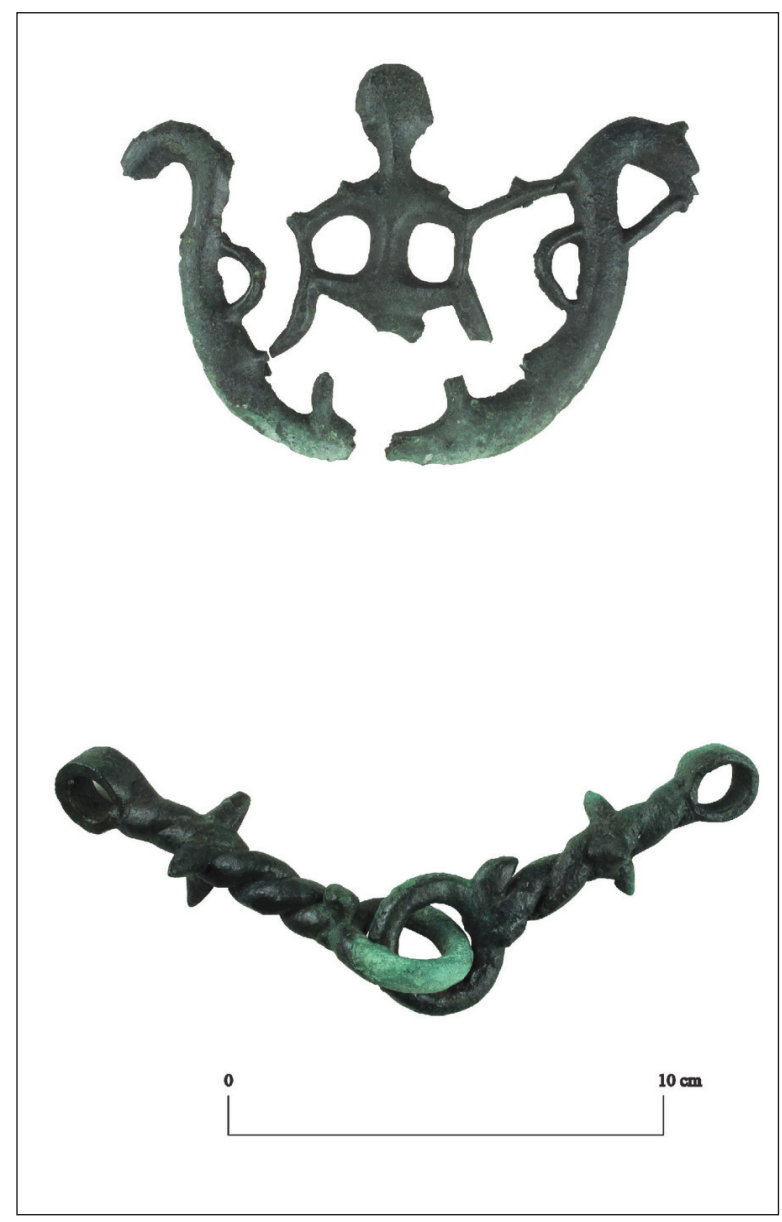

Figura 43. "Conjunto sepulcral de Guerreiro”. Cama lateral de bocado (cat. 5) y bocado articulado (cat. 6), Museu Nacional de Arqueologia de Lisboa (Fotos P. Barros).

7.- Falera. MNA 997.83.100.

Bronce fundido en molde abierto.

$11,8 \varnothing \times 0,3 \mathrm{~cm} ; 168,40 \mathrm{~g}$.

Disco trabajado en una placa de bronce fundido que presenta cinco perforaciones en cruz, siendo circulares las más próximas a los bordes e irregular y algo mayor la central. Se decora con cinco series de circunferencias concéntricas formadas por agrupaciones de número variable. Las circunferencias se han grabado a compás, seguramente en los moldes. Las perforaciones se han realizado en el bronce ya frío. Corroído y desgastado por los bordes de manera que dos de las perforaciones perimetrales se hallan actualmente abiertas.

Se conservan además ocho clavos (MNA 997.83.86 a 997.83.93) de los que cuatro deben pertenecer a esta falera. Están formados por una cabeza hemisférica maciza que se une a un vástago de tendencia cilíndrica. Sus dimensiones son variables oscilando el diámetro de la cabeza entre 0,9 y 1,3 cm estando la 
mayoría de ellos próximos a esta última dimensión. También las longitudes de los vástagos varían entre los 1,1 y los $2 \mathrm{~cm}$. En el número MNA 997.83.89 se aprecian las costuras y discontinuidades que denuncian una fundición a molde bivalvo.

Figs. 11.7 y 44.

\section{8.- Falera. MNA 997.83.101.}

Bronce fundido en molde abierto.

$$
11,4 \varnothing \times 0,3 \mathrm{~cm} ; 180,08 \mathrm{~g} \text {. }
$$

Disco similar al anterior pero con la decoración grabada menos visible debido a la corrosión superficial. Conserva todas las perforaciones completas. Cuatro de los ocho clavos antes descritos podrían pertenecer a esta pieza, sin que sea posible determinar cuáles.

Figs. 11.8 y 44.

\section{9.- Pasarriendas de crestería. MNA 997.83.102. \\ Bronce fundido a la cera perdida. \\ 11,35 x 8,9 x $1 \mathrm{~cm} ; 152,06 \mathrm{~g}$.}

Pasarriendas fundido en una sola pieza maciza formado por un vástago de sección rectangular, una anilla segmentada por una barra horizontal y una crestería calada que festonea tres cuartas partes de la zona superior de la anilla. La crestería representa una sucesión de seis capullos cerrados unidos a cinco flores abiertas trabajadas con dos pétalos laterales y una yema central. El trabajo de la crestería es bastante tosco y sumario.

Figs. 15.9 y 45.

10.- Pasarriendas de crestería. MNA 997.83.103.

Bronce fundido a la cera perdida.

$13,5 \times 10,6 \times 1,1 \mathrm{~cm} ; 372,58 \mathrm{~g}$.

Pasarriendas fundido en una sola pieza formado por un vástago de forma rectangular y sección oblonga y una anilla segmentada por una gruesa barra de sección cuadrada situada en el tercio inferior. La parte baja de la anilla, en su unión con el vástago, aparece desdibujada y se encaja en dos bordes rectos que le dan a la parte inferior de la pieza una forma de Y griega. La parte superior de la anilla se decora con una crestería calada de 14 capullos cerrados.

Fig. 15.10 y 45 .

\section{1.- Alamar. MNA 997.83.97. \\ Bronce fundido a la cera perdida. \\ $10,3 \times 2,4 \times 1,45 \mathrm{~cm} ; 121,65 \mathrm{~g}$.}

Elemento de cierre formado por un cuerpo prismático de seis caras horadado por una gran ranura rectangular que presenta en sus caras pequeñas dos apéndices troncocónicos de perfiles arqueados que crecen hacia el exterior. La ranura, de disposición

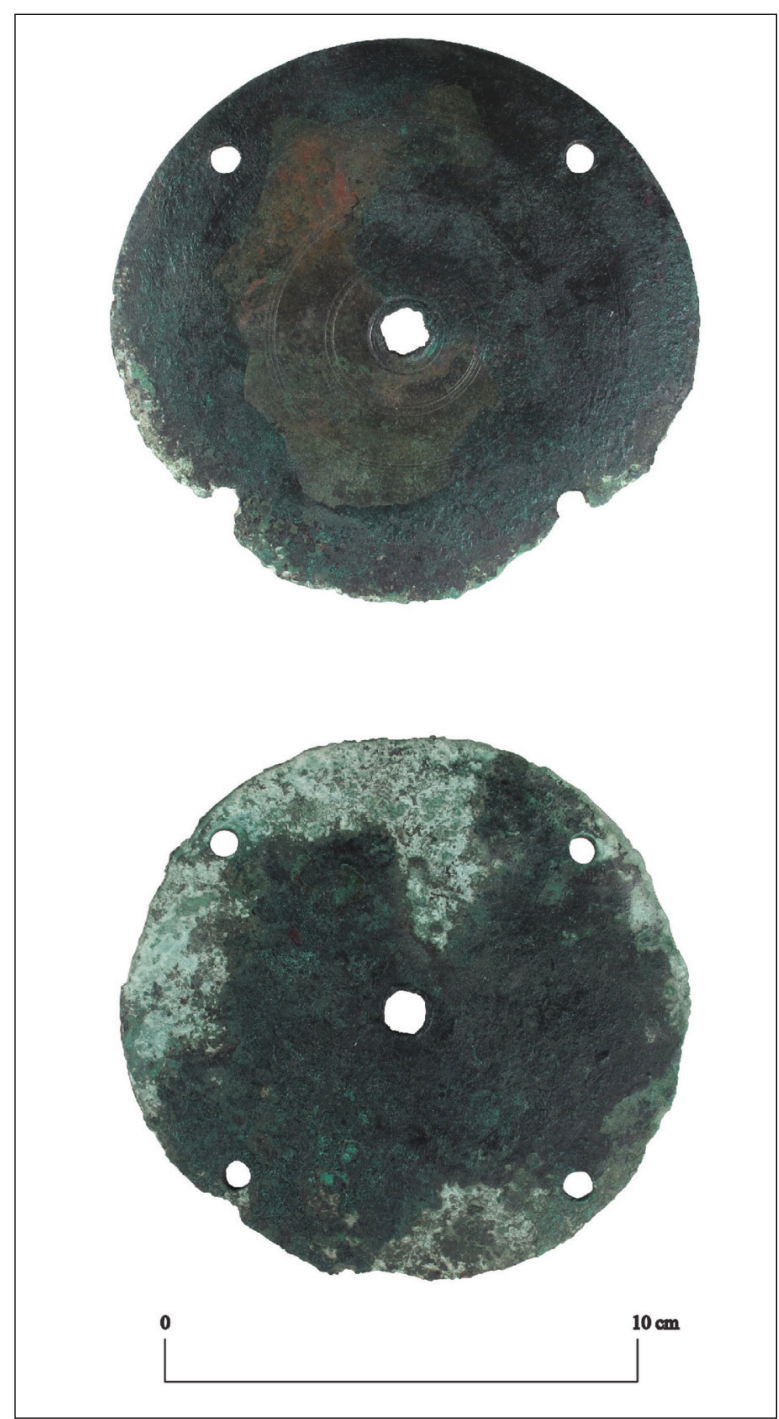

Figura 44. "Conjunto sepulcral de Guerreiro". Faleras (cat. 7 y 8), Museu Nacional de Arqueologia de Lisboa (Fotos P. Barros).

oblicua, presenta huellas de desgaste.

Figs. 17.11 y 45 .

\section{2.- Pasador sagital. MNA 997.83.98A. \\ Bronce fundido. \\ $8 \times 10$ × $0,8 \mathrm{~cm} ; 20,11 \mathrm{~g}$.}

Pasador en forma de flecha de extremo apuntado con sección triangular y vástago curvado de sección redondeada más ancha por la parte central. Es muy posible que le falte el extremo proximal, aunque la zona de posible fractura está muy desgastada de antiguo. Fundido, probablemente, a la cera perdida. Este número del catálogo del MNA agrupa además cuatro barras amorfas (98B-98E) que parecen formar parte de otro u otros objetos y que se recogen aquí con el número 101.

Figs. 17.12 y 45 . 
13.- Colgante con campanillas (5 piezas). MNA 997.83.107.

Bronce fundido.

Placa calada: $11,2 \times 6 \times 0,4 \mathrm{~cm}$

Campanillas: $4,1-4,4 \mathrm{~cm} \times 21 \varnothing \mathrm{cm}$.

Anilla: $1,6 \varnothing \times 0,2 \mathrm{~cm}$.

Peso total: $106,78 \mathrm{~g}$.

Colgante sonoro formado por una bastidor calado y tres campanillas colgantes de las que solo una permanece ligada al cuerpo principal. El bastidor está fundido en una pieza en forma de placa, probablemente a molde abierto, como denuncia su sección planoconvexa, y se conserva prácticamente completo a falta de un pequeño fragmento del calado. Se compone de una gran anilla proximal, una zona central de similar anchura, formada por un cuerpo calado de tres registros de perforaciones pareadas cuyos contornos oscilan entre la forma circular y la de un rombo y que alternan con dos perforaciones centrales en forma de rombo, de manera que la sensación que produce es la de una rejilla ordenada oblicuamente y festo-

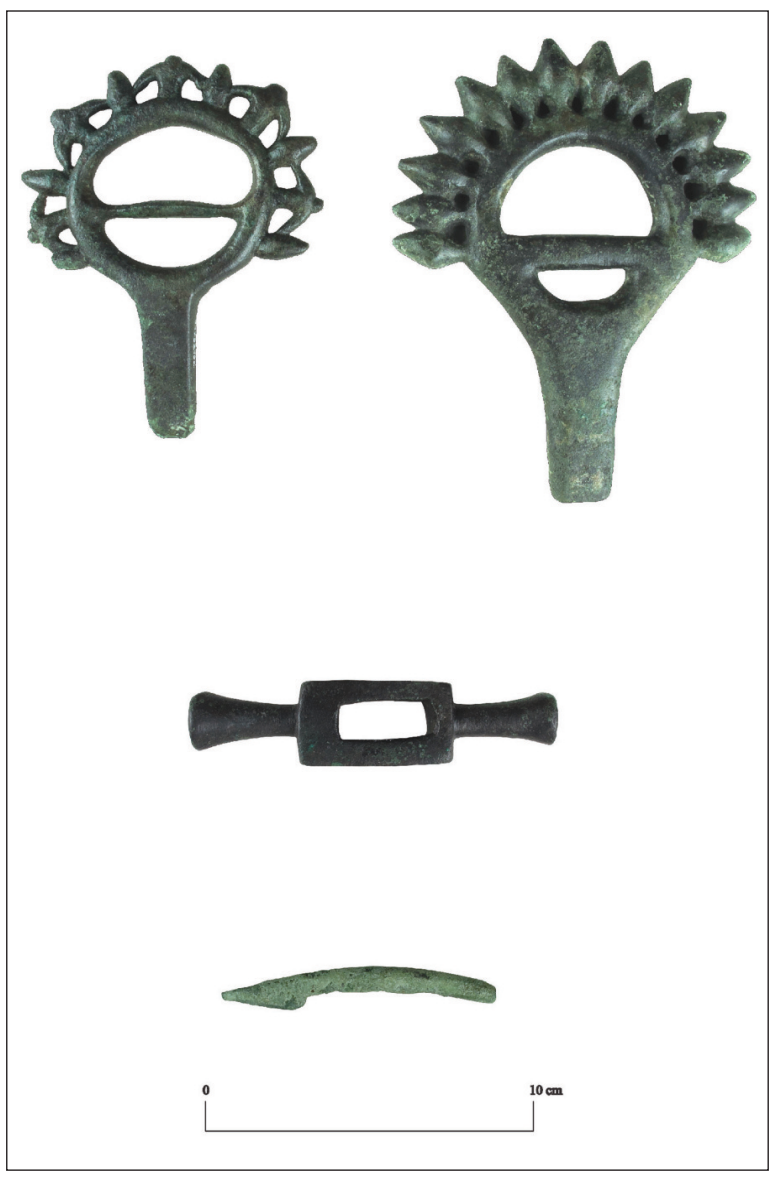

Figura 45. "Conjunto sepulcral de Guerreiro". Pasarriendas (cat. 9 y 10), alamar (cat. 11) y pasador sagital (cat. 12), Museu Nacional de Arqueologia de Lisboa (Fotos P. Barros). neada en lóbulos redondeados al exterior. Remata por la parte inferior en un cuerpo más ancho formado por tres anillas alineadas de igual tamaño y contorno circular de las que penderían las campanillas. Estas, semejantes entre sí, se configuran en forma de tronco de cono hueco al que se sobrepone una gruesa asa diametral maciza de sección redondeada y perfil curvado. En la parte superior se conservan, en los tres casos, las perforaciones opuestas que denuncian la existencia de sendos travesaños para los badajos, actualmente perdidos unos y otros. Las campanas han debido de ser fundidas a la cera perdida en hueco. Solo una de las tres cuelga aún de la anilla derecha del bastidor a través de una argolla circular realizada con alambre de bronce vuelto sobre sí mismo. Las otras dos se conservan sueltas. Las campanillas sueltas se agrupan arbitrariamente, por lo que podrían corresponder a cualquiera de las otras dos placas de este tipo que se conservan (nos. 14 y 15).

Figs. 22 y 46.

\section{4.- Colgante con campanillas (6 piezas).} MNA 997.83.106.

Bronce fundido.

Placa calada: 2 partes de $5,5 \times 3,8$ x 0,4 cm y 5 $\mathrm{x} 6$ x $0,4 \mathrm{~cm}$.

Campanillas: 4,2 $\times 2-2,3 \emptyset \mathrm{cm}$.

Anillas: $1,8 \varnothing \times 0,2 \mathrm{~cm}$.

Peso total: $89,96 \mathrm{~g}$.

Colgante sonoro similar al anterior pero preservado en peor estado. Se conservan cuatro fragmentos. Uno de ellos corresponde a la anilla proximal y al arranque de la placa calada. Los otros tres permiten reconstruir la zona distal del bastidor, con las tres sujeciones alineadas unidas también a restos del calado. La parte central de la placa está perdida. Junto a estos restos se conservan tres campanillas de dos formatos diferentes. Dos de ellas son lisas y troncocónicas, como las del n. ${ }^{\circ} 13$, conservando una de ellas la anilla que la uniría al bastidor. La tercera es algo más pequeña y esbelta, de perfil cóncavo, asa de sección laminar y líneas incisas que la decoran por el exterior en la zona de los bordes. Esta campanilla es la única que conserva el travesaño y el badajo, constituido como una barra de alambre de sección cuadrada doblada sobre sí misma. Se conserva, además, un segundo fragmento de anilla suelto.

Uno de los fragmentos que permiten recomponer la parte distal de la placa tiene el número de inventario MNA 997.83.105D y ha sido erróneamente adscrito a una de las camas laterales del bocado. 


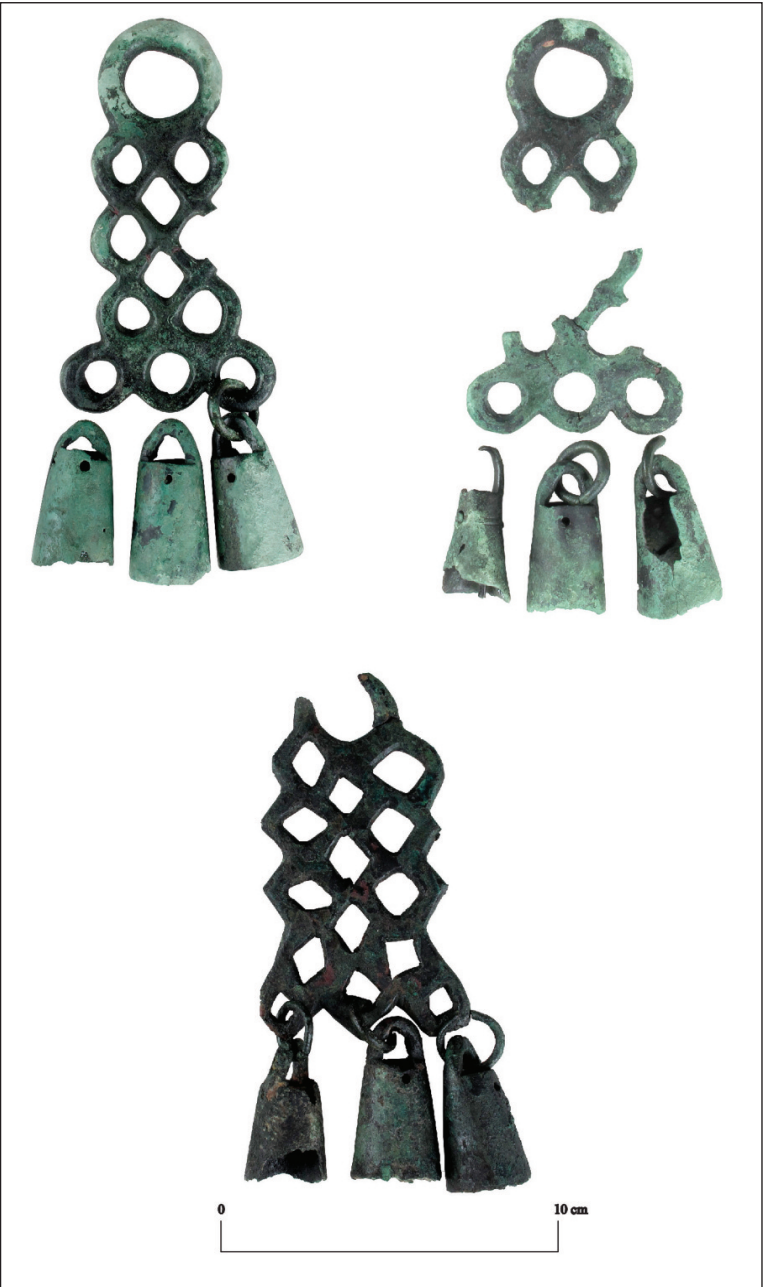

Figura 46. "Conjunto sepulcral de Guerreiro". Colgantes de campanillas (cat. 13, 14 y 15), Museu Nacional de Arqueologia de Lisboa (Fotos P. Barros).

Las campanillas sueltas se agrupan arbitrariamente, por lo que podrían corresponder a cualquiera de las otras dos placas de este tipo que se conservan (nos. 13 y 15).

Figs. 23 y 46.

\section{5.- Colgante con campanillas (7 piezas). \\ MNA 997.83.108. \\ Bronce fundido. \\ Placa calada: 10,6 x 5,8 x 0,24 cm. \\ Campanillas: 4 - 4,5 cm x $2-2,5 \varnothing \mathrm{cm}$. \\ Anillas: 1,6 - 1,7 Ø x 0,2 cm. \\ Peso total: $124,02 \mathrm{~g}$.}

Colgante sonoro similar a los anteriores, pero de factura mucho más tosca. Se compone de placa calada, de la que se conservan dos fragmentos, uno pequeño correspondiente a la anilla proximal (que no se conserva completa) y el otro formado por todo el calado. El diseño de la pieza es irregular, con líneas abruptas y quebradizas que dificultan su percepción como una retícula regularizada. No obstante, sigue a grandes rasgos una cadencia de dos series de cuatro rombos laterales y una central de tres, colocados al tresbolillo, pero en un orden muy deficiente. Los lóbulos externos son angulares en lugar de redondeados. Las tres anillas de las que penden las campanas apenas se distinguen del resto del calado, siendo tres perforaciones similares al resto que terminan en otras tantas lengüetas o lóbulos sin que en esta zona la placa sea más ancha. Se conservan tres campanillas del tipo troncocónico de similares características que las de los colgantes 13 y 14 . Ninguna conserva el badajo ni el travesaño de sujeción del que quedan sus agujeros de sostén. Dos de ellas están aún trabadas a la placa a través de sendas argollas circulares realizadas con alambre de bronce. La tercera se halla suelta pues, aunque conserva la argolla, ésta se encuentra abierta.

Uno de los fragmentos que permiten recomponer la parte proximal de la placa, correspondiente a la anilla tiene el número de inventario MNA 997.83.105E y ha sido erróneamente adscrito a una de las camas laterales del bocado.

Las campanillas sueltas de estos colgantes se agrupan arbitrariamente, por lo que podrían corresponder a cualquiera de las otras dos placas de este tipo que se conservan (nos. 13 y 14).

Figs. 24 y 46.

16-100.- 85 botones de disco y cúspide cónica.

MNA 997.83.1 a 85.

Bronce fundido.

Medidas individuales en tabla 1.

Corresponden a tres modalidades/tamaños básicos. El grupo de mayor tamaño (A), de en torno a 3,5 $\mathrm{mm}$ de diámetro, cuenta con 10 ejemplares; los de tamaño mediano (grupo B), de 2,5 mm de diámetro aprox., son cinco y los pequeños (C), de alrededor de $2 \mathrm{~mm}$ de diámetro, suman 70 unidades. La estructura de los botones es, en todos los casos, similar: una cúspide cónica hueca al interior que descansa sobre un disco plano y una presilla curva por la parte inferior. El anverso ha sido pulido a torno lo que genera perfiles abalaustrados y líneas concéntricas en muchas unidades. La parte inferior está sin tratar. Los grupos A y C parecen fundidos a molde bivalvo, como denuncian las continuas líneas de costuras y rebabas que se observan en casi todos los ejemplares. El grupo $\mathrm{B}$, formado por botones más robustos y proporcionalmente más pesados, parece fundido a la cera perdida.

Figs. 26-33. 
101.- Fragmentos de barra (4 fragmentos). MNA 997.83.98B: 4,3 x 0,7 x 0,5 cm; 11,70 g. Barra de perfil recto y sección rectangular. MNA 997.83.98C: 4,1 x 0,7 x 0,5 cm; 6,62 g. Barra de perfil recto y sección subrectangular. MNA 997.83.98D: 4,1 x 0,7 x 0,6 cm; 8,45 g. Barra de perfil curvo y sección subrectangular. MNA 997.83.98E: 5,6 x 0,7 x 0,5 cm; 12,23 g. Barra de perfil curvo y sección subcuadrada. Cuatro fragmentos de barra de bronce de tamaño similar pero de distintas secciones y grosores. Aunque se han asociado al pasador sagital sus perfiles y secciones son muy distintos, por lo que es poco verosímil que pertenezcan a objetos similares. Fig. 39.

\section{Bibliografía}

Abad, L. (1988): "Un tipo de olpe de bronce de yacimientos ibéricos levantinos". Archivo de Prehistoria Levantina, 18: 329-345.

Abascal, J.M. y Sanz, R. (1993): Bronces antiguos del Museo de Albacete. Albacete.

Albergaria, J. y Melro, R. (2002): "Trabalhos arqueológicos realizados no âmbito do Bloco 9". Al-Madan (II série), 11: 128-133.

Albergaria, J.; Melro, S.; Ramos, A.C. y Jorge, A. (2013): Ocupação Proto-Histórica da margem esquerda do Guadiana. Memórias d'Odiana. Estudos Arqueológicos do Alqueva 7. Beja.

Almagro-Gorbea, M. (1974): "Los asadores de bronce del Suroeste peninsular". Revista de Archivos, Bibliotecas y Museos, 77 (1): 351-395.

Almagro-Gorbea, M. (1977): El Bronce Finaly el Periodo Orientalizante en Extremadura. Biblioteca Praehistorica Hispana, XIV. Madrid.

Almagro-Gorbea, M. (1996): Ideología y poder en Tartessos y el Mundo Ibérico. Madrid.

Almagro-Gorbea, M. (dir.) (2007): La necrópolis de Medellín. I. La excavacion y sus hallazgos. Madrid.

Almagro-Gorbea, M. (dir.) (2008): La necrópolis de Medellín. III, Estudio analíticos. IV, Interpretación de la necrópolis. V, El marco histórico de Medellín-Conisturgis. Madrid.

Almagro-Gorbea, M. y Domínguez, A. (1988-89): "El palacio de Cancho Roano y sus paralelos arquitectónicos y funcionales". Zephyrus, 41-42: 340-382.
Amo, M. (1978): "El Castañuelo. Un poblado céltico en la provincia de Huelva". Huelva Arqueológica, 4: 299-340.

Antunes, A.S. (2008): “'Castro' da Azougada (Moura, Portugal): percursos do Pós-Orientalizante no Baixo Guadiana”. En J. Jiménez Ávila (ed.): Sidereum Ana I. El río Guadiana en época Postorientalizante. Anejos de Archivo Español de Arqueología, XLVI. Mérida: 327-351.

Antunes, A.S. (2009a): Um conjunto cerámico da Azougada. Em torno da Idade do Ferro PósOrientalizante da margem esquerda do Baixo Guadiana. O Arqueólogo Português Supl. 5. Lisboa.

Antunes, A.S. (2009b): “«Castro» da Azougada (Moura, Portugal): sacralidade e dinamismo comercial no Baixo Guadiana durante o PósOrientalizante". IV Simposio Internacional de Arqueología de Mérida. Santuarios, oppida y ciudades: arquitectura sacra en el origen y desarrollo urbano del Mediterráneo Occidental. Anejos de Archivo Español de Arqueología, XLV. Mérida: 131142.

Antunes, A.S. (2014): "Alentejo (O)". Dizionario Enciclopedico della Civiltà Fenicia. Roma. (http://www.decf-cnr.org).

Antunes, A.S. (2017): "A Azougada (Moura) e o sistema metrológico da Idade do Ferro PósOrientalizante do Baixo e Médio Guadiana”. II Encontro da Associação dos Arqueólogos Portugueses. Arqueologia em Portugal. Estado da Questão. Lisboa: 905-926.

Antunes, A.S. (e.p.): "Um unguentário de alabastro na Azougada (Moura, Portugal)". O Arqueólogo Português (série V), 6. Lisboa.

Antunes, A.S. y Cosme, S. (e.p.): "Casa Branca 11 (Serpa, Portugal): Um sítio de planície da I Idade do Ferro no Alentejo Interior". X Encuentro de Arqueología del Suroeste Peninsular (Zafra, 9, 10 e 11 de novembro de 2018).

Antunes, A.S.; Deus, M. de; Soares, A.M.; Santos, F.; Arêz, L.; Dewulf, J.; Baptista, L. y Oliveira, L. (2012): "Povoados abertos do Bronze Final no Médio Guadiana". En J. Jiménez Ávila (ed.): Sidereum Ana II. El río Guadiana en el Bronce Final. Anejos de Archivo Español de Arqueología, LXII. Mérida: 277-308.

Antunes, A.S.; Deus, M. de; Estrela, S.; Larrazabal, J.; Soares, A.M. y Salvador, R.M. (2017): "Monte do Bolor 3, Monte do Pombal 2, Salsa 3 e Torre Velha 3: Contextos de Planície da I Idade do Ferro do Alentejo Interior". En J. 
Jiménez Ávila (ed.): Sidereum Ana III. El río Guadiana y Tartessos. Serie Compacta, 1. Mérida: 159-186.

Antunes, A.S.; Guerreiro, A.; Castro, A.N.; Fialho, L.; Manteiga, M.; Viegas, V. y Braga, J.T. (2012): "Serpa entre a Idade do Ferro e a Época Moderna. Breve leitura dos resultados das escavações arqueológicas realizadas no Castelo". V Congresso de Arqueologia do Sudoeste Peninsular. Almodôvar: 441-464.

Antunes, A.S.; Soares, A.M.; Deus, M. de y Soares, R.M. (2017): "Povoamento «orientalizante» na margen esquerda do Guadiana. Uma leitura a partir do Passo Alto e do Castelo de Serpa”. En J. Jiménez Ávila (ed.): Sidereum Ana III. El río Guadiana y Tartessos. Serie Compacta, 1. Mérida: 131-158.

Arancibia, A.; San José, L.G.; Juzgado, M.: Dumas, M. y Sánchez-Moreno, V.M. (2011): "Aportaciones de las últimas intervenciones a la arqueología fenicia de la Bahía de Málaga". En M.Á. Martí-Aguilar (ed.): Fenicios en Tartessos: nuevas perspectivas. BAR International Series, 2245. Oxford: 129-149.

Armada, X.L. (2005): "Asadores de la Península Ibérica y cuestión orientalizante. Un ensayo de síntesis". En S. Celestino y J. Jiménez Ávila (eds.): El Periodo Orientalizante. III simposio internacional de arqueología de Mérida. Anejos de Archivo Español de Arqueología, XXXV. Mérida: 1249-1267.

Arnaud, J.M. (1979): “Corôa do. Frade. Fortificação do Bronze Final dos arredores de Évoraescavações de 1971/1972". Madrider Mitteilungen, 20: $56-100$.

Arnaud, J.M.; Martins, A. y Ramos, C. (1994): "Necrópole da Nora Velha (Ourique). Informação da 1. campanha de escavação". Actas das V fornadas Arqueológicas 2. Lisboa: 199210.

Arribas, A. (1967): "La necrópolis bastitana del Mirador de Rolando (Granada)". Pyrenae, 3: 67107.

Arribas, A. y Molina, F. (1969): La Necrópolis Ibérica del Molino de Caldona (finca Torrubia). Oretania, 28-33. Linares.

Arruda, A.M. (1999-2000): Los fenicios en Portugal. Fenicios y mundo indígena en el Centro y Sur de Portugal (siglos VIII-VI a.C.). Cuadernos de Arqueología Mediterránea, 5-6. Barcelona.
Arruda, A.M. (2001): "A Idade do Ferro PósOrientalizante no Baixo-Alentejo". Revista Portuguesa de Arqueologia, 4 (2): 207-291.

Arruda, A.M. (2005a): "O 1. ${ }^{\circ}$ milénio a.n.e. no Centro e no Sul de Portugal: leituras possíveis no início de um novo século". O Arqueólogo Português (série IV), 23: 9-156.

Arruda, A.M. (2005b): “Orientalizante e PósOrientalizante no Sudoeste peninsular: geografias e cronologías". En S. Celestino y J. Jiménez Ávila (eds.): El Periodo Orientalizante. Actas del III Simposio Internacional de Arqueología de Mérida. Anejos de Archivo Español de Arqueología, XXXV. Mérida: 277-304.

Arruda, A.M. (2008): "O Baixo Guadiana durante os séculos VI e V. A.N.E.”. En J. Jiménez Ávila (ed.): Sidereum Ana I. El Rio Guadiana en época postorientalizante. Anejos de Archivo Español de Arqueología, XLVI. Mérida: 399-414.

Arruda, A. M.; Barbosa; R.; Gomes F. y Sousa, E. de (2017): "A necrópole da Vinha das Caliças (Beja, Portugal)". En J. Jiménez Ávila (ed.): Sidereum Ana III. El río Guadiana y Tartessos. Serie Compacta, 1. Mérida: 187-226.

Arruda, A.M. y Freitas, V.T. de (2008): “O Castelo de Castro Marim durante os séculos VI e V a.n.e.". En J. Jiménez Ávila (ed.): Sidereum Ana I. El río Guadiana en época post-orientalizante. Anejos de Archivo Español de Arqueología, XLVI. Mérida: 429-446.

Arruda, A.M.; Freitas V.T. de e Oliveira C.F.P. (2007): "Os fenícios e a urbanização no Extremo Ocidente: o caso de Castro Marim". En J.L. López Castro (ed.): III Coloquio Internacional del Centro de Estudios Fenicios y Púnicos. Las ciudades fenicio-púnicas en el Mediterráneo Occidental. Almería: 459-482.

Aubet, M.E. (2008): "Political and economic implications of the new Phoenician chronologies". En C. Sagona (ed.): Beyond the homeland: markers in Phoenician chronology. Lovaina: 247-259.

Balkwill, G. (1973): "The Earliest Horse-bits of Western Europe". Proceedings of the Prehistoric Society, 39: 425-452, https://doi.org/10.1017/ S0079497X00011737.

Bandera, M.L. (1979-80): "Nuevas figuras zoomorfas del Bajo Guadalquivir". Habis, 10-11: 391-400.

Barbosa, R. (inédito): "Caliças 4 - O último suspiro de bravos guerreiros e de suas donzelas 
aformoseadas". Comunicación presentada al $4^{\circ}$ Colóquio de Arqueologia do Alqueva - O Plano de Rega (2002-2010) (Beja, 24-26 febrero 2010).

Bargão, P. y Fernandes, D. (2017): “A necrópole de Pisões (Beja)". En J. Jiménez Ávila (ed.): Sidereum Ana III. El río Guadiana y Tartessos. Serie Compacta, 1. Mérida: 407-419.

Barros, L.; Cardoso, J.L. y Sabrosa, A. (1993): "Fenícios na margem sul do Tejo. Economia e integração cultural do povoado do AlmarazAlmada". Estudos Orientais. Os fenícios no território português IV. Lisboa: 143-182.

Barros, P. (2007): "Mértola, plataforma comercial durante a Idade do Ferro. A colecção de Estácio da Veiga". En A.M. Arruda (ed.): Fenícios e púnicos, por terra e por mar. VI Congresso Internacional de Estudos Fenícios e Púnicos. Lisboa: 688-697.

Barros, P. (2008): "Mértola durante os séculos VI e V a.G.”. En J. Jiménez Ávila (ed.): Sidereum Ana I. El Rio Guadiana en época Post-Orientalizante. Anejos de Archivo Español de Arqueología, XLVI. Mérida: 399-414.

Beirão, G.M. (1986): Une civilization Protohistorique du Sud de Portugal (1 ${ }^{\text {er }}$ Âge du Fer). París.

Beirão, C.M. (1990): "Epigrafia da I Idade do Ferro do Sudoeste da Península Ibérica. Novos dados arqueológicos". Estudos Orientais. Presenças orientalizantes em Portugal. Da pré-história ao período romano I. Lisboa: 107-118.

Beirão, G.M. y V.H. Correia (1991): "A cronologia do povoado de Fernão Vaz (Ourique, Beja)". Conimbriga, 30: 5-11, https://doi.org/10.14195/ 1647-8657_30_1.

Beirão, C.M. y Correia, V.H. (1993): "Novos dados arqueológicos sobre a área de Fernão Vaz". En J. Manga y J. Alvar (eds.): Homenaje a Fosé $M^{a}$ Blázquez I. Madrid: 285-302.

Berrocal-Rangel, L., y Silva, A.C. (2007): “O Castro dos Ratinhos (Moura, Portugal). Um complexo defensivo no Bronze Final do Sudoeste Peninsular". Paisajes Fortificados de la Edad del Hierro. Madrid: 169-190.

Berrocal-Rangel, L., y Silva. A.C. (2010): O Castro dos Ratinhos (Barragem do Alqueva, Moura). Escavações num povoado proto-histórico do Guadiana, 2004-2007. O Arqueólogo Português, Supl. 6. Lisboa.

Blanco Frejeiro, A. (1965): El ajuar de una tumba de Cástulo. Oretania, 19. Linares.
Blánquez, J.J. (ed.) (2011): ¿Hombres o dioses? Una nueva mirada a la escultura del mundo ibérico. Madrid.

Blech, M. (2003): "Elementos de atalaje de Cancho Roano". En S. Celestino (ed.): Cancho Roano IX. Los materiales arqueológicos II. Badajoz: 159-192.

Bonsor, G. (1931): An archaeological Sketch-book of the Roman Necropolis at Carmona. Nueva York.

Borges, S.; Pereira, J.A.; Silva, B.C.; Salvador, R. y Gonçalves, A. (2012): "Monte do Bolor 3 (S. Brissos, Beja): Resultados preliminares". V Congresso de Arqueologia do Sudoeste Peninsular. Almodôvar: 113-132.

Botto, M. y Vives-Ferrándiz, J. (2006): "Importazioni etrusche tra le Baleari e la Penisola Iberica (VIII - prima metà del V sec. a.c.)". En G.M. Della Fina (ed.): Gli Etruschi e il Mediterraneo. Commerci e politica. Atti del XIII Convegno Internazionale di Studi sulla Storia e l'Archeologia dell'Etruria. Roma: 33112.

Cabré, J. (1930): Excavaciones arqueológicas en la necrópoli celtibérica del Altillo del Cerropozo, Atienza (Guadalajara), practicadas bajo la dirección de Don Juan Cabré con la cooperación de Don Justo Fuberías. Memorias de la Junta Superior de Excavaciones y Antigüedades, 121. Madrid.

Cabré, J.; Cabré E. y Molinero A. (1950): El castro y la necrópolis del hierro céltico de Chamartín de la Sierra (Ávila). Acta Arqueológica Hispánica, 5. Madrid.

Calado, M. (2002): "Povoamento Pré e ProtoHistórico da margem direita do Guadiana". AlMadan (II série), 11: 122-127.

Calado, M.; Gonçalves, L.; Mataloto, R. y Jiménez Ávila, J. (2018): "Lapa da Cova: un santuario costero en los acantilados de Sesimbra (Portugal)". En M. Martínez Alcaide; J.M. García Cano; J. Blánquez y A. Iniesta (eds.): Mazarrón II. Contexto arqueológico, viabilidad científica y perspectiva patrimonial del barco B-2 de la bahía de Mazarrón (Murcia). En homenaje a fulio Mas García. Madrid: 525-546

Calado, M.; Barradas, M.P. y Mataloto, R. (1999): "Povoamento Proto-Histórico no Alentejo Central". Actas do Congresso de Proto-História Europeia. Centenário da morte de Francisco Martins Sarmento. Revista de Guimarães, volume especial. Guimarães: 363-388.

Calado, M. y Mataloto, R. (2008): "O PostOrientalizante da margem direita do regolfo de Alqueva (Alentejo Central)". En J. Jiménez Ávila 
(ed.): Sidereum Ana I. El río Guadiana en época postorientalizante. Anejos de Archivo Español de Arqueología, XLVI. Mérida: 185-217.

Calado, M.; Mataloto, R. y Rocha, A. (2007): "Povoamento proto-histórico na margem direita do regolfo de Alqueva (Alentejo, Portugal)". En A. Rodríguez Díaz e I. Pavón (eds.): Arqueología de la tierra. Paisajes rurales de la Protohistoria Peninsular. Cáceres: 129-179.

Calvo, E. y Simão, P. (2017): "La sepultura 38 de Quinta do Castelo 5 (Salvada, Beja). Nota preliminar". En J. Jiménez Ávila (ed.): Sidereum Ana III. El río Guadianay Tartessos. Serie Compacta 1. Mérida: 187-226.

Cañal, G. (1894): Sevilla Prehistórica. Tacimientos prehistóricos de la Provincia de Sevilla. Sevilla.

Celestino, S. y Jiménez Ávila, J. (1993): El PalacioSantuario de Cancho Roano IV. El Sector Norte. Badajoz.

Celestino, S. y Zulueta, P. (2003): "Los bronces de Cancho Roano". En S. Celestino (ed.): Cancho Roano IX. Los materiales arqueológicos II. Badajoz: 11-123.

Chapa, T. (1985): La escultura ibérica zoomorfa. Madrid.

Chapa, T.; Pereira, J.; Madrigal, A. y Mayoral, V. (1998): La necrópolis ibérica de los Castellones de Céal (Hinojares, Faén). Sevilla.

Coffyn, A.; Gómez de Soto, J. y Mohen, J.P. (1981): L'Apogée du Bronze Atlantique: le dépôt de Venat. París.

Correia, V.H. (1986): "Um bronze tartéssico inédito: o lose de Mourão". Trabalhos de Arqueologia do Sul, 1: 33-48.

Correia, V.H. (1993): “As necrópoles da Idade do Ferro do Sul de Portugal: arquitectura e rituais". Actas do $1^{\circ}$ Congresso de Arqueologia Peninsular. II. Trabalhos de Antropologia e Etnologia, 33 (3-4): 351-375.

Correia, V.H. (1995): "The Iron Age in South and Central Portugal and the emergence of urban centres". Proceedings of the British Academy, 86: 237-262

Correia, V.H. (1996): "Os povoados da 1. a Idade do Ferro do Sul de Portugal". De Ulisses a Viriato. O primeiro milénio a.C. (catálogo de la exposición). Lisboa: 82-87.

Correia, V.H. (1997): "Um modelo historiográfico para a Idade do Ferro do Sul de Portugal e a sua arqueología". Trabalhos de Antropologia e Etnologia, 37 (3-4): 41-89.
Correia, V.H. (1999): "Fernão Vaz (Ourique, Beja). Balanço da investigação arqueológica". Vipasca. Arqueologia e História, 8: 23-31.

Correia, V.H. (2001): "Arquitectura oriental e orientalizante em território português: uma revisão”. En D. Ruiz Mata y S. Celestino (eds.): Arquitectura oriental y orientalizante en la Península Ibérica. Madrid: 57-68.

Correia, V.H. (2007): "Fernão Vaz. Um caso de estudo da paisagem rural do Sudoeste no período Orientalizante". En A. Rodríguez Díaz e I. Pavón (eds.): Arqueología de la tierra. Paisajes rurales de la Protohistoria Peninsular. Cáceres: 181194.

Crowel, J.H. (1992): Charriots and other Wheeled Vehicles in Iron Age Greece. Amsterdam.

Crowel,J.H. (2012): Chariots and other Wheeled Vehicles in Italy before the Roman Empire. Oxford - Oakville, https://doi.org/10.2307/j.ctvhldvgq.

Cuadrado, E. (1950): Excavaciones en el santuario ibérico de El Cigarralejo (Mula, Murcia). Informes y Memorias de la Comisaría de Excavaciones, 21. Madrid.

Cuadrado, E. (1987): La necrópolis ibérica de «El Cigarralejo» (Mula, Murcia). Bibliotheca Praehistorica Hispana, XXIII. Madrid.

Deus, M.; Antunes, A.S y Soares, A.M. (2009): "Santa Margarida 1 (Serpa) no contexto do Bronze Final do Sudoeste". Actas do V Congresso de Arqueologia do Sudoeste Peninsular. Almodôvar: 171188.

Donder, H. (1980): Zaumzeug in Griechenland und Cypern. Prähistorische Bronzefunde, 16.3. Munich.

Estrela, S.; Costeira, C.; Alves, C.; Porfírio, E.y Serra, M. (2012): "Torre Velha 3 (Serpa): um novo ponto no mapa da Idade do Ferro do Sudoeste". V Congresso de Arqueologia do Sudoeste Peninsular. Almodôvar: 235-268.

Fernández Gómez, F. (1992-1993): “Un asador excepcional y un excepcional conjunto de asadores del Bajo Guadalquivir". Tabona, 8 (2): 465-480.

Fernández Gómez, F. (1986): Excavaciones arqueológicas en el Raso de Candeleda. Ávila.

Fernández Gómez, F. (1997): La necrópolis de la Edad del Hierro de "El Raso» (Candeleda. Ávila). "Las Guïas, B». Arqueología en Castilla y León. Memorias 4. Toledo. 
Ferrer, E. y Mancebo, J. (1991): "Nuevos elementos de carros orientalizantes en la Alta Andalucía. Algunas precisiones en torno a su función, significado y distribución". Cuadernos de Prehistoria y Arqueología de la Universidad Autónoma de Madrid 18: 113-148, https://doi.org/10.15366/ cupauam 1991.18.005.

Figueiredo, M. y Mataloto, R. (2017): “Necrópoles rurais sidéricas do Baixo Alentejo setentrional: sociedade e mundo funerário nos Barros de Beja". En J. Jiménez Ávila. ed. Sidereum Ana III. El río Guadiana y Tartessos. Serie Compacta 1. Mérida: 353-398.

Garrido, J.P. y Orta, E.M. (1978): Excavaciones en la necrópolis de "La Foya» Huelva. II. (3 ${ }^{a}, 4^{a}$ y $5^{a}$ Campañas). Excavaciones Arqueológicas en España, 96. Madrid.

Gibson, C.; Correia, V. y Burgess, C. (1998): "Alto do Castelinho da Serra (Montemor-o-Novo, Évora, Portugal). A Preliminary report on the excavation at the Late Bronze Age to Medieval Site, 1990-1993". Fournal of Iberian Archaeology, 0: 189-244.

Gomes, F. (2016): Contactos culturais e discursos identitários na I Idade do Ferro do Sul de Portugal (séculos VIII-V a.n.e.): leituras a partir do registo funerário. Tesis de doutoramento, Universidade de Lisboa.

Gomes, M.V. (1983): "El «Smiting God» de Azougada (Moura)". Trabajos de Prehistoria, 40: 200-220.

Gomes, M.V. (1997): “O touro de Mourão: um bronze Urartu”. Homenagem ao Professor António Augusto Tavares. Estudos Orientais, VI. Lisboa: 67-87.

Gomes, M.V. (2001): "Divinidades e santuarios púnicos, ou de influencia púnica, no sul de Portugal". Os púnicos no extremo occidente. Lisboa: 99-148.

Gónzalez de Canales, F.; Serrano, L. y Llompart, J. (2004): El emporio fenicio precolonial de Huelva (c. 900-770 a.C.). Madrid.

Graells, R.; Bardelli, G. y Barril, M. (2014): "Ein bronzener Stabdreifuß aus Las Cogotas (Cardeñosa, Prov. Ávila). Eine Übernahme technischer und formaler Vorbilder aus dem Mittelmeergebiet in die Archaische Bronzekunst der Iberischen Halbinsel". Archaologisches Korrespondenzblatt 44 (1): 59-70.

Hill, D.K. (1942): "Wine Ladels and Strainers from Ancient Times". The Gournal of the Walters Art Gallery, 5: 40-55.
Jiménez Ávila, J. (1997): “Cancho Roano y los complejos monumentales post-orientalizantes del Guadiana”. Complutum, 8: 1241-159.

Jiménez Ávila, J. (1999): La Toréutica orientalizante en la Península Ibérica (700-550 a. C.). Cáceres. Tesis doctoral inédita. Universidad de Extremadura.

Jiménez Ávila, J. (2001): “Los complejos monumentales post-orientalizantes del Guadiana y su integración en el panorama del Hierro Antiguo de Suroeste Peninsular". En D. Ruiz Mata y S. Celestino (eds.): Arquitectura Oriental y Orientalizante de la Península Ibérica. Madrid: 193-226.

Jiménez Ávila, J. (2002): La Toréutica orientalizante en la Península Ibérica. Bibliotheca Archaeologica Hispana, 16. Madrid.

Jiménez Ávila, J. (2006-2007): "La vajilla de bronce en le edad del hierro del Mediterráneo Occidental: procesos económicos e ideológicos". Revista de Arqueología de Ponent, 16-17: 300-309.

Jiménez Ávila, J. (2007): "El Período PostOrientalizante entre las provincias de Córdoba y Badajoz". Anales de Arqueología Cordobesa, 18: 2346.

Jiménez Ávila, J. (2008): "El final del Hierro Antiguo en el Guadiana Medio". En J Jiménez Ávila (ed.): Sidereum Ana I. El río Guadiana en época postorientalizante. Anejos de Archivo Español de Arqueología, XLVI. Mérida: 101-134.

Jiménez Ávila, J. (2009a): “Arquitectura y modalidad: la construcción del poder en el mundo post-orientalizante". Archivo Español de Arqueología, 82: 65-95, http://dx.doi.org/ 10.3989/aespa.082.009.003.

Jiménez Ávila, J. (2009b): "Modelos arquitectónicos en la Protohistoria de Suroeste Peninsular: edifícios «en tridente»". Santuários, oppida y ciudades: arquitectura sacra en el origen y desarrollo urbano del Mediterráneo Occidental. Anejos de Archivo Español de Arqueología, XLV. Mérida: 89-100.

Jiménez Ávila, J. (2015a): "Phoenician Bronzes in Spain. A Western Phoenician Metalwork". En J. Jiménez Ávila (ed.): Phoenician Bronzes in Mediterranean. Bibliotheca Archaeologica Hispana, 45. Madrid: 395-442.

Jiménez Ávila, J. (2015b): “Alamares metálicos. Un sistema de cierre para correajes ecuestres en la Protohistoria de la Península Ibérica”. Gladius, 35: 35-60, https://doi.org/10.3989/ gladius. 2015.0003. 
Jiménez Ávila, J. (2017): “Ancha es Tartessos. El Periodo Orientalizante (siglos VIII a VI a.C.) en el tramo extremeño del Guadiana". En J. Jiménez Ávila (ed.): Sidereum Ana III. El río Guadiana y Tartessos. Serie Compacta 1. Mérida: 69106.

Jiménez Ávila, J. (2018a): "Un conjunto de arreos de bronce de la Colección Juan Cabré: Aportaciones al estudio del atalaje ecuestre en la Protohistoria Ibérica". Espacio, Tiempo y Forma, Serie I (Prehistoria y Arqueología) 11: 49-73, https://doi.org/10.5944/etfi.11.2018.21188.

Jiménez Ávila, J. (2018b): "The chariot from tomb 17 in the Orientalizing cemetery of La Joya, Huelva (1971-2016)". En M. Botto (ed.): De Huelva a Malaka, los fenicios en Andalucía a la luz de los descubrimientos más recientes. Collezione di Studi Fenici 48, Roma: 183-215.

Jiménez Ávila, J. (e.p.): "El potro desempotrado: El caballo ibérico de La Covatilla (Marchena, Sevilla)". IX Encontro de Arqueologia do Sudoeste Peninsular (Tróia-Setúbal, 4-6 de Noviembre de 2016).

Jiménez Ávila J. y González Cordero, A. (1996): "Broncística y poblamiento post-orientalizante en la Alta Extremadura: a partir de unos materiales de «El Risco» (Sierra de Fuentes, Cáceres)". Zephyrus, 49: 169-189.

Jiménez Ávila J. y González Cordero, A. (2012): "Una tumba 'de carro' en la necrópolis orientalizante de Talavera La Vieja (Cáceres)". V Encontro de Arqueologia do Sudoeste Peninsular. Almodôvar: 213-233.

Jiménez Ávila, J. y Muñoz, K. (1997): "Pasarriendas de bronce en la Protohistoria Peninsular: a propósito del hallazgo del Soto del Hinojar-Las Esperillas (Aranjuez, Madrid)". Cuadernos de Prehistoria y Arqueología de la Universidad Autónoma de Madrid, 24. Madrid: 119-158, https://doi.org/ 10.15366/cupauam 1997.24.004.

Jiménez Ávila, J. y Ortega, J. (2004): La cerámica griega en Extremadura. Cuadernos Emeritenses, 28. Mérida.

Jiménez Ávila, J. y Ortega, J. (2008): “El Torrejón de Abajo, un yacimiento orientalizante en el entorno periurbano de Cáceres." En P.J. Sanabria (ed.): Arqueología Urbana en Cáceres. Investigaciones recientes en la ciudad de Cáceres y su entorno. Memorias del Museo de Cáceres, 7. Cáceres: 83-114.
Jiménez Ávila, J.; Ortega, J. y López Guerra, A.M. (2005): "El poblado de «El Chaparral» (Aljucén) y el asentamiento del Hierro Antiguo en la comarca de Mérida". Excavaciones Arqueológicas 2002. Memoria 8. Mérida: 457-485.

Jiménez Ávila, J.; Mataloto, R.; Calado, M. y Gonçalves, L. (2018): "Lapa da Cova (Sesimbra, Portugal): a Coastal Sanctuary on the Western Border of Mediterranean". Atti del VIII Congresso Internazionale di Studi Fenici e Punici. Folia Phoenicia, 2: 309-316.

Koch, J.K. (1999): Der Wagen und das Pferdegeschirr aus dem späthallstattzeitlichen Fürstengrab von EberdingenHochdorf (Kr. Ludwigsburg). Tesis doctoral, Universidad Christian-Albrechts. Kiel.

Koch, J.K. (2004): Hochdorf VI: Der Wagen und das Pferdegeschirr aus dem späthallstattzeitlichen Fürstengrab von Eberdingen-Hochdorf (Kr. Ludwigsburg). Forschungen und Berichte zur Vor- und Frühgeschichte in Baden-Württemberg, 89. Stuttgart.

Kossack, G. (1954): "Pferdegeschirr aus Gräbern der älteren Hallstattzeit Bayerns". Fahrbuch des Römisch-Germanischen Zentralmuseums, 1: 111-178.

Kurtz, W.S. (1986-87): "Los arreos de caballo en la necrópolis de Las Cogotas (Cardeñosa, Ávila)". Zephyros, 49-50: 59-472.

Lillio, P. y D. Serrano (1989): "Los fragmentos escultóricos ibéricos del Agua Salada (Alcantarilla, Murcia)". Archivo de Prehistoria Levantina, 19: 77-89.

Littauer, M. y Crowel, J.H. (1979): Wheeled Vehicles and Ridden Animals in the Ancient Near East. Leiden.

Louis, M.; Taffanel, O. y Taffanel, J. (1958): Le premier âge du fer languedocien II, Les nécropoles à incineration. Bordighera-Montpellier.

Maia, M.G.P. (1985-86): "Neves II e a «fácies» cultural de Neves-Corvo". Arquivo de Beja (II série), 3: 23-42.

Maia, M. (2008): "Reflexões sobre os Complexos Arquitectónicos de Neves-Corvo, na região central do Baixo Alentejo, em Portugal". En J. Jiménez Ávila (ed.): Sidereum Ana I. El Rio Guadiana en época post-orientalizante. Anejos de Archivo Español de Arqueología, LXII. Mérida: 353-364.

Maia, M. y Maia, M. (1986): Arqueologia da área mineira de Neves-Corvo. Trabalhos realizados no triénio 19821984. Lisboa. 
Maia, M. y Maia, M. (1996): "Arqueologia do couto mineiro de Neves-Corvo". Mineração do Baixo Alentejo. Castro Verde: 83-93.

Maluquer de Motes, J. (1957): "De metalurgia tartésica: el Bronce Carriazo". Zephyros, 8: 157 168.

Maluquer de Motes, J. (1981): El Santuario Protohistórico de Zalamea de la Serena, Badajoz. 1978-1981. Programa de Investigaciones Protohistóricas, 4. Barcelona.

Maluquer de Motes, J. (1982): "Notas de arqueología extremeña. Los asadores de bronce del yacimiento de Cancho Roano, en Zalamea de La Serena (Badajoz)". Homenaje a Conchita Fernández Chicarro. Madrid: 187-193.

Maluquer de Motes, J. (1983): El Santuario Protohistórico de Zalamea de la Serena, Badajoz. 1981-1982. Programa de Investigaciones Protohistóricas, 5. Barcelona.

Mansel, K. (2004): "Vajilla de bronce en la Hispania republicana". En R. Olmos; P. Rouillard, coords. La vajilla ibérica en época helenística (siglos IVIII a. C. al cambio de era). Collection de la Casa de Velázquez, 89. Madrid: 19-30.

Martín de la Cruz, J.C. (1987): El Llanete de los Moros. Montoro, Córdoba. Excavaciones Arqueológicas en España, 151. Madrid.

Mataloto, R. (2004a): "Meio Mundo: o início da Idade do Ferro no cume da Serra d'Ossa (Redondo, Alentejo Central)". Revista Portuguesa de Arqueologia, 7 (2): 139-173.

Mataloto, R. (2004b): Um "monte" da Idade do Ferro na Herdade da Sapatoa: ruralidade e povoamento no $1 .^{\circ}$ Milénio a.C. do Alentejo Central. Trabalhos de Arqueologia, 37. Lisboa.

Mataloto, R. (2005): "Em busca do Mediterrâneo: a Idade do Ferro no Alentejo Central (Portugal)". En S. Celestino y J. Jiménez Ávila (eds.): Actas del III Simposio Internacional de Arqueología de Mérida. El Periodo Orientalizante. Anejos de Archivo Español de Arqueología, XXXV. Mérida: 955-966

Mataloto, R. (2007): "Viver no campo: a Herdade da Sapatoa (Redondo) e o povoamento rural centro-alentejano em meados do I milénio a.C.". Revista Portuguesa de Arqueologia, 10 (2): 135160.

Mataloto, R. (2008): "O Pós-Orientalizante que nunca foi. Uma comunidade camponesa na Herdade da Sapatoa". En J. Jiménez Ávila (ed.):
Sidereum Ana I. El Rio Guadiana en época postorientalizante. Anejos de Archivo Español de Arqueología, LXVI. Mérida: 219-250.

Mataloto, R. (2009): “Através dos campos: arquitectura e sociedade na Idade do Ferro alto alentejana". L'espai domèstic $i$ l'organització de la societat a la protohistòria de la Mediterrània ocidental (Ier mil lenni aC). Actes de la IV Reunió Internacional d'Arqueologia de Calafell. ArqueoMediterrania, 11. Barcelona: 279-298.

Mataloto, R. (2013): "Os Senhores da Terra: necrópoles e comunidades rurais do território alto alentejano nos sécs. VI-V a.C.". Arqueologia e História, 62-63: 77-100.

Mataloto, R. (2014): “A propósito de um conjunto de glandes plumbeae: o Castelo das Juntas (Moura) no contexto do episódio Sertoriano das Guerras". Actas do congreso Conquista e Romanização do Vale do Tejo. Cira-Arqueologia, vol. III. Vila Franca de Xira: 343-384.

Mataloto, R.; Martins, J.M.M. y Soares, A.M.M. (2013): "Cronologia absoluta para o Bronze do Sudoeste". Estudos Arqueológicos de Oeiras, 20: 303338.

Monraval, M. (1992): La necrópolis ibérica de El Molar (San Fulgencio-Guardamar del Segura, Alicante). Catálogo de fondos del Museo Arqueológico. Alicante.

Neguerela, I. (1990): Los monumentos escultóricos ibéricos del Cerrillo Blanco de Porcuna (faén). Madrid.

Olmos, R. (1992): "Broncística fenicia y orientalizante en el Sur Peninsular y en Ibiza. Una aproximación iconográfica y simbólica". VI Fornadas de Arqueología fenicio-púnica. Trabajos del Museo Arqueológico de Ibiza y Formentera, 27. Ibiza: 41-64.

Pare, C.F.E. (1992): Wagons and Wagon-Graves of the Early Iron Age in Central Europe. Oxford Committee for Archaeology - Monographs, 35. Oxford.

Pereira, T.R. (2008): Os Artefactos Metálicos do Castelo de Castro Marim na Idade do Ferro e em Época Romana. Metalurgia em transição: a amostra numa análise de conjunto. Tesis de Mestrado, Universidad de Lisboa. Lisboa.

Pereiro, T.; Mataloto, R. y Borges, N. (2017): "Alentejo, a Sul de Beja: a necrópole sidérica da Quinta do Estácio 6". En J. Jiménez Ávila (ed.): Sidereum Ana III. El río Guadiana y Tartessos. Serie Compacta 1. Mérida: 303-332. 
Piggott, S. (1983): The earliest wheeled transport: from the Atlantic Coast to the Caspian Sea. Londres.

Pozo, S.F. (2003): "Recipientes y vajilla metálica de época pre-romana (fenicia, griega y etrusca) del sur de la Península Ibérica”. Antiquitas, 15: 5-50.

Prados, F. (2010): "La arquitectura sagrada: Un santuario del siglo IX a.C.”. En L. BerrocalRangel y A.C. Silva (coords.): O Castro dos Ratinhos (Barragem do Alqueva, Moura). Escavações num povoado proto-histórico do Guadiana, 2004-2007. O Arqueólogo Português Supl. 6. Lisboa: 259276.

Quesada, F. (2002-2003): "Un elemento de bocado de caballo de tradición Orientalizante en el Museo Arqueológico de Murcia". Homenaje a Encarnación Ruano. Boletín de la Asociación Española de Amigos de la Arqueología, 42: 231-242.

Quesada, F. (2005): "El gobierno del caballo montado en la antigüedad clásica con especial referencia al caso de Iberia. Bocados, espuelas y la cuestión de la silla de montar, estribos y herraduras". Gladius, 25: 97-150, https://doi.org/10.3989/gladius.2005.26.

Rodríguez Díaz, A. (ed.) (2004): El edificio protohistórico de La Mata (Campanario, Badajoz), y su estudio territorial. Cáceres.

Rodríguez Díaz, A. (2009): Campesinos y "señores del campo". Tierra y poder en la protohistoria extremeña. Barcelona.

Rodríguez Díaz, A. (2010): “"Colonizaciones agrarias» y procesos regionales en la Protohistoria del Suroeste de la Península Ibérica”. XVII International Congress of Classical Archaeology. Session: Conexiones Rurales: Explotaciòn colonial, intensificaciòn agraria y poblamiento rural en el Mediterràneo occidental. Bollettino di Archeologia on line. I / Volume speciale.

Rodríguez Díaz, A.; Pavón, I.; Duque, D.M. y Ortiz, P. (2007): "La «señorialización» del campo postartésica en el Guadiana Medio: el edificio protohistórico de La Mata (Campanario, Badajoz) y su territorio". En A. Rodríguez Díaz e I. Pavón (eds.): Arqueología de la tierra. Paisajes rurales de la protohistoria peninsular. Cáceres: 71101.

Rodríguez Díaz, A. y Ortiz, P. (2004): “«La Mata», un edificio organizado". En A. Rodríguez Díaz (ed.): El edificio protohistórico de "La Mata» (Campanario, Badajoz) y su estudio territorial. Cáceres: 75-313.
Rovira, S.; Montero, I.; Ortega, J. y Jiménez Ávila, J. (2005): "Bronce y Trabajo del Bronce en el poblado orientalizante de El Palomar (Oliva de Mérida, Badajoz)". En S. Celestino y J. Jiménez Ávila (eds.): El Periodo Orientalizante. Actas del III simposio internacional de arqueología de Mérida. Anejos de Archivo Español de Arqueología, XXXV. Mérida: 1231-1240.

Ruano, E. (ed.) (1998): Museo de El Cigarralejo, Mula, Murcia. Boletín de la Asociación Española de Amigos de la Arqueología, 38. Madrid.

Salvador, R. y Pereira, J.A. (2012): “A necrópole da Carlota (S. Brissos, Beja) no contexto cultural da $\mathrm{I}^{\mathrm{a}}$ Idade do Ferro no Baixo Alentejo: dados preliminares". Actas do V Encontro de Arqueologia do Sudoeste Peninsular. Almodôvar: 317-330.

Salvador, R. y Pereira, J.A. (2017): "A paisagem funeraria a Oeste de Beja no Período Orientalizante: as necrópoles de Carlota (São Brissos) e Cinco Reis 8 (Santiago Maior)". En J. Jiménez Ávila (ed.): Sidereum Ana III. El río Guadiana y Tartessos. Serie Compacta, 1. Mérida: 333-352.

Santos, F.; Antunes, A.S.; Grilo, G.B.R. y Deus, M. de (2009): "A necrópole da I Idade do Ferro de Palhais (Beringel, Beja). Resultados preliminares de uma intervenção de emergência no BaixoAlentejo". IV Encuentro de Arqueología del Suroeste Peninsular. Huelva: 746-804.

Santos, F.; Antunes, A.S.; Grilo, G.B.R. y Deus, M. de (2017): "A necrópole de Palhais (Beringel, Beja)". En J. Jiménez Ávila (ed.): Sidereum Ana III. El río Guadiana y Tartessos. Serie Compacta 1. Mérida: 227-262.

Schüle, W. (1969): Die Meseta-Kulturen der Iberischen Halbinsel. Madrider Forschungen, 3. Berlin.

Shefton, B.B. (1995): "Greek Imports at the Extremities of the Mediterranean, West and East. Reflections on the Case of Iberia in the Fifth Century BC.". En B. Cunliffe y S. Keay (eds.): Social Complexity and the Development of Towns in Iberia. From the Copper Age to the Second Century $A D$. London: 127-155.

Silva, A.C.F. y Gomes, M.V. (1992): Proto-História de Portugal. Lisboa.

Siret, L. (1906): Villaricos y Herrerias. Antigüedades púnicas, romanas, visigóticas y árabes. Madrid.

Soares, A.M.M.; Antunes, A.S.; Queiróz, P.F.; Deus, M. de; Soares, R.M. y Valério, P. (2010): "A ocupação sidérica do Passo Alto (V.V. de 
Ficalho, Serpa)". IV Encuentro de Arqueología del Suroeste Peninsular. Huelva: 544-575.

Soares, R.M. (2012): Cabeço Redondo. Um edificio da Idade do Ferro Pós-Orientalizante na Herdade do Metum (Moura). Tesis de Mestrado. Lisboa.

Soares, R.M. y Soares, A.M.M. (2017): “O Cabeço Redondo (Moura). Um edifício monumental e singular na margem esquerda do Guadiana". En J. Jiménez Ávila (ed.): Sidereum Ana III. El río Guadiana y Tartessos. Serie Compacta, 1. Mérida: 421-442.

Soares, R.M.; Baptista, L.; Pinheiro, R.; Oliveira, L. de; Rodrigues, Z. y Vale, N. (2017): "A necrópole da I Idade do Ferro do Monte do Bolor 1-2 (São Brissos, Beja)". En J. Jiménez Ávila (ed.): Sidereum Ana III. El río Guadiana y Tartessos. Serie Compacta, 1. Mérida: 263-302.

Sousa, E. (2014): A ocupação pré-romana da foz do Estuário do Tejo. Estudos e Memórias, 7. Lisboa.

Spruytte, J. (1983): Early Harness Systems. London.

Tarditi, C. (1996): Vasi di Bronzo in area Apula. Produzione greche ed italice di età arcaica e classica. Lecce.

Teichner, F. (2000): "Dois fragmentos de «recipientes rituais» da fase orientalizante, provenientes do Alto Alentejo". A Cidade de Évora (II série), 4: 8597.

Trachsel, M. (2004): Untersuchungen zur relativen und absoluten Chronologie der Hallstattzeit. Universitätsforschungen zür Prähistorischen Ärchäologie, 104. Bonn.

Valério, P.; Soares, A.M.M.; Araújo, M.F.; Silva, R.J.C. y Santos, F.J.C. (2013): "The distinctive grave goods from Palhais (Beja, Portugal). New insights into the metallurgical evolution under Orientalizing influence in the southwestern end of Iberia". Trabajos de Prehistoria, 70 (2): 340-350, https://doi.org/10.3989/tp.2013.12119.

Van der Vaart-Verschoof, S. (2011): Hail to the chieftain. A detailed examination of grave goods from Dutch chiefly burials and their role in funerary rituals during the Hallstatt Period. Tesis de Máster, Universidad de Leiden. Leiden.

Vasconcellos, J.L. (1924): "Figuras de bronze antigas do Museu Ethnologico Português. Toiro de bronze de Safara". O Archeólogo Português, 26: 1942.

Viana, A. (1961): "Nossa Senhora da Cola. Notas Históricas, Arqueológicas e Etnográficas do Baixo Alentejo". Arquivo de Beja, 16: 3-48.

Vilhena, J. (2006): O sentido da permanência. As envolventes do Castro da Cola nos 2. ${ }^{\circ}$ e $1 .^{\circ}$ Milénios a.C. Tesis de mestrado, Universidad de Lisboa. Lisboa.

Vilhena, J. (2008): "As armas e os barões assinalados? Reflexões em torno das necrópoles monumentais do «Ferro de Ourique» (sul de Portugal)". En J. Jiménez Ávila (ed.): Sidereum Ana I. El Rio Guadiana en época post-orientalizante. Anejos de Archivo Español de Arqueología, XLVI. Mérida: 373-397.

Vives-Ferrándiz, J. (2006-2007): "La vida social de la vajilla de bronce etrusca en el este de la Península Ibérica. Notas para un debate". Revista de Arqueología de Ponent, 16-17: 319-324.

Zuffa, M. (1960): "Infundibula". Studi Etruschi, 38: 165-207. 